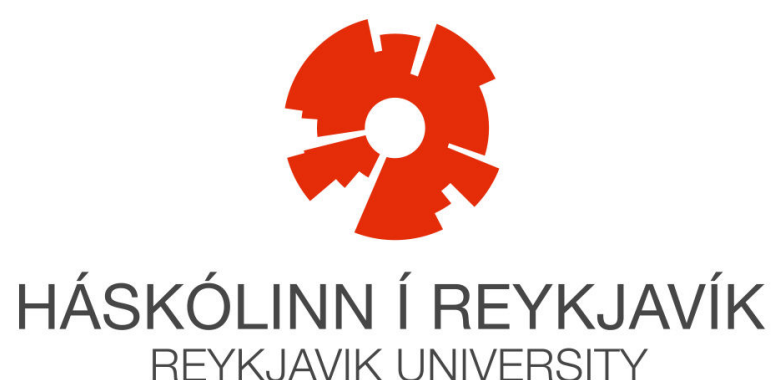

REYKJAVIK UNIVERSITY

\title{
ANTICIPATED FOOD SCARCITY AND \\ FOOD PREFERENCES
}

\author{
Michał Folwarczny
}

A thesis submitted for the degree of Doctor of

Philosophy

Department of Business Administration

Reykjavik University

September 2021 


\section{Acknowledgments}

I would like to thank the Ph.D. Thesis Committee-Valdimar Sigurdsson, Asle Fagerstrøm and Jacob Lund Orquin - as well as the two external reviewers - Gareth J. Hollands and Sarah Xiao - for reviewing my work, many valuable comments, and highlighting changes that made this thesis stronger.

Valdimar, thank you for the time you have invested in teaching me critical thinking that is a cornerstone in academia. I will remember the numerous extended lunch breaks that we used to take - especially during my first semester - when we discussed many important matters that helped me successfully progress as a Ph.D. candidate. In addition, you have helped me develop competencies that I will use outside academia, with calculating opportunity costs being likely the most important of them. As my journey with this thesis is coming to an end, I value these skills even more. Although at the beginning of my Ph.D. I was craving for additional projects and opportunities to learn, now I struggle with their numbers, and hence I have to weigh the costs and benefits of participating in projects carefully. Finally, I have to thank you for your non-directive supervision style, which resulted in me developing a strong inner motivation to pursue my own research ideas and additional projects that I found worthwhile and interesting. Although it is yet too early to say where this journey with academia will lead me to, I am confident that your supervision style considerably increased my chances of being a prolific researcher.

Asle, although our collaboration has been relatively minor due to your role as a cosupervisor and different research interests, I thank you for cheering me up and providing many valuable suggestions after my failures in conducting the first experiments. Thanks to that, I realized that there was a long way ahead of me until I learn to design and 
conduct empirical research properly.

Jacob, a big thank you for reminding me many times that academia is not a sprint; instead, it is a life-long marathon. Indeed, I have an innate tendency to take in too much and too early, which hinders researchers who aim to publish in the most prestigious journals. Also, thank you for supervising my 3-month research stay at Aarhus University. Although I have developed many skills vital for adjusting to a competitive academic environment during this stay, I firmly believe that you have taught me something more critical - doing things better and then starting over again, as "better" is never enough in this business.

Whereas all the supervisors played a crucial role throughout my Ph.D., more people positively impacted my academic performance.

Tobias Otterbring - although you have formally never belonged to my Thesis Committee, working with you has tripled, if not quadrupled, my publication potential during these years. We have written over a dozen papers together in two years, and there are many more to come in the nearest future. Thank you for sharing your valuable time and helping me develop a much more expansive publication portfolio.

Finally, I would also like to thank my key collaborators-Agata Gasiorowska, Lynn K. L. Tan, and Norman P. Li. All of you had a considerable and positive impact on my research.

With my deepest gratitude,

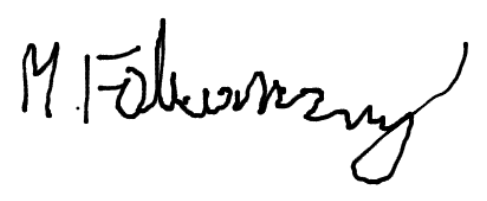




\section{Abstract}

In the recent decade, marketing literature has acknowledged the advantages of applying an evolutionary lens to understand consumer behavior in different domains. Food choice context is one such domain, having implications for societal well-being, especially for public health and addressing environmental issues. In this thesis, I investigate how mechanisms that have emerged as adaptations to food scarcity - frequent throughout human history —affect modern consumers' food preferences, potentially leading to maladaptive outcomes.

In Paper I, we highlight that selection pressures adjusted humans to forage in ancestral, hostile environments when they were wandering between periods of food scarcity and food sufficiency. Consequently, consumers often fail to choose foods appropriate to their current needs in contemporary retail contexts. Rather than attempting to override these hardwired and evolutionarily outdated food preferences, we recommend policymakers leverage them in such a way that facilitates healthier food choices.

A series of studies reported in Paper II show that exposing people to climate changeinduced food scarcity distant in time and space shifts their current food preferences. Specifically, people exposed to such video content exhibit a stronger preference toward energy-dense (vs. low-calorie) foods than their peers exposed to a control video.

In Paper III, we aimed to account for potential confounds stemming from the control video used in studies reported in Paper II. Additionally, we strived to conceptually replicate these earlier findings by exposing participants to subtle cues to food scarcity - a winter forest walk. Although not all studies yielded significant results at conventional levels, this empirical package — when taken together - corroborated the earlier findings. 
Despite that studies described in Papers II-III provided a shred of empirical evidence showing a potency of food scarcity cues in increasing preferences toward energy-dense (vs. low-calorie) products, it was still unclear what drove such a shift in food liking. Thus, in Paper IV, we have developed and psychometrically validated the Anticipated Food Scarcity Scale (AFSS), measuring the degree to which people perceive food resources as becoming less available in the future. Aside from being a candidate mechanism partially explaining findings reported in Papers II-III, anticipated food scarcity (AFS) is also related to some aspects of prosociality.

Studies presented in this thesis suggest that when environmental cues to food scarcity are present, people show a stronger preference toward energy-dense (vs. low-calorie) foods than their peers unexposed to such cues. Policymakers should consider these results when designing climate change and other similar campaigns, as such communication often depicts food scarcity. Additional research may explore the possibility that exposure to food scarcity cues affects food choices. Considering that we found AFS correlated with certain prosocial attitudes, it is a new psychological construct that warrants future investigation through multidisciplinary research. 


\section{Contents}

Acknowledgements $\quad$ ii

Abstract iv

1 Introduction and overview of Academic Papers 1

1.1 Introduction . . . . . . . . . . . . . . . . . . . . 2

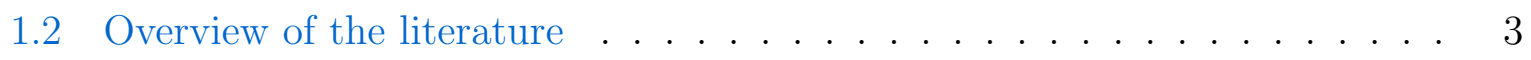

1.3 The current research . . . . . . . . . . . . . . . . . . 8

1.4 Overview of Academic Papers . . . . . . . . . . . . . . . . 9

1.5 References . . . . . . . . . . . . . . . . . 16

2 Old minds, new marketplaces: How evolved psychological mechanisms trigger mismatched food preferences $\quad 25$

2.1 Introduction . . . . . . . . . . . . . . . 27

2.2 The law of law's leverage . . . . . . . . . . . . . . . . 27

2.3 Adaptations to ancestral foraging environments . . . . . . . . . . . . 29

2.4 Mismatches between ancestral and modern foraging . . . . . . . . . . . . . 32

2.5 Policy recommendations . . . . . . . . . . . . . . . . . 33

2.6 Conclusion . . . . . . . . . . . . . . . . . . . . 40 


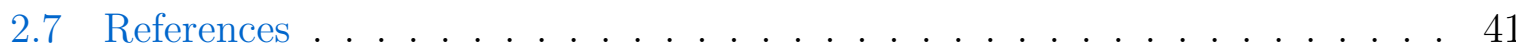

3 Crisis communication, anticipated food scarcity, and food preferences:

Preregistered evidence of the insurance hypothesis

3.1 Introduction . . . . . . . . . . . . . . . . . 51

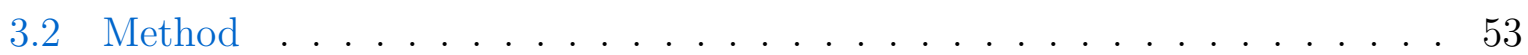

3.3 Results . . . . . . . . . . . . . . . . . . 57

3.4 Discussion . . . . . . . . . . . . . . . . . . . . . . 59

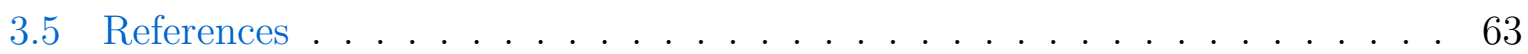

4 Seasonal cues to food scarcity and calorie cravings: Winter cues elicit preferences for energy-dense foods

4.1 Introduction . . . . . . . . . . . . . . . . . . . . . 69

4.2 General method and overview of studies . . . . . . . . . . . . . 75

4.3 Study $1 \mathrm{a} \ldots \ldots \ldots \ldots \ldots \ldots$. . . . . . . . . . . . . . . . . . . . .

4.4 Study 1 b. . . . . . . . . . . . . . . . . . 78

4.5 Study $2 \mathrm{a} \ldots \ldots \ldots \ldots \ldots$. . . . . . . . . . . . . . . . . 80

4.6 Study $2 b \ldots \ldots \ldots \ldots$. . . . . . . . . . . . . . . . 83

4.7 Study $2 c \ldots \ldots \ldots \ldots \ldots$. . . . . . . . . . . . . . . 86

4.8 General discussion . . . . . . . . . . . . . . . . . . . . . . . . . . . 89

4.9 Supplementary online materials . . . . . . . . . . . . . . . 94

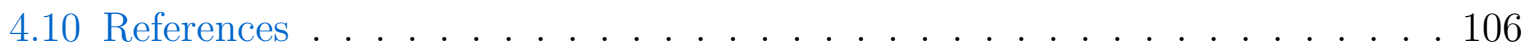

5 Development and psychometric evaluation of the Anticipated Food Scarcity

$\begin{array}{lr}\text { Scale (AFSS) } & 117\end{array}$ 
5.1 Introduction . . . . . . . . . . . . . . . . . . . . . . 119

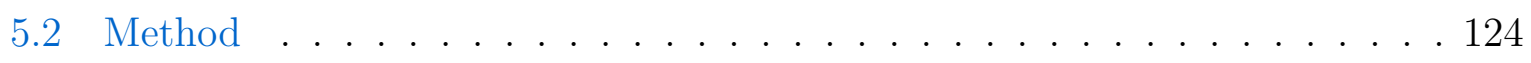

5.3 General discussion . . . . . . . . . . . . . . . . . . . 147

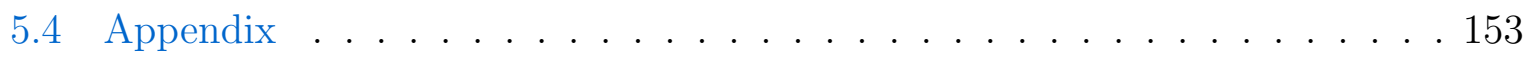

5.5 References . . . . . . . . . . . . . . . . . 156

6 Concluding discussion $\quad 166$

6.1 Summary of the findings . . . . . . . . . . . . . 167

6.2 Contribution to the academic literature . . . . . . . . . . . 171

6.3 Managerial implications . . . . . . . . . . . . . . . . . 173

6.4 Limitations and future research . . . . . . . . . . . . 176

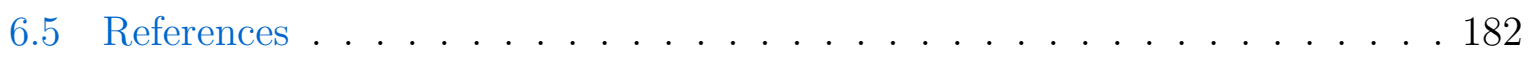




\section{Chapter 1}

Introduction and overview of Academic Papers

Michał Folwarczny

Department of Business Administration, Reykjavik University 


\subsection{Introduction}

Each year, billions of people fight against their growing waists, with almost $50 \%$ of the world population currently trying to become slimmer (IPSOS, 2021). Yet, despite these attempts, "most of the world's population live in countries where overweight and obesity kills more people than underweight" (WHO, 2021). Experts, academic literature, and public campaigns warn people against consuming excessive calories contributing to weight gain and its associated health ailments. However, this public health crisis is prevalent across the globe. Despite many health hazards linked to high adiposity (WHO, 2021), current marketing activities aggressively promote foods that are culprits of gaining weight quickly (Kessler, 2009). Eons of evolution created consumers who are predisposed to value convenient, cheap, tasty, and safe foods; hence, many marketers sell a myriad of such products (Folwarczny et al., 2021; Griskevicius et al., 2012).

Consumers' food preferences may also shift temporarily as a response to, for instance, cues to threats found in ancestral environments (Li et al., 2018; Tooby \& Cosmides, 1990). This research focuses on one set of such cues associated with food scarcity. Responding to food scarcity cues with - as Papers II-III suggest - an increased preference toward energydense (vs. low-calorie) foods is maladaptive nowadays in many cases, potentially leading to harmful health outcomes. Thus, it is vital to explore how food scarcity cues affect food choices and preferences and how to ameliorate their potentially harmful effect on selecting healthy, low-calorie products. Notably, lowering consumption of energy-dense foods belongs to critical steps in addressing not only public health challenges but also environmental issues such as climate change, because these foods are associated with a relatively high carbon footprint as compared to low-calorie products such as beans, 
legumes, fruits, and most vegetables (Willett et al., 2019; Wynes \& Nicholas, 2017).

\subsection{Overview of the literature}

This chapter is organized as follows. I first outline the basic tenets of evolutionary psychology and explain how evolutionarily-informed theories may complement traditional approaches dominant in marketing literature. In the subsequent section, I delineate anticipated food scarcity (AFS), which is a construct of interest in this thesis. I also explain how AFS differs from food insecurity, understood as a physical experience of food unavailability in the current food science and public health literature. Next, I explain why food preferences, shaped by eons of food scarcity experienced by early Homo sapiens, are mismatched against present-day needs. Finally, I highlight the key contributions of this research to the theory. This introductory chapter concludes with an overview of Academic Papers included in the thesis.

\subsubsection{Evolutionary psychology in marketing research}

Marketing literature has established numerous state and trait predictors of consumer behavior (Belk, 1975; Haugtvedt et al., 1992; Vinson et al., 1977). With respect to healthy (vs. unhealthy) food choices, the mainstream literature focuses on proximate explanations such as quality expectations, nutrition information, and certification (Grunert, 2002; Nikolova \& Inman, 2015; Sigurdsson et al., 2020; Thøgersen et al., 2019), but also instore product placement (Sigurdsson et al., 2011, 2014), individual differences (Otterbring, 2019; Rojas-Rivas et al., 2020), and message framing (Ares et al., 2020; Ares et al., 2021), as well as shopping habits (Machín et al., 2020), visual imagery (Banovic \& Otterbring, 
2021; Otterbring \& Shams, 2019), and visual attention to food products (Folwarczny et al., 2019; Gidlöf et al., 2021; Wästlund et al., 2018). However, to fully understand human decision-making, it is crucial to also consider ultimate explanations. Whereas proximate explanations are concerned with how specific mechanisms operate, ultimate explanations focus on answering why such behaviors exist in the first place (Bateson \& Laland, 2013; Nesse, 2019; Scott-Phillips et al., 2011). In other words, investigating ultimate explanations of consumer behavior eventually leads to seeking the adaptive function of these behaviors throughout human history. The evolutionary approach encompasses both these explanations, thus complementing traditional approaches to consumer behavior.

When considering the ultimate causes of consumer behavior, researchers can draw hypotheses that would not have been developed otherwise. For instance, Durante et al. (2008) predicted and found that women dress sexier at peak fertility when attracting mates is most likely to yield reproductive benefits - the ultimate cause of their actions. Further, female consumers at peak fertility are more variety-seeking (Durante \& Arsena, 2015). Importantly, asking female consumers why they choose a skimpier dress at that time would likely be futile, even if they attempted to answer such a question honestly, as they are probably unaware of all motives underlying their choices (cf. Otterbring, 2021). Similarly, shoppers, marketers, and policymakers are frequently unaware of the motives shaping their decisions in the food domain. For example, when in a mating state of mind, women want to eat healthier, whereas men want to spend more on expensive foods and extra-large burgers, with these male consumption patterns being mediated by a desire to display status - a key asset for men in the mating market (Chan \& Zlatevska, 2019; Otterbring, 2018). 
Given that many (ultimate) motives that guide people's decision-making are universal rather than culture-specific (e.g., Anderson et al., 2015; Hepper et al., 2013), findings stemming from evolutionarily informed theorizing can be more generalizable than those stemming from theorizing accounting only for proximate explanations of consumer behavior. For example, in the food choice context, studies have found that people living in developed countries show similar preferences toward sweet and energy-dense foods as Hadza foragers in Tanzania, who still lead non-commercialized lifestyles (Berbesque \& Marlowe, 2009). Although the consumer behavior literature often disregards ultimate causes of behavior and instead focuses only on proximate explanations, consumer behavior carries with it extensive, broad psychological implications. Accordingly, applying an evolutionary lens seems vital to advance consumer behavior as a discipline (Durante \& Griskevicius, 2018; Otterbring et al., 2020; Saad, 2017, 2020).

\subsubsection{Anticipated food scarcity vs. food insecurity}

Throughout this thesis, I focus on how perceivable — but not actual-scarcity of food resources impacts food preferences. Notably, this construct, also referred to as anticipated food scarcity (AFS) in Paper IV, and defined as "the perception of future food resources becoming insufficient in terms of availability and accessibility" therein, does not entail physical experience of food unavailability (i.e., hunger). Food availability refers to perceiving food resources as existing in sufficient quantities (e.g., high and stable agricultural production). Food accessibility denotes an individual's perceived ability to obtain food (e.g., living close to grocery stores or having stable employment providing income high enough to buy desired food products). 
As such, food scarcity/AFS as treated herein is a perception; therefore, it should be influenced by various external cues and top-down processes (e.g., past knowledge, experience, expectations). It is plausible that people, who have experienced poverty in the past, will deem food resources as scarcer than their peers who have never experienced such hurdles. Further, Brexit, trade wars, climate change, and other similar worldly events potentially threatening global food chains' security may be inferred as cues to upcoming food scarcity. Additionally, even relatively short exposure to food scarcity cues through text or videos increases AFS levels among people (see Paper IV, Study 4).

Anticipated food scarcity studied herein differs from food insecurity — which has been extensively investigated in food science literature - in that it is a perception, whereas food insecurity denotes emotions such as anxiety or fear (Merriam-Webster, 2021). Furthermore, high levels of household food insecurity are positively related to poverty and happen more frequently in low-income countries (Webb et al., 2006). Thus, food insecurity is a problem pervasive primarily across specific populations. However, all people, regardless of their socioeconomic status, may perceive food resources as becoming scarcer; therefore, findings from the empirical package presented herein should be broadly generalizable.

\subsubsection{Mismatched food preferences}

The human cognitive system has evolved through millennia to solve challenges found in ancestral environments that have been vastly different from many challenges found in the contemporary world (Tooby \& Cosmides, 1990). For example, car accidents associated with countless premature deaths each year are more dangerous for modern consumers than snakes or spiders; however, the former has not been a pervasive threat in ances- 
tral environments (cars are relatively novel stimuli when considered human evolutionary history). As a result, modern humans usually do not fear cars and often drive too fast even without realizing dangers associates with such behaviors. Still, they are terrified by snakes and spiders, with many phobias preventing them from approaching these animals (Ornstein \& Ehrlich, 2000).

By the same token, overweight and obesity resulting from overconsumption of calories have not been a pervasive challenge during most human evolutionary history. Famine, in contrast, has been a critical threat for thousands of years, with many episodes of global food shortages happening even in recent centuries (Fagan, 2001). As a consequence of going from short periods of food availability to periods of food scarcity, humans have developed mechanisms protecting them against the latter (Neel, 1962; Prentice et al., 2005; Rozin, 1996). Some of these mechanisms, as described in the insurance hypothesis (Nettle et al., 2017), trigger an increased energy consumption once environmental cues signal scarcity of food.

Although many people suffer from acute hunger in the least developed countries, most people in the world have already stored more fat than they will ever need during their relatively rare and short fasts, especially given that consumers in developing and developed countries usually enjoy stable access to food resources. Thus, responding to cues to food scarcity with increased energy intake is maladaptive in their cases, potentially causing unnecessary weight gain. However, the human cognitive system cannot differentiate between cues to threats found in ancestral environments and similar cues found in the contemporary world (that are not actual threats), triggering evolutionary mismatch-a situation when mechanisms that emerged in ancestral times are activated by evolution- 
arily novel stimuli, leading to negative consequences (Li et al., 2018; Li et al., 2020). For example, Schaller et al. (2010) exposed participants to photographs of people looking like if they were carrying infectious diseases. Such exposure activated their immune systems in a similar way to contact with actual pathogens. However, this effect was not observed among people exposed to the control stimuli, that is, healthy-looking people with guns (Schaller et al., 2010). Notably, photographs of sick-looking people are evolutionarily novel cues to ancestral threats that have continuously accompanied humans-pathogens. Still, increased activity of an immune system is unnecessary in this case-possibly even maladaptive because such immune functions drain energy - as photographs of infected people are not actual pathogens that an immune system has to address. In this thesis, I focus on evolutionary mismatches in food selection domains.

\subsection{The current research}

The insurance hypothesis has been developed to explain a higher prevalence of obesity and overweight among food-insecure populations rather than among people where food insecurity is rare (Nettle et al., 2017; Nettle et al., 2019). Although Nettle et al. (2017) provided a theoretical account supported by a meta-analysis, the authors have not empirically tested the potential influence of cues to food scarcity on shaping food preferences. Instead, this theoretical account explains how environmental cues signaling food shortages trigger increased overall energy intake. However, throughout their evolutionary history, humans had to address yet another set of adaptive challenges occurring during relatively rare times of food abundance - selecting products that are the best buffers against periods of food shortages; hence, they had to develop mechanisms not only adjusting how much 
to eat but also what to eat (Neel, 1962; Prentice et al., 2005; Rozin, 1996). Furthermore, by focusing primarily on food-insecure populations, the insurance hypothesis neglects the role of such cues in shaping food preferences among the general population.

I aim to expand this theoretical account by investigating how food scarcity cues affect food preferences qualitatively among populations where food insecurity is unlikely. Specifically, studies reported in Papers II-III tested the hypothesis that people exposed to food scarcity cues prefer foods deemed as higher in calories more than their peers unexposed to such cues. Finally, in Paper IV, I have delineated a potential psychological mechanism that may partially explain the effects reported across studies in Papers II-III. The second overarching goal of this research is to shed light on whether public communication of events such as Brexit, trade wars, and climate change - as well as marketing communication - does not bear "side effects" in the form of changing food preferences in such a way that may hinder attempts to develop sustainable and healthy food systems (Willett et al., 2019).

\subsection{Overview of Academic Papers}

In this section, I provide an overview of the four Academic Papers included in the thesis (see Table 1.1), organized thematically. Here, I summarize the key aims, methods, results, and conclusions of each paper. Taken together, these papers show how food scarcity cues affect food preferences as a function of their estimated calorie content and delineate a new psychological construct - anticipated food scarcity (AFS) - that can be used in the multidisciplinary study of consumer behavior. 
Table 1.1: Overview of Academic Papers

\begin{tabular}{|c|c|c|c|c|}
\hline Paper & Title & Participants & Aims & Status \\
\hline \multirow[t]{6}{*}{$\mathrm{I}$} & Old minds, new marketplaces: & $\mathrm{N} / \mathrm{A}$ & (1) Outline how eons of evolution- & Conditional \\
\hline & How evolved psychological & & ary history have affected modern con- & acceptance in \\
\hline & mechanisms trigger mis- & & sumers' food preferences & Evolutionary $\mathrm{Be}-$ \\
\hline & matched food preferences & & (2) Propose strategies based on evo- & havioral Sciences \\
\hline & & & lutionarily informed theories that & \\
\hline & & & may facilitate healthier food choices & \\
\hline \multirow[t]{6}{*}{ II } & Crisis communication, antici- & Experts panel $=9$ & (1) Investigate how exposure to food & Published in \\
\hline & pated food scarcity, and food & Pretest Study $1=54$ & scarcity distant in time and space af- & Food Quality and \\
\hline & preferences: Preregistered evi- & Pretest Study $2=56$ & fects food preferences & Preference \\
\hline & dence of the insurance hypoth- & Study $1=98$ & (2) Conduct a preliminary empirical & \\
\hline & esis & Study $2=110$ & examination of the insurance hypoth- & \\
\hline & & Study $3=100$ & esis & \\
\hline \multirow[t]{8}{*}{ III } & Seasonal cues to food scarcity & Pretest $=140$ & (1) Conceptually replicate and ex- & Published in \\
\hline & and calorie cravings: Win- & Study $1 \mathrm{a}=106$ & tend the results reported in Paper II & Food Quality and \\
\hline & ter cues elicit preferences for & Study $1 \mathrm{~b}=105$ & (2) Rule out several potential alter- & Preference \\
\hline & energy-dense foods & Study $2 \mathrm{a}=119$ & native explanations and confounds & \\
\hline & & Study $2 b=120$ & that emerged in Paper II & \\
\hline & & Study $2 \mathrm{c}=420$ & (3) Propose a candidate psychologi- & \\
\hline & & & cal mechanism that may partially ex- & \\
\hline & & & plain the findings & \\
\hline \multirow[t]{8}{*}{ IV } & Development and psychome- & Study $1 \mathrm{a}=10$ & (1) Develop and psychometrically & Published in \\
\hline & tric evaluation of the An- & Study $1 b=26$ & validate a scale measuring antici- & Appetite \\
\hline & ticipated Food Scarcity Scale & Study $1 \mathrm{c}=52$ & pated food scarcity (AFS) - a con- & \\
\hline & $(\mathrm{AFSS})$ & Study $2=303$ & struct that may be a mediator or a & \\
\hline & & Study $3 \mathrm{a}=212$ & moderator of the effects found in $\mathrm{Pa}-$ & \\
\hline & & Study $3 b 140$ & pers II-III & \\
\hline & & Study $4=175$ & (2) Highlight how AFS may be ex- & \\
\hline & & Ancillary Study $=415$ & trapolated to other disciplines & \\
\hline
\end{tabular}




\subsubsection{Paper I}

\section{Aims}

In Paper I, we aimed to briefly show how selection pressures have impacted food preferences among modern consumers. Then, we strived to propose several ways through which policymakers may increase the cost-effectiveness of campaigns promoting healthy eating.

\section{Methods}

In this paper, we reviewed relevant literature that concluded with drawing implications for policymakers.

\section{Conclusions}

We highlighted how the human food acquisition system evolved to cope with threats and opportunities found in ancestral environments, making healthy and low-calorie food promotion arduous, as such foods have had a relatively little adaptive function in the past. Finally, we draw recommendations for policymakers based on the law of law's leverage (Jones, 2001) that account for the degree to which behaviors have been adaptive during the long, evolutionary history of Homo sapiens. These proposed solutions were developed for the relatively high cost-effectiveness of campaigns designed to promote healthier food choices. Notably, to make our solutions feasible, we acknowledged the importance of considering all three main stakeholders in the food industry: retailers, policymakers, and consumers. 


\subsubsection{Paper II}

\section{Aims}

The central aim of the studies reported in Paper II was to provide the first empirical evidence behind the insurance hypothesis (Nettle et al., 2017). Specifically, we tested if mechanisms highlighted therein yield a higher preference toward energy-dense (vs. lowcalorie) foods in response to food scarcity cues. The second aim of Paper II was to test if this effect differed across sexes. Finally, by recruiting samples from the two countries, we strived to test the generalizability of the findings.

\section{Methods}

In the main studies, participants were exposed to either a video showing climate changeinduced food scarcity (i.e., famine in distant parts of the world or drought leading to crop failures that may be more prevalent in the future) or a video showing food abundance (i.e., the rise of obesity in the world). Next, participants had to estimate the calorie content of 30 foods and stated their preferences toward these foods.

\section{Conclusions}

Watching climate change-induced food scarcity distant in time and space increases preferences toward foods deemed as higher in calories. This effect-replicated in all three studies, including a preregistered study — was found across online US samples recruited through MTurk and among Danish university students in a laboratory setting. The studies also provide preliminary evidence behind the sex-specificity of the effects, with females showing a stronger preference toward energy-dense (vs. low-calorie) foods than males after 
exposure to food scarcity cues. In sum, the findings suggest that the insurance hypothesis (Nettle et al., 2017) is applicable not only to food-insecure populations. Instead, food scarcity cues may impact food preferences across the general population in developed countries.

\subsubsection{Paper III}

\section{Aims}

Although the effects reported in Paper II appeared generalizable among WEIRD ${ }^{1}$ samples (Henrich et al., 2010), replicable, and we found no significant differences in the control measures across conditions, the control video depicted obese individuals. Viewing such body types may alter food preferences, potentially leading to lower preferences toward energy-dense dishes (Banovic \& Otterbring, 2021; Campbell \& Mohr, 2011; Otterbring \& Shams, 2019). Aside from this confounding variable that could have driven the effects, there was little evidence that our experimental manipulation successfully elicited desired thoughts related to scarcity, survival, and energy-dense foods.

Thus, in Paper III, we aimed to test whether the effects were generalizable to stimuli that do not show humans and stimuli with low emotional load (i.e., nonexplicit cues to food scarcity). Additionally, we investigated if subtle cues to food scarcity increase the accessibility of concepts linked to survival, scarcity, and energy-dense (but not low-calorie) foods.

\footnotetext{
${ }^{1}$ This acronym stands for overrepresented participants in psychological research who are White, Educated, and come from Industrialized, Rich, and Democratic countries (Henrich et al., 2010).
} 


\section{Methods}

After being exposed to the experimental (a winter forest walk) or the control video stimuli (a summer forest walk), participants filled out the word fragment completion tasks (for details, see Gasiorowska et al., 2018; Nelson et al., 1989; Roediger et al., 1992; Tulving et al., 1982). Specifically, they had to complete 15-word fragments that could be completed in several ways. Here, we tested whether exposure to food scarcity cues increases the number of created words related to survival, scarcity, and energy-dense foods, but not those related to low-calorie foods.

Procedure in Studies 2a-2c mirrored that reported in Paper II, with one exception - we used different experimental and control stimuli, as described in Studies 1a-1b.

\section{Conclusions}

Cues to food scarcity increase accessibility to concepts related to survival and energy-dense foods, but not to concepts related to scarcity and low-calorie foods. Additionally, watching videos depicting subtle cues to food scarcity (a winter forest walk) increases preferences toward energy-dense (vs. low-calorie) foods, with this effect likely being stronger for males than females.

\subsubsection{Paper IV}

\section{Aims}

Papers II-III provide empirical evidence behind the generalizability of the insurance hypothesis (Nettle, 2017) across samples and food scarcity cues of varying intensity, at least in developed countries. However, mechanisms through which cues to food scarcity affect 
food preferences still remain unexplored. Therefore, in Paper IV, we intended to delineate a potential psychological construct — anticipated food scarcity (AFS), with a psychometric scale capturing it - that could partially predict response patterns in the earlier research. An additional goal of research conducted in Paper IV was to test whether AFS is a construct that can be applied to other disciplines studying social behavior.

\section{Methods}

We have applied the six-step psychometric protocol by Dima (2018), focusing primarily on the Mokken scale analysis (MSA) to test the scale's hypothesized unidimensionality and whether its set of items meets the criteria for the double monotonicity model (Van der Ark, 2007, 2012). We established its convergent and divergent validity by correlating the 8-item Anticipated Food Insecurity Scale (AFSS) with existing food insecurity measures, prosocial attitudes, and several other scales, primarily capturing affect. Moreover, we tested the scale's sensitivity to food scarcity cues by exposing participants to textual and video stimuli depicting food scarcity or by exposing them to control stimuli.

\section{Conclusions}

The 8-item AFSS forms a strong, unidimensional scale that can be used to measure people's perceptions of food resources as becoming scarcer. The scale showed significant, albeit low correlations with the existing measures of food insecurity; it is sensitive to food scarcity cues and related to aspects of prosociality. Notably, AFS captured by the scale is a candidate psychological mechanism that may partially explain a shift in food preferences after exposure to food scarcity cues. In sum, AFSS may foster novel experimental research in sustainability, food waste, prosociality, and other related topic areas. 


\subsection{References}

Anderson, C., Hildreth, J. A. D., \& Howland, L. (2015). Is the desire for status a fundamental human motive? A review of the empirical literature. Psychological Bulletin, 141(3), 574. https://doi.org/10.1037/0022-3514.81.1.116

Ares, G., Machıén, L., Vidal, L., Otterbring, T., Aschemann-Witzel, J., Curutchet, M. R., \& Bove, I. (2020). Uruguayan citizens' perception of messages to promote healthy eating through the use of nutritional warnings. Journal of Nutrition Education and Behavior, 52(10), 918-927. https://doi.org/10.1016/j.jneb.2020.05.012

Ares, G., Vidal, L., Otterbring, T., Aschemann-Witzel, J., Curutchet, M. R., Giménez, A., \& Bove, I. (2021). Communication campaigns to support the use of nutritional warnings: Different messages for different people? Health Education 86 Behavior. https://doi.org/10.1177/10901981211003510

Banovic, M., \& Otterbring, T. (2021). Athletic abs or big bellies: The impact of imagery, arousal levels, and health consciousness on consumers' attitudes towards plantbased protein products. Food Quality and Preference, 87, 104067. https://doi.org/ 10.1016/j.foodqual.2020.104067

Bateson, P., \& Laland, K. N. (2013). Tinbergen's four questions: An appreciation and an update. Trends in Ecology \& Evolution, 28(12), 712-718. https://doi.org/10.1016/ j.tree.2013.09.013

Belk, R. W. (1975). Situational variables and consumer behavior. Journal of Consumer Research, 2(3), 157-164. https://doi.org/10.1086/208627 
Berbesque, J. C., \& Marlowe, F. W. (2009). Sex differences in food preferences of Hadza hunter-gatherers. Evolutionary Psychology, 7(4), 147470490900700409. https:// doi.org/10.1177/147470490900700409

Campbell, M. C., \& Mohr, G. S. (2011). Seeing is eating: How and when activation of a negative stereotype increases stereotype-conducive behavior. Journal of Consumer Research, 38(3), 431-444. https://doi.org/10.1086/659754

Chan, E. Y., \& Zlatevska, N. (2019). Is meat sexy? Meat preference as a function of the sexual motivation system. Food Quality and Preference, 74, 78-87. https://doi. $\operatorname{org} / 10.1016 /$ j.foodqual.2019.01.008

Dima, A. L. (2018). Scale validation in applied health research: Tutorial for a 6-step Rbased psychometrics protocol. Health Psychology and Behavioral Medicine, 6(1), 136-161. https://doi.org/10.1080/21642850.2018.1472602

Durante, K. M., \& Arsena, A. R. (2015). Playing the field: The effect of fertility on women's desire for variety. Journal of Consumer Research, 41(6), 1372-1391. https: //doi.org/10.1086/679652

Durante, K. M., \& Griskevicius, V. (2018). Evolution and consumer psychology. Consumer Psychology Review, 1(1), 4-21. https://doi.org/10.1002/arcp.1001

Durante, K. M., Li, N. P., \& Haselton, M. G. (2008). Changes in women's choice of dress across the ovulatory cycle: Naturalistic and laboratory task-based evidence. Personality and Social Psychology Bulletin, 34(11), 1451-1460. https://doi.org/ $10.1177 / 0146167208323103$

Fagan, B. (2001). The Little Ice Age: how climate made history 1300-1850. Basic Books. 
Folwarczny, M., Otterbring, T., Sigurdsson, V., Tan, L. K., \& Li, N. P. (2021). Old minds, new marketplaces: How evolved psychological mechanisms trigger mismatched consumption responses. PsyArXiv. https://doi.org/10.31234/osf.io/zdrpq

Folwarczny, M., Pawar, S., Sigurdsson, V., \& Fagerstrøm, A. (2019). Using neuro-is/consumer neuroscience tools to study healthy food choices: A review. Procedia Computer Science, 164, 532-537. https://doi.org/10.1016/j.procs.2019.12.216

Gasiorowska, A., Zaleskiewicz, T., \& Kesebir, P. (2018). Money as an existential anxiety buffer: Exposure to money prevents mortality reminders from leading to increased death thoughts. Journal of Experimental Social Psychology, 79, 394-409. https: //doi.org/10.1016/j.jesp.2018.09.004

Gidlöf, K., Ares, G., Aschemann-Witzel, J., \& Otterbring, T. (2021). Give us today our daily bread: The effect of hunger on consumers' visual attention towards bread and the role of time orientation. Food Quality and Preference, 88, 104079. https: //doi.org/10.1016/j.foodqual.2020.104079

Griskevicius, V., Cantú, S. M., \& Van Vugt, M. (2012). The evolutionary bases for sustainable behavior: Implications for marketing, policy, and social entrepreneurship. Journal of Public Policy \& Marketing, 31(1), 115-128. https://doi.org/10.1509/ jppm.11.040

Grunert, K. G. (2002). Current issues in the understanding of consumer food choice. Trends in Food Science E Technology, 13(8), 275-285. https://doi.org/10.1016/ S0924-2244(02)00137-1

Haugtvedt, C. P., Petty, R. E., \& Cacioppo, J. T. (1992). Need for cognition and advertising: Understanding the role of personality variables in consumer behavior. 
Journal of Consumer Psychology, 1(3), 239-260. https://doi.org/10.1016/S10577408(08)80038-1

Henrich, J., Heine, S. J., \& Norenzayan, A. (2010). Most people are not WEIRD. Nature, 466, 29. https://doi.org/10.1038/466029a

Hepper, E. G., Sedikides, C., \& Cai, H. (2013). Self-enhancement and self-protection strategies in China: Cultural expressions of a fundamental human motive. Journal of Cross-Cultural Psychology, 44(1), 5-23. https://doi.org/10.1177/0022022111428515

IPSOS. (2021). $45 \%$ of people globally are currently trying to lose weight. https://www. ipsos.com/en/global-weight-and-actions

Jones, O. D. (2001). Time-shifted rationality and the law of law's leverage: Behavioral economics meets behavioral biology. Northwestern University Law Review, 95(4), 1141-1205. https://doi.org/10.2139/ssrn.249419

Kessler, D. A. (2009). The end of overeating: Taking control of the insatiable American appetite. Rodale.

Li, N. P., van Vugt, M., \& Colarelli, S. M. (2018). The evolutionary mismatch hypothesis: Implications for psychological science. Current Directions in Psychological Science, 27(1), 38-44. https://doi.org/10.1177/0963721417731378

Li, N. P., Yong, J. C., \& Van Vugt, M. (2020). Evolutionary psychology's next challenge: Solving modern problems using a mismatch perspective. Evolutionary Behavioral Sciences, 14(4), 362-367. https://doi.org/10.1037/ebs0000207

Machín, L., Curutchet, M. R., Gugliucci, V., Vitola, A., Otterbring, T., de Alcantara, M., \& Ares, G. (2020). The habitual nature of food purchases at the supermarket: 
Implications for policy making. Appetite, 155, 104844. https://doi.org/10.1016/j. appet.2020.104844

Merriam-Webster. (2021). Insecurity. Merriam-Webster.com dictionary. Retrieved February 23, 2021, from https://www.merriam-webster.com/dictionary/insecure

Neel, J. V. (1962). Diabetes mellitus: A "thrifty" genotype rendered detrimental by "progress"? American Journal of Human Genetics, 14(4), 353-362.

Nelson, D. L., Keelean, P. D., \& Negrao, M. (1989). Word-fragment cuing: The lexical search hypothesis. Journal of Experimental Psychology: Learning, Memory, and Cognition, 15(3), 388-397. https://doi.org/10.1037/0278-7393.15.3.388

Nesse, R. M. (2019). Tinbergen's four questions: Two proximate, two evolutionary. Evolution, Medicine, and Public Health, 2019(1), 2-2. https://doi.org/10.1093/emph/ eoy035

Nettle, D. (2017). Does hunger contribute to socioeconomic gradients in behavior? Frontiers in Psychology, 8, 358. https://doi.org/10.3389/fpsyg.2017.00358

Nettle, D., Andrews, C., \& Bateson, M. (2017). Food insecurity as a driver of obesity in humans: The insurance hypothesis. Behavioral and Brain Sciences, 40. https: //doi.org/10.1017/S0140525X16000947

Nettle, D., Joly, M., Broadbent, E., Smith, C., Tittle, E., \& Bateson, M. (2019). Opportunistic food consumption in relation to childhood and adult food insecurity: An exploratory correlational study. Appetite, 132, 222-229. https://doi.org/10.1016/ j.appet.2018.07.018 
Nikolova, H. D., \& Inman, J. J. (2015). Healthy choice: The effect of simplified point-of-sale nutritional information on consumer food choice behavior. Journal of Marketing Research, 52(6), 817-835. https://doi.org/10.1509/jmr.13.0270

Ornstein, R. E., \& Ehrlich, P. R. (2000). New world new mind: Moving toward conscious evolution. ISHK.

Otterbring, T. (2018). Healthy or wealthy? Attractive individuals induce sex-specific food preferences. Food Quality and Preference, 70, 11-20. https://doi.org/10.1016/j. foodqual.2017.02.014

Otterbring, T. (2019). Time orientation mediates the link between hunger and hedonic choices across domains. Food Research International, 120, 124-129. https:// doi. org/10.1016/j.foodres.2019.02.032

Otterbring, T. (2021). Evolutionary psychology in marketing: Deep, debated, but fancier with fieldwork. Psychology \& Marketing, 38(2), 229-238. https://doi.org/10.1002/ mar.21453

Otterbring, T., \& Shams, P. (2019). Mirror, mirror, on the menu: Visual reminders of overweight stimulate healthier meal choices. Journal of Retailing and Consumer Services, 47, 177-183. https://doi.org/10.1016/j.jretconser.2018.11.019

Otterbring, T., Sundie, J., Li, Y. J., \& Hill, S. (2020). Evolutionary psychological consumer research: Bold, bright, but better with behavior. Journal of Business Research, 120, 473-484. https://doi.org/10.1016/j.jbusres.2020.07.010

Prentice, A. M., Rayco-Solon, P., \& Moore, S. E. (2005). Insights from the developing world: Thrifty genotypes and thrifty phenotypes. Proceedings of the Nutrition Society, 64 (2), 153-161. https://doi.org/https://doi.org/10.1079/PNS2005421 
Roediger, H. L., Weldon, M. S., Stadler, M. L., \& Riegler, G. L. (1992). Direct comparison of two implicit memory tests: Word fragment and word stem completion. Journal of Experimental Psychology: Learning, Memory, and Cognition, 18(6), 1251-1269. https://doi.org/10.1037//0278-7393.18.6.1251

Rojas-Rivas, E., Antúnez, L., Cuffia, F., Otterbring, T., Aschemann-Witzel, J., Giménez, A., \& Ares, G. (2020). Time orientation and risk perception moderate the influence of sodium warnings on food choice: Implications for the design of communication campaigns. Appetite, 147, 104562. https://doi.org/10.1016/j.appet.2019.104562

Rozin, P. (1996). Towards a psychology of food and eating: From motivation to module to model to marker, morality, meaning, and metaphor. Current Directions in Psychological Science, 5(1), 18-24. https://doi.org/10.1111/1467-8721.ep10772690

Saad, G. (2017). On the method of evolutionary psychology and its applicability to consumer research. Journal of Marketing Research, 54(3), 464-477. https://doi.org/ 10.1509/jmr.14.0645

Saad, G. (2020). Building a global database of nomological networks of cumulative evidence. Evolutionary Behavioral Sciences. https://doi.org/10.1037/ebs0000223

Schaller, M., Miller, G. E., Gervais, W. M., Yager, S., \& Chen, E. (2010). Mere visual perception of other people's disease symptoms facilitates a more aggressive immune response. Psychological Science, 21(5), 649-652. https://doi.org/10.1177/ 0956797610368064

Scott-Phillips, T. C., Dickins, T. E., \& West, S. A. (2011). Evolutionary theory and the ultimate-proximate distinction in the human behavioral sciences. Perspectives on Psychological Science, 6(1), 38-47. https://doi.org/10.1177/1745691610393528 
Sigurdsson, V., Larsen, N. M., Alemu, M. H., Gallogly, J. K., Menon, R. V., \& Fagerstrøm, A. (2020). Assisting sustainable food consumption: The effects of quality signals stemming from consumers and stores in online and physical grocery retailing. Journal of Business Research, 112, 458-471. https://doi.org/10.1016/j. jbusres.2019.11.029

Sigurdsson, V., Larsen, N. M., \& Gunnarsson, D. (2011). An in-store experimental analysis of consumers' selection of fruits and vegetables. The Service Industries Journal, 31 (15), 2587-2602. https://doi.org/10.1080/02642069.2011.531126

Sigurdsson, V., Larsen, N. M., \& Gunnarsson, D. (2014). Healthy food products at the point of purchase: An in-store experimental analysis. Journal of Applied Behavior Analysis, 47(1), 151-154. https://doi.org/10.1002/jaba.91

Thøgersen, J., Pedersen, S., \& Aschemann-Witzel, J. (2019). The impact of organic certification and country of origin on consumer food choice in developed and emerging economies. Food Quality and Preference, 72, 10-30. https://doi.org/10.1016/j. foodqual.2018.09.003

Tooby, J., \& Cosmides, L. (1990). The past explains the present: Emotional adaptations and the structure of ancestral environments. Ethology and Sociobiology, 11(4-5), 375-424. https://doi.org/10.1016/0162-3095(90)90017-Z

Tulving, E., Schacter, D. L., \& Stark, H. A. (1982). Priming effects in word-fragment completion are independent of recognition memory. Journal of Experimental Psychology: Learning, Memory, and Cognition, 8(4), 336-342. https://doi.org/10. 1037/0278-7393.8.4.336 
Van der Ark, L. A. (2007). Mokken scale analysis in R. Journal of Statistical Software, 20(11), 1-19. https://doi.org/10.18637/jss.v020.i11

Van der Ark, L. A. (2012). New developments in mokken scale analysis in R. Journal of Statistical Software, 48(5), 1-27. https://doi.org/10.18637/jss.v048.i05

Vinson, D. E., Scott, J. E., \& Lamont, L. M. (1977). The role of personal values in marketing and consumer behavior. Journal of Marketing, 41(2), 44-50. https: //doi.org/10.1177/002224297704100215

Wästlund, E., Shams, P., \& Otterbring, T. (2018). Unsold is unseen. . or is it? Examining the role of peripheral vision in the consumer choice process using eye-tracking methodology. Appetite, 120, 49-56. https://doi.org/10.1016/j.appet.2017.08.024

Webb, P., Coates, J., Frongillo, E. A., Rogers, B. L., Swindale, A., \& Bilinsky, P. (2006). Measuring household food insecurity: Why it's so important and yet so difficult to do. The Journal of Nutrition, 136(5), 1404S-1408S. https://doi.org/10.1093/jn/ 136.5.1404S

WHO. (2021). Obesity and overweight. https://www.who.int/news-room/fact-sheets/ detail/obesity-and-overweight

Willett, W., Rockström, J., Loken, B., Springmann, M., Lang, T., Vermeulen, S., Garnett, T., Tilman, D., DeClerck, F., Wood, A., et al. (2019). Food in the Anthropocene: the EAT-Lancet Commission on healthy diets from sustainable food systems. The Lancet, 393(10170), 447-492. https://doi.org/10.1016/S0140-6736(18)31788-4

Wynes, S., \& Nicholas, K. A. (2017). The climate mitigation gap: Education and government recommendations miss the most effective individual actions. Environmental Research Letters, 12(7), 074024. https://doi.org/10.1088/1748-9326/aa7541 


\title{
Chapter 2
}

\section{Old minds, new marketplaces: How evolved psychological} mechanisms trigger mismatched food preferences

Conditional acceptance in Evolutionary Behavioral Sciences

\begin{abstract}
Michał Folwarczny
Department of Business Administration, Reykjavik University

Tobias Otterbring

Department of Management, University of Agder, Institute of Retail Economics
\end{abstract}

Valdimar Sigurdsson

Department of Business Administration, Reykjavik University

Lynn K. L. Tan and Norman P. Li

School of Social Sciences, Singapore Management University 


\begin{abstract}
Principally due to unhealthy food choices, almost half of adults worldwide are overweight or obese. Current food retail practices bear some responsibility for such public health issues. We argue that numerous attempts to promote healthy eating have been unsuccessful due to the failure to account for our outdated evolved food selection mechanisms. Building on the evolutionary mismatch hypothesis and contrasting ancestral versus present-day foraging environments, we discuss how marketing activities exploit evolutionarily old food preferences and elicit unhealthy food choices for profit maximization at the expense of public health in terms of food consumption. We conclude by explaining how to mitigate this harmful trend by applying the law of law's leverage to facilitate effective strategies to increase healthy food choices. Notably, we show how evolutionary psychology principles can be used to reconcile competing interests between consumers, retailers, and decisionmakers responsible for public health policies.
\end{abstract}

Keywords: consumer behavior, evolutionary mismatch, food preferences, food marketing

\title{
Public Significance Statement
}

Consumers often make unhealthy food choices, partially because of mismatches between their food preferences that have evolved due to frequent food scarcity in ancestral environments and the ample availability of food products in the current consumption landscape. Marketers often exploit these evolutionarily old food preferences to increase sales of foods and beverages, including unhealthy ones. Accordingly, understanding how evolutionary mismatches operate can inform more efficient policymaking, improve public health, and boost consumer well-being. 


\section{$2.1 \quad$ Introduction}

During the past few decades, the obesity rate has tripled worldwide, with $40 \%$ of adults now being overweight or obese (Perkovic et al., 2021; WHO, 2020). Overconsumption of unhealthy and energy-dense foods is a pivotal contributor to this public health crisis, which begs for urgent development of healthy food systems (Willett et al., 2019). Considering that consumers acquire foods mainly in retail environments, marketers bear a certain degree of responsibility for these public health issues. However, many retailers are concerned with maximizing profits rather than focusing on consumer well-being. On the other hand, governmental agencies have a high interest in developing effective campaigns that promote healthy eating habits - all 193 United Nations member states have agreed to work toward universal healthcare coverage by 2030 (UN, n.d.), which will increase government expenditures related to treating excessive bodyweight consequences such as cardiovascular diseases and certain forms of cancer (WHO, 2020). In this article, we argue that applying an evolutionary perspective to understand consumer behavior - the evolutionary mismatch framework (Li et al., 2018) and the law of law's leverage (Jones, 2001) - is essential to balancing the competing interests between consumers, retailers, and policymakers, such that retailers can profit sustainably from providing available food options that do not compromise consumers' health.

\subsection{The law of law's leverage}

In line with the law of law's leverage (Jones, 2001), the amount of resources needed to achieve desired behavioral changes is an inverse function of the extent to which the 
behavior solves adaptive challenges related to survival and reproduction (see Figure). Facilitating behaviors that had little adaptive benefits throughout human history is difficult and costly, whereas behaviors that led to solving adaptive challenges need minimal, if any, incentives to occur. In contrast, behaviors that had a high adaptive value in the past are difficult to discourage, whereas even minor deterrents sufficiently prevent behaviors that had a marginal adaptive value. Governmental agencies may increase the cost-effectiveness of their policies by leveraging fundamental motives that emerged as a response to adaptive challenges (Griskevicius \& Kenrick, 2013). For example, publishing names of pickpocketers may be cheaper and provide a stronger deterrent than keeping them in custody that ends with a fine, as people are generally more driven to defend their status in groups than to avoid being in custody (Jones, 2001).

Consuming energy-dense foods has been critical for survival in the past when calories were scarce, and average energy expenditure was relatively high compared to that in modern, sedentary lifestyles. Thus, governments do not have to incentivize consuming chocolate bars, burgers, and pizzas that resemble the taste of foods found in nature that had a high value for promoting survival. In contrast, consuming low-calorie foods has been less critical, especially given that an average lifespan was shorter before the advent of modern medicine. Thus, it is more challenging to promote low-calorie, healthier options such as vegetables, berries, and meats that are close to their natural forms over tastier, high-calorie foods that are processed, sweetened, and genetically modified. Policies that governments may offer to promote substituting unhealthy foods with healthier alternatives should, therefore, leverage these evolved food preferences that influence consumers while shopping. An example of applying such strategies can be to offer foods that taste similar 
and provide the convenience of junk foods like vegan burgers that are lower in sodium and fat than their traditional alternatives. Governmental institutions may further increase the effectiveness of such solutions by creating and publicizing rankings of companies offering the healthiest options, thus rewarding companies and their management with heightened social status. On the other hand, these institutions may create lists of manufacturers adding most sugar, salt, and other unhealthy ingredients to create a "blacklist," with no manufacturers arguably wanting to be located at the bottom of this list.

Figure: The law of law's leverage

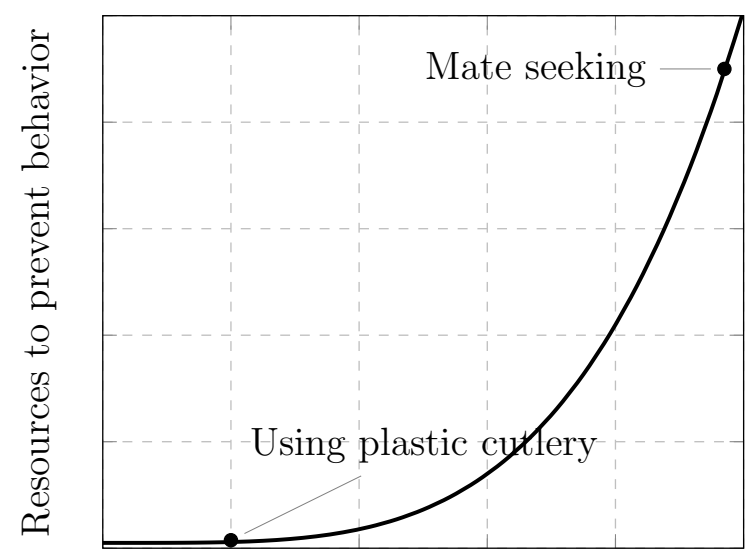

Adaptive value in the past

\subsection{Adaptations to ancestral foraging environments}

To understand what drives a modern consumer to select specific foods from a plethora of alternatives found among the supermarket shelves, we need to understand the ancestral environments in which our predecessors foraged. Modern homo sapiens emerged approximately 300,000 years ago in Southern Africa (Schlebusch et al., 2017). Ancestral humans lived close to nature in tribes usually not exceeding 150 members (Aiello \& Dunbar, 1993; Dunbar, 1993). Ancient foragers did not enjoy stable access to food resources. Instead, 
they faced environments that fluctuated between — often lethal-periods of famine and food availability; thus, they had to develop adaptations against times of food scarcity (Rozin, 1996). Even after farming replaced hunting and gathering, humans experienced famine. For instance, "The Year Without Summer" brought massive crop failures that led to worldwide starvation in 1816 (Fagan, 2001).

As a result of an ancestral lineage that largely lived in hostile habitats, modern-day humans still carry food acquisition and bodyweight regulation mechanisms specialized in protecting them against food shortages (but not against food abundance). Thrifty genotype is an example of such adaptation (Neel, 1962; Prentice et al., 2005). This "thriftiness" takes several forms: (1) the metabolism that favors energy-saving; (2) a tendency to gain weight quickly; (3) an ability to limit physiological processes to a minimum; (4) a predisposition to consume large amounts of food whenever availability allows; (5) a preference toward physical inactivity to conserve energy; and (6) behaviors aimed at maximizing access to food resources such as food hoarding (Prentice et al., 2005).

According to the insurance hypothesis (Nettle et al., 2017), humans possess adaptive mechanisms that respond to environmental cues to food unavailability. These mechanisms increase energy intake over maintenance levels, contributing to higher energy storage in the form of body fat. However, this adaptation appears to be sex-specific, with foodinsecure females more likely than males to be overweight and obese in developed countries (Nettle et al., 2017). This account has received recent empirical support in a series of studies, including preregistered scientific work (Folwarczny, Li, et al., 2021; Folwarczny, Christensen, et al., 2021), where exposure to content showing food scarcity distant in time and space prompted participants to immediately prefer higher calorie foods. These 
findings indicate that humans may react not only to actual food scarcity (cf. Nettle et al., 2017), but also to anticipated food scarcity and perceivable cues linked to such scarcity by shifting their food preferences toward products deemed higher in calories (Folwarczny, Li, et al., 2021).

Unlike specialists eating only one type of food, such as carnivores, humans can consume a wide array of different food options. Thus, when feasting, ancient humans had to select the most nutritious and diverse menus that maximized the chances of surviving an impending famine while minimizing risks associated with consumption-some foods could have been poisonous (Breslin, 2013). Consequently, humans developed a preference toward sweet, salty, and energy-dense foods rich in proteins that provided high doses of nutrients needed for prolonged fasts, but formed an aversion toward sour and bitter tastes, as these flavors may signal that the food contains toxins (Beauchamp et al., 1986; Krebs, 2009; Otterbring, 2021). Although human food preferences have historically been adaptive, these evolved preferences may now lead consumers to indulge in innutritious food products that are available in abundance. Consequently, the nutritional profile of modern-day diets vastly differs from that of ancient diets, leading to adverse health outcomes (Eaton \& Konner, 1985). Indeed, consumers tend to prefer high-fat, highsodium, and high-caloric beef burgers rather than dressing-free salads.

Hunter-gatherers share many similarities in their food preferences with the abovementioned consumers. For instance, the Hadza of Tanzania are hunter-gatherers inhabiting areas where early hominins resided millions of years ago (Berbesque \& Marlowe, 2009). They are opportunistic foragers, usually not seeking specific items. The foods they eat consist of five main categories: honey, meat, berries, baobab, and tubers. High-sugar 
and energy-dense honey is their preferred food option, whereas tubers rich in complex carbohydrates that are more difficult to digest and lower in energy density are the least preferred food items. Interestingly, the Hadza males prefer honey to a larger extent than do females, who instead value berries more (Berbesque \& Marlowe, 2009). However, due to traditional lifestyles, these hunter-gatherers consume primarily unprocessed foods and moderate amounts of calories; thus, their food preferences remain adaptive.

\subsection{Mismatches between ancestral and modern for- aging}

In contrast to ancestral humans who frequently experienced food scarcity and had to invest a considerable amount of time and energy in finding something to eat, modern consumers "forage" conveniently in supermarkets and usually maintain a substantial amount of food in their refrigerators and pantries. In fact, food has become even more accessible, as the retail sector is shifting to online platforms (Sigurdsson et al., 2017), with this trend accelerating due to the current COVID-19 pandemic (Chang \& Meyerhoefer, 2021). Moreover, the number of products offered by an average supermarket has increased from 9,000 to almost 50,000 between 1975 and 2008, with many products offered in dozens of flavors (Consumer Reports, 2014). On top of that, an average person is exposed to thousands of appetite-inducing ads daily (Story, 2007). Additionally, retailers offer products mimicking supernormal versions of the best-tasting foods found in ancestral environments: over half of the calories Americans consume are ultra-processed, high in sodium, and sugar-laden (Steele et al., 2016). 
Given the striking differences between ancestral and modern foraging environments, it becomes evident that the rapid change in which food alternatives that typically occupy most consumers' minds (and most supermarket shelves) has outpaced the changes in the specific psychological mechanisms that evolved throughout our evolutionary past (Tooby \& Cosmides, 1990). Consequently, consumers may fail to cope well with various aspects of modern-day food selection challenges. Such a divergence between evolutionary mechanisms specialized to respond to threats and opportunities found in ancestral environments and modern-day stimuli activating these mechanisms frequently leads to maladaptive outcomes or evolutionary mismatches (Li et al., 2018; Li et al., 2020; Van Vugt et al., 2020). Mismatches occur when psychological and physiological mechanisms, which originated to produce adaptive responses to cues and other inputs found in ancestral environments, encounter evolutionarily novel stimuli (Gidlöf et al., 2021). Mismatched psychological mechanisms then produce cognitive, affective, and behavioral responses that may no longer be adaptive and, sometimes, may even be maladaptive, although evolutionarily novel stimuli do not always yield undesired consequences (cf. Kanazawa, 2010).

\subsection{Policy recommendations}

We argue that applying evolutionarily informed theories may help reconcile the interests of three key stakeholders in the food industry: governmental agencies, retailers, and consumers. The primary interest of governments is to facilitate healthy eating habits to improve public health. Indeed, most countries in the world have agreed to work toward universal health coverage (UN, n.d.), and unhealthy eating results in diseases that are typically extremely expensive to treat at population and national levels (WHO, 2020). 
Food retailers, like retailers in other industries, strive to maximize their profits. Finally, most consumers express a desire to eat healthier and agree that people tend to eat too much and too unhealthily (Pew Research Center, 2016). Unfortunately, consumers' attempts to change their eating habits usually fail. For example, weight-loss diets typically lead to higher body weight subsequently than before starting the program (Mann et al., 2007) and consumers often select cheap, convenient, and tasty foods instead of focusing on healthy nutrition (Wansink \& Huckabee, 2005). These seemingly strange behaviors are understandable if we consider the fact that modern consumers' decision-making machinery has been shaped by thousands of generations of struggle against food unavailability.

\subsubsection{Make healthy foods appealing to evolutionarily-shaped}

\section{taste buds}

Inspired by the evolutionary mismatch framework (Li et al., 2018) and the law of law's leverage (Jones, 2001), we posit that the most promising form of promoting healthy foods consumption is to make them taste as good as or even better than unhealthy options, which usually mimic the taste of sweet, protein-rich, and energy-dense foods found in ancestral environments. Studies show that consumers are only modestly aware of unhealthy snacks being substituted with healthier products at the point of purchase (Winkler et al., 2016). Such interventions increase sales of healthy foods, given that (healthy) product alternatives closely mimick (unhealthy) goods that consumers used to buy before interventions (Hoek et al., 2017; Sigurdsson et al., 2014). Some governments have already introduced policies that facilitate substituting animal-based and unhealthy foods with plant-based and healthier alternatives that closely resemble foods that modern 
consumers - similar to their ancestors - prefer. For example, Singapore strives to become a global leader in plant-based (cholesterol-free) protein production and consumption - the country's state-owned venture has recently invested significant funds into companies producing plant-based animal meat substitutes (Ramli, 2021). Although the future profitability of companies offering meat alternatives is currently uncertain, the value of Impossible Foods and Beyond Meat that belong to leaders in this industry has already surpassed expectations (Sen \& Franklin, 2021). However, in contrast to Singapore, many countries have merely limited consumers' access to certain products without offering any alternatives. We believe that such attempts will be politically unpopular, as consumers' food preferences which have developed through thousands of generations, cannot be wiped out by merely increasing the cost and/or limiting the availability of some products. In fact, higher prices of specific food products may paradoxically make them even more desirable due to the scarcity principle, whereby items that are difficult to access or afford are viewed as more desirable (Lynn, 1991; Otterbring, 2016; Otterbring \& Rolschau, 2021). In the worst case, this may create a rebound effect, where people are more inclined to buy these foods. Additionally, unlike promoting healthy food consumption, imposing taxes on unhealthy foods may hurt the interests of retailers, making them oppose the changes. Retailers can be incentivized to offer more nutritious products, such as snacks made of low-calorie root vegetables seasoned with low-sodium salt instead of omnipresent and unhealthy potato chips. To help retailers stay profitable while phasing out unhealthy foods, governments may financially support them by, for example, offering tax deductions on revenues from healthy foods. 


\subsubsection{Make healthy food choices convenient}

As our ancestors had to conserve energy (Prentice et al., 2005), they could not direct much attention to foods that were especially challenging to obtain. This may partially explain the worldwide success of fast-food chains such as McDonald's, offering low prices and convenience. These low-cost chain restaurants are often the only options for consumers who frequently live in "food deserts" where healthier alternatives are unavailable or difficult to find, making healthy eating inconvenient. Still, the cost of healthy diets rich in fruits and vegetables is only marginally higher per calorie than the cost of diets filled with unhealthy, "cheap" calories (Rao et al., 2013). Therefore, with adequate governmental incentives, fast-food chains may consider introducing more unprocessed, healthier, and plant-based dishes that are as tasty and convenient as their existing offerings without imposing a higher financial burden on consumers. Additionally, it is crucial to make healthy food more prominent (in terms of attention) and easy to buy (in terms of behavioral and cognitive effort and time). The store layout should make it as easy as possible for consumers to select healthy products. For instance, Sigurdsson et al. (2014) conducted experiments in two grocery stores in Norway. The authors substituted sugary snacks in the most convenient places in grocery stores (i.e., check-out counters) with healthier alternatives like dried fruits and dried fish. They found a substantial increase in sales of healthier products and a decrease in sales of sugary snacks. Policymakers may therefore prohibit the sales of foods high in fat and sugar in these locations in grocery stores without lowering overall sales that would harm retailers. In many countries, it is illegal to sell alcohol in grocery stores; thus, similar policies are already applied. 


\subsubsection{Minimize the impact of food scarcity cues}

Ancestral humans have developed mechanisms sensitive to food scarcity cues (Nettle et al., 2017). Thus, instead of featuring public campaigns that bombard consumers with food scarcity cues, governments can reassure people that shelves will remain full during events such as Brexit or the COVID-19 pandemic. Environmental cues may similarly signal food scarcity and elicit calorie cravings among consumers (Folwarczny et al., 2022). On the other hand, moving people from poor to more affluent neighborhoods is associated with decreasing obesity rates (Ludwig et al., 2011). Therefore, policies aimed at minimizing economic inequalities may contribute to addressing obesity in societies. Indeed, income inequality and economic insecurity increase the risk of obesity across countries (Nettle et al., 2017).

\subsubsection{Limit excessive collaborative consumption of food}

Humans, like many other social living species, usually care for their kin, with many goods and services appealing to this fundamental motive (Griskevicius \& Kenrick, 2013). For example, Dopperlerz - a German health tonic - is often advertised as a gift for family members boosting their vitality. Collaborative consumption with consumers contributing to and eating from a shared pool of food (Parker et al., 2019), is a chance for consumers to show their kin care motivation. However, these generosity displays lead people to buy and consume more foods on average than in private settings, potentially contributing to weight gain and food waste (Parker et al., 2019). Nevertheless, kin care motives may be leveraged to lower consumption of unhealthy foods. For example, healthy food sets that will be consumed with others during parties may be advertised similarly to the famous 
German health tonic, potentially making collaborative consumption a "healthier" event.

\subsubsection{Make existing products healthier}

Manufacturers often optimize the amount of sugar, fat, and salt as well as aromas, appearance, and texture of food in a way that maximizes a hedonic pleasure from food consumption, making it more difficult for consumers to stop eating when they are full, mainly because consumers are often unaware of what they are ingesting (Kessler, 2009, p. 140). Therefore, policymakers should help consumers notice the ingredients they ingest. Field experiments have demonstrated that providing calorie information and making healthy foods more convenient to order than unhealthy alternatives reduces overall calorie intake; yet, the effect of convenience is present only when unhealthy options are more challenging to order than healthier alternatives (Wisdom et al., 2010). Thus, such policies may not be feasible and raise ethical concerns regarding consumers' rights. Moreover, it is unlikely that eating healthy belongs to important, adaptive goals that inform a myriad of consumer behaviors. Therefore, a more plausible intervention is selling healthier foods "in disguise." For instance, in Finland, some of Kellogg's cereals have 10\% less sugar and sodium than their US alternatives, with few countries using only $20 \%$ of sodium in Kellogg's Honey Snacks that is used in the US (The Center for Science in the Public Interest, 2016).

\subsubsection{Educate the public}

Consumers are generally not aware of evolutionary mechanisms driving their food choices; hence, making them aware of these mechanisms can facilitate healthier eating (Ares et 
al., 2021; Kessler, 2009, p. 247). Four strategies that policymakers can embrace to help consumers make informed food choices are as follows: (1) listing calories of all items in the restaurant menus; (2) labeling foods in such a way that makes information about unhealthy ingredients salient; (3) conducting public education campaigns highlighting health risks associated with eating unhealthy foods; and (4) demarketing companies that promote unhealthy products by publicly exposing their business practices (Kessler, 2009, pp. 247-248).

Human behavior is largely driven by self-protection (e.g., avoiding pathogens) motives (Griskevicius \& Kenrick, 2013), which may be used as a way to increase the effectiveness of campaigns aimed at curbing unhealthy eating. For instance, Palomo-Vélez et al. (2018) compared the effectiveness of various messages aimed at discouraging meat consumption. The authors found disgust-oriented messages (e.g., informing consumers that meat has contact with faces in slaughterhouses) more potent in making attitudes toward meat consumption more negative than appeals showing the negative impact of meat consumption on the environment, animal welfare, and health. Disgust-eliciting messages are currently used worldwide in anti-smoking campaigns. Thus, policymakers may use disgust-eliciting messages that show the consequences of eating unhealthy foods, such as showing images of stomach cancer developed due to eating high-sodium products.

\subsubsection{If everything fails — use strong incentives}

In some cases - especially when behaviors had a considerable adaptive value in the pastsolid governmental interventions are vital for behavioral change (Jones, 2001). Strong interventions have been successful in reducing undesired behaviors in the past. For in- 
stance, workplace smoking bans reduced smoking prevalence and the average number of cigarettes consumed daily among smokers (Evans et al., 1999). Regarding food choices, one strategy could be to tax unhealthy ingredients. The UK soft drinks industry levy - a tax imposed on manufacturers, importers, and bottlers of soft drinks, with higher rates for drinks high in sugar and lower rates on less sugary products - reduced an average sugar intake from these drinks by $10 \%$ per household, without impacting overall sales of soft drinks, thus not harming the industry (Pell et al., 2021). Similar policies may be implemented to reduce calories, saturated fat, and salt in other product categories. Manufacturers may be incentivized through grants covered by such taxes to produce healthier products appealing to human evolutionarily old taste buds by, for instance, substituting some sugar with stevia.

\subsection{Conclusion}

Ancestral foragers had to select foods promoting survival in times of frequent food scarcity. As a result, modern consumers inherited these outdated food preferences, which are mismatched against their current needs, with almost half of adults now being overweight or obese. As modern consumers carry food acquisition mechanisms specialized in coping with ancestral challenges, they often fail to perceive threats posed by unhealthy diets, even if these threats are communicated (e.g., nutrition facts labels). Still, retailers - incentivized by governments - can facilitate healthier food choices by applying evolutionarily informed solutions into their marketing mix. 


\subsection{References}

Aiello, L. C., \& Dunbar, R. I. M. (1993). Neocortex size, group size, and the evolution of language. Current Anthropology, 34(2), 184-193.

Ares, G., Vidal, L., Otterbring, T., Aschemann-Witzel, J., Curutchet, M. R., Giménez, A., \& Bove, I. (2021). Communication campaigns to support the use of nutritional warnings: Different messages for different people? Health Education $\&$ Behavior. https://doi.org/10.1177/10901981211003510

Beauchamp, G. K., Cowart, B. J., \& Moran, M. (1986). Developmental changes in salt acceptability in human infants. Developmental Psychobiology: The Journal of the International Society for Developmental Psychobiology, 19(1), 17-25. https://doi. $\operatorname{org} / 10.1002 / \operatorname{dev} .420190103$

Berbesque, J. C., \& Marlowe, F. W. (2009). Sex differences in food preferences of Hadza hunter-gatherers. Evolutionary Psychology, 7(4), 147470490900700409. https:// doi.org/10.1177/147470490900700409

Breslin, P. A. (2013). An evolutionary perspective on food and human taste. Current Biology, 23(9), R409-R418. https://doi.org/10.1016/j.cub.2013.04.010

Chang, H.-H., \& Meyerhoefer, C. D. (2021). COVID-19 and the demand for online food shopping services: Empirical evidence from Taiwan. American Journal of Agricultural Economics, 103(2), 448-465. https://doi.org/10.1111/ajae.12170

Consumer Reports. (2014). What to do when there are too many product choices on the store shelves? https://www. consumerreports.org/cro/magazine/2014/03/toomany-product-choices-in-supermarkets /index.htm\#: : text $=\mathrm{We} \%$ 20eyeballed $\%$ 2053\%20varieties.,Marketing\%20Institute\%2C\%20a\%20trade\%20group 
Dunbar, R. I. M. (1993). Coevolution of neocortical size, group size and language in humans. Behavioral and Brain Sciences, 16(4), 681-694. https://doi.org/10.1017/ S0140525X00032325

Eaton, S. B., \& Konner, M. (1985). Paleolithic nutrition: A consideration of its nature and current implications. New England Journal of Medicine, 312(5), 283-289. https: //doi.org/10.1056/NEJM198501313120505

Evans, W. N., Farrelly, M. C., \& Montgomery, E. (1999). Do workplace smoking bans reduce smoking? American Economic Review, 89(4), 728-747. https://doi.org/10. $1257 /$ aer.89.4.728

Fagan, B. (2001). The Little Ice Age: how climate made history 1300-1850. Basic Books.

Folwarczny, M., Li, N. P., Sigurdsson, V., Tan, L. K., \& Otterbring, T. (2021). Development and psychometric evaluation of the Anticipated Food Scarcity Scale (AFSS). Appetite, 166, 105474. https://doi.org/10.1016/j.appet.2021.105474

Folwarczny, M., Otterbring, T., Sigurdsson, V., \& Gasiorowska, A. (2022). Seasonal cues to food scarcity and calorie cravings: Winter cues elicit preferences for energydense foods. Food Quality and Preference, 96, 104379. https://doi.org/10.1016/j. foodqual.2021.104379

Folwarczny, M., Christensen, J. D., Li, N. P., Sigurdsson, V., \& Otterbring, T. (2021). Crisis communication, anticipated food scarcity, and food preferences: Preregistered evidence of the insurance hypothesis. Food Quality and Preference, 91, 104213. https://doi.org/10.1016/j.foodqual.2021.104213

Gidlöf, K., Ares, G., Aschemann-Witzel, J., \& Otterbring, T. (2021). Give us today our daily bread: The effect of hunger on consumers' visual attention towards bread 
and the role of time orientation. Food Quality and Preference, 88, 104079. https: //doi.org/10.1016/j.foodqual.2020.104079

Griskevicius, V., \& Kenrick, D. T. (2013). Fundamental motives: How evolutionary needs influence consumer behavior. Journal of Consumer Psychology, 23(3), 372-386. https://doi.org/10.1016/j.jcps.2013.03.003

Hoek, A., Pearson, D., James, S., Lawrence, M., \& Friel, S. (2017). Healthy and environmentally sustainable food choices: Consumer responses to point-of-purchase actions. Food Quality and Preference, 58, 94-106. https://doi.org/10.1016/j. foodqual.2016.12.008

Jones, O. D. (2001). Time-shifted rationality and the law of law's leverage: Behavioral economics meets behavioral biology. Northwestern University Law Review, 95(4), 1141-1205. https://doi.org/10.2139/ssrn.249419

Kanazawa, S. (2010). Evolutionary psychology and intelligence research. American Psychologist, 65(4), 279-289. https://doi.org/10.1037/a0019378

Kessler, D. A. (2009). The end of overeating: Taking control of the insatiable American appetite. Rodale.

Krebs, J. R. (2009). The gourmet ape: Evolution and human food preferences. The American Journal of Clinical Nutrition, 90(3), 707S-711S. https://doi.org/10.3945/ ajcn.2009.27462B

Li, N. P., van Vugt, M., \& Colarelli, S. M. (2018). The evolutionary mismatch hypothesis: Implications for psychological science. Current Directions in Psychological Science, 27(1), 38-44. https://doi.org/10.1177/0963721417731378 
Li, N. P., Yong, J. C., \& Van Vugt, M. (2020). Evolutionary psychology's next challenge: Solving modern problems using a mismatch perspective. Evolutionary Behavioral Sciences, 14(4), 362-367. https://doi.org/10.1037/ebs0000207

Ludwig, J., Sanbonmatsu, L., Gennetian, L., Adam, E., Duncan, G. J., Katz, L. F., Kessler, R. C., Kling, J. R., Lindau, S. T., Whitaker, R. C., et al. (2011). Neighborhoods, obesity, and diabetes - a randomized social experiment. New England Journal of Medicine, 365(16), 1509-1519. https://doi.org/10.1056/NEJMsa1103216

Lynn, M. (1991). Scarcity effects on value: A quantitative review of the commodity theory literature. Psychology \& Marketing, 8(1), 43-57. https://doi.org/10.1002/mar. 4220080105

Mann, T., Tomiyama, A. J., Westling, E., Lew, A.-M., Samuels, B., \& Chatman, J. (2007). Medicare's search for effective obesity treatments: Diets are not the answer. American Psychologist, 62(3), 220-233. https://doi.org/10.1037/0003-066X.62.3.220

Neel, J. V. (1962). Diabetes mellitus: A "thrifty" genotype rendered detrimental by "progress"? American Journal of Human Genetics, 14(4), 353-362.

Nettle, D., Andrews, C., \& Bateson, M. (2017). Food insecurity as a driver of obesity in humans: The insurance hypothesis. Behavioral and Brain Sciences, 40. https: //doi.org/10.1017/S0140525X16000947

Otterbring, T. (2016). Touch forbidden, consumption allowed: Counter-intuitive effects of touch restrictions on customers' purchase behavior. Food Quality and Preference, 50, 1-6. https://doi.org/10.1016/j.foodqual.2015.12.011 
Otterbring, T. (2021). Evolutionary psychology in marketing: Deep, debated, but fancier with fieldwork. Psychology \& Marketing, 38(2), 229-238. https://doi.org/10.1002/ $\operatorname{mar} .21453$

Otterbring, T., \& Rolschau, K. (2021). Beauty is in the eye of the beer holder but rarely because of the beer. Personality and Individual Differences, 179, 110921. https: //doi.org/10.1016/j.paid.2021.110921

Palomo-Vélez, G., Tybur, J. M., \& Van Vugt, M. (2018). Unsustainable, unhealthy, or disgusting? comparing different persuasive messages against meat consumption. Journal of Environmental Psychology, 58, 63-71. https://doi.org/10.1016/j.jenvp. 2018.08 .002

Parker, J. R., Umashankar, N., \& Schleicher, M. G. (2019). How and why the collaborative consumption of food leads to overpurchasing, overconsumption, and waste. Journal of Public Policy \& Marketing, 38(2), 154-171. https://doi.org/10.1177/ 0743915618823783

Pell, D., Mytton, O., Penney, T. L., Briggs, A., Cummins, S., Penn-Jones, C., Rayner, M., Rutter, H., Scarborough, P., Sharp, S. J., et al. (2021). Changes in soft drinks purchased by British households associated with the UK soft drinks industry levy: Controlled interrupted time series analysis. BMJ, 372. https://doi.org/10.1136/ bmj.n254

Perkovic, S., Otterbring, T., Schärli, C., \& Pachur, T. (2021). The perception of food products in adolescents, lay adults, and experts: A psychometric approach. Journal of Experimental Psychology: Applied. https://doi.org/10.1037/xap0000384 
Pew Research Center. (2016). The new food fights: U.S. public divides over food science. https://www.pewresearch.org/science/2016/12/01/the-new-food-fights/

Prentice, A. M., Rayco-Solon, P., \& Moore, S. E. (2005). Insights from the developing world: Thrifty genotypes and thrifty phenotypes. Proceedings of the Nutrition Society, 64(2), 153-161. https://doi.org/https://doi.org/10.1079/PNS2005421

Ramli, D. (2021). Temasek makes rare seed investment in plant-based chicken maker. https: / / www . bloomberg. com/news / articles / 2021- 02- 25/temasek- makes- rareseed-investment-in-plant-based-chicken-maker

Rao, M., Afshin, A., Singh, G., \& Mozaffarian, D. (2013). Do healthier foods and diet patterns cost more than less healthy options? A systematic review and meta-analysis. BMJ Open, 3(12), e004277. https://doi.org/10.1136/bmjopen-2013-004277

Rozin, P. (1996). Towards a psychology of food and eating: From motivation to module to model to marker, morality, meaning, and metaphor. Current Directions in Psychological Science, 5(1), 18-24. https://doi.org/10.1111/1467-8721.ep10772690

Schlebusch, C. M., Malmström, H., Günther, T., Sjödin, P., Coutinho, A., Edlund, H., Munters, A. R., Vicente, M., Steyn, M., Soodyall, H., et al. (2017). Southern African ancient genomes estimate modern human divergence to 350,000 to 260,000 years ago. Science, 358(6363), 652-655. https://doi.org/10.1126/science.aao6266

Sen, A., \& Franklin, J. (2021, April 8). Exclusive: Impossible Foods in talks to list on the stock market - sources. https://www.reuters.com/article/us-impossible-foods-ma-exclusive-idUSKBN2BV2SF 
Sigurdsson, V., Larsen, N. M., \& Gunnarsson, D. (2014). Healthy food products at the point of purchase: An in-store experimental analysis. Journal of Applied Behavior Analysis, 47(1), 151-154. https://doi.org/10.1002/jaba.91

Sigurdsson, V., Menon, R. V., \& Fagerstrøm, A. (2017). Online healthy food experiments: Capturing complexity by using choice-based conjoint analysis. The Behavior Analyst, 40(2), 373-391. https://doi.org/10.1007/s40614-017-0114-9

Steele, E. M., Baraldi, L. G., da Costa Louzada, M. L., Moubarac, J.-C., Mozaffarian, D., \& Monteiro, C. A. (2016). Ultra-processed foods and added sugars in the us diet: Evidence from a nationally representative cross-sectional study. BMJ Open, 6(3). https://doi.org/10.1136/bmjopen-2015-009892

Story, L. (2007). Anywhere the eye can see, it's likely to see an ad. https://www.nytimes. com/2007/01/15/business/media/15everywhere.html

The Center for Science in the Public Interest. (2016, November 29). U.S. cereals higher in sugar and sodium than in certain other countries. https://cspinet.org/news/uscereals-higher-sugar-and-sodium-certain-other-countries-20161129

Tooby, J., \& Cosmides, L. (1990). The past explains the present: Emotional adaptations and the structure of ancestral environments. Ethology and Sociobiology, 11(4-5), 375-424. https://doi.org/10.1016/0162-3095(90)90017-Z

UN. (n.d.). Goal 3: Good health and well-being. https://www.un.org/development/desa/ disabilities/envision2030-goal3.html

Van Vugt, M., De Vries, L. P., \& Li, N. P. (2020). Nudging evolutionary mismatched behaviors: Implications for social psychology and public policy. In J. P. Forgas, W. D. Crano, \& K. Fiedler (Eds.), Applications of social psychology: How social 
psychology can contribute to the solution of real world problems (pp. 40-57). Taylor \& Francis. https://doi.org/10.4324/9780367816407

Wansink, B., \& Huckabee, M. (2005). De-marketing obesity. California Management Review, 47(4), 6-18. https://doi.org/10.2139/ssrn.2473723

WHO. (2020). Obesity and overweight. https://www.who.int/news-room/fact-sheets/ detail/obesity-and-overweight

Willett, W., Rockström, J., Loken, B., Springmann, M., Lang, T., Vermeulen, S., Garnett, T., Tilman, D., DeClerck, F., Wood, A., et al. (2019). Food in the Anthropocene: the EAT-Lancet Commission on healthy diets from sustainable food systems. The Lancet, 393(10170), 447-492. https://doi.org/10.1016/S0140-6736(18)31788-4

Winkler, L. L., Christensen, U., Glümer, C., Bloch, P., Mikkelsen, B. E., Wansink, B., \& Toft, U. (2016). Substituting sugar confectionery with fruit and healthy snacks at checkout - a win-win strategy for consumers and food stores? A study on consumer attitudes and sales effects of a healthy supermarket intervention. BMC Public Health, 16(1), 1-12. https://doi.org/10.1186/s12889-016-3849-4

Wisdom, J., Downs, J. S., \& Loewenstein, G. (2010). Promoting healthy choices: Information versus convenience. American Economic Journal: Applied Economics, 2(2), 164-78. https://doi.org/10.1257/app.2.2.164 


\section{Chapter 3}

\section{Crisis communication, anticipated food scarcity, and food}

preferences: Preregistered evidence of the insurance hypothesis

Published in Food Quality and Preference

Michał Folwarczny

Department of Business Administration, Reykjavik University

Jacob D. Christensen

Department of Economics, Swedish University of Agricultural Sciences

Norman P. Li

School of Social Sciences, Singapore Management University

Valdimar Sigurdsson

Department of Business Administration, Reykjavik University

Tobias Otterbring

Department of Management, University of Agder,

Institute of Retail Economics 


\begin{abstract}
Whereas large-scale consumption of energy-dense foods contributes to climate change, we investigated whether exposure to climate change-induced food scarcity affects preferences toward these foods. Humans' current psychological mechanisms have developed in their ancestral evolutionary past to respond to immediate threats and opportunities. Consequently, these mechanisms may not distinguish between cues to actual food scarcity and cues to food scarcity distant in time and space. Drawing on the insurance hypothesis, which postulates that humans should respond to environmental cues to food scarcity through increased energy consumption, we predicted that exposing participants to climate change-induced food scarcity content increases their preferences toward energy-dense foods, with this effect being particularly pronounced in women. Three experimentsincluding one preregistered laboratory study - confirm this notion. Our findings jointly demonstrate that receiving information about food shortages distant in time and space can influence current food preferences.
\end{abstract}

Keywords: climate change, media exposure, the insurance hypothesis, food preferences, food scarcity 


\subsection{Introduction}

The current literature points at energy-dense foods - often derived from animal sourcesas some of the most significant climate change culprits. Accordingly, avoiding such products is an essential step toward developing sustainable and healthy food systems (Willett et al., 2019). However, it is unlikely that the current media appeals and experts' recommendations to eat more low-calorie fruits and vegetables instead of energy-dense foods are effective in encouraging pro-environmental food choices: the number of overweight and obese people has been rising for decades, and energy-dense foods are the prime contributors to this trend (WHO, 2020).

Numerous barriers affect sustainable and healthy food choices, such as personal values, product familiarity, or lack of knowledge (De Boer et al., 2007; Hoek et al., 2017; Laureati et al., 2013; Siegrist et al., 2015). Recent research has shown that communication efforts can influence attitudes toward sustainable foods (Aschemann-Witzel \& Peschel, 2019). However, no studies have investigated if climate change communication that often highlights the negative impact on food security worldwide can affect food preferences. We explore this possibility, questioning the effectiveness of omnipresent climate change campaigns that vividly emphasize the consequences for food security worldwide. For instance, a public campaign by Greenpeace International aimed to promote biodiversity in farming and extensively highlighted the negative impact of weather anomalies on crop yields and food production (Cotter \& Tirado, 2008).

Climate change has been extensively argued to harm the food supply (Schmidhuber \& Tubiello, 2007; Wheeler \& Von Braun, 2013); yet, the harm comes in the future, perhaps as far away as a generation or two later (Battisti \& Naylor, 2009). However, 
mass media already inform societies about these threats, and over $60 \%$ of Americans and Australians have declared themselves to be somewhat or very concerned about climate change (Clayton, 2019).

According to the insurance hypothesis (Nettle et al., 2017), humans and other vertebrates possess evolutionary mechanisms protecting them against food shortages. In their distant evolutionary past, humans rarely experienced times of food abundance; rather, they wandered between periods of food sufficiency and food scarcity. Thus, they have likely developed decision-making mechanisms that facilitate the consumption of foods that maximized their odds of survival (Rozin, 1996). Consistent with this notion, the insurance hypothesis postulates that environmental cues linked to food insecurity prompt people to eat and store more fat as a buffer against impending caloric deficits. Indeed, studies conducted in different countries link actual food insecurity to choosing energydense foods instead of fruits and vegetables (Gulliford et al., 2003; Robaina \& Martin, 2013).

Notably, the current psychological mechanisms, which were developed in our distant evolutionary past, have been primarily designed to respond to immediate threats and opportunities and cannot differentiate between cues that have consequences for an individual in the coming days or weeks from similar cues that have-like in the case of climate change-induced food scarcity - consequences in the distant future (Ornstein \& Ehrlich, 2000). However, cues to climate change-induced food scarcity occurring in distant parts of the world may activate the same psychological mechanisms as cues to actual food scarcity in one's neighborhood. Therefore, drawing on the insurance hypothesis that has been developed primarily to explain responses to impending food shortages (Nettle 
et al., 2017), we contend that perceivable cues to food scarcity may also induce people to prefer energy-dense foods over low-calorie alternatives, despite the apparent absence of an adaptive function of such preferences today.

Because the energetic value of food is conventionally expressed in calories, and these play a role in food choices (Gerend, 2009; Wisdom et al., 2010), our main hypothesis is that people exposed to climate change-induced food scarcity content prefer foods they deem to be higher in calories. Moreover, carrying extra fat reserves poses survival-related costs, and these costs have been presumably higher for men than women in the past due to sex-specific roles in society. In particular, men, being responsible for hunting and fighting, could not afford as much extra weight as women in ancestral times (Nettle et al., 2017; Silverman \& Eals, 1992). Therefore, our secondary hypothesis states that women exposed to food scarcity content prefer higher-calorie foods more than men.

\subsection{Method}

Study 1 provided initial support of our two key predictions and confirmed that the sample size estimated a priori was sufficient. Study 2 replicated the results from our first study while simultaneously ruling out a potential confound from Study 1, thereby strengthening the confidence in our findings. Because both initial studies were run online on Amazon Mechanical Turk (MTurk), we preregistered Study 3 (https://osf.io/3rbk2), which was conducted in a laboratory facility, to test the robustness, generalizability, and replicability of our findings.

Raw data, analysis code, and materials are publicly available at the Open Science Framework (OSF; https://osf.io/vkdha/). Studies 1-2 follow the same analytical ap- 
proach as the preregistered Study 3. Coefficients, standard errors, and confidence intervals reported in Studies 1-3 were multiplied by 100 for readability (see the Supplementary Information available on OSF for additional results and raw coefficients). We did not measure anticipated food scarcity after watching the videos in Studies 1-3, as these measures could prompt participants to think extensively about food scarcity and therefore alter subsequent responses.

\subsubsection{Stimuli development}

Nine experts (four certified nutritionists and five athletes who measured the calorie content of foods daily evaluated the calorie content and healthfulness of 60 food pictures. The results suggested moderate to good reliability between raters $\left(I C C=0.82, C I_{95}=[0.73\right.$, 0.88]). We then divided standard deviations by means to obtain coefficients of variations in calorie estimates for each food item. We chose 30 foods below the median coefficient of variation for Studies 1-3. That yielded a final set of food images ranging from 166 to 711 calories ( $M=367, S D=122$; see https://osf.io/vkdha/ for these materials).

We composed two 100-second-long videos depicting either climate change-induced food scarcity (experimental condition) or the rise of obesity in the world (control condition; links available through OSF). Each video consisted of three short clips that were played continuously. We extensively pretested the stimuli videos to ensure that they differed on the desired key dimension - anticipated food scarcity — while producing comparable results on a set of potentially confounding variables. In the main pretest study, we measured anticipated food scarcity, as well as positive and negative affect, as elicited by the videos. Participants from the United States recruited via MTurk $(N=54)$ stated 
their anticipated food scarcity on a randomized-order scale $(1=$ strongly disagree, $7=$ strongly agree). The scale consisted of six items ("The availability of my favorite foods will decrease next decade"; "The beverages I drink will be less affordable by 2030"; "I will see less food variety in grocery stores in the future"; "Certain foods I eat now will disappear at some stage of my life"; "My future diet will be more monotonous"; "I will have to eat less protein-rich dishes for some time") that we averaged $(\alpha=0.92)$. Participants who watched the experimental (climate change-induced food scarcity) video considered future food resources to be more insecure (experimental condition: $M=4.59, S D=1.48$; control condition: $M=3.75, S D=1.35), t(52)=-2.03, p=.047, d=0.58$. We used the Positive and Negative Affect Schedule (PANAS) to evaluate positive and negative affect elicited by either video on a five-point scale (Watson et al., 1988). We randomized the order of all items: 10 for positive $(\alpha=0.93)$ and 10 for negative $(\alpha=0.94)$ affect and averaged each subscale's items. The groups did not differ in terms of negative (experimental condition: $M=1.82, S D=0.84$; control condition: $M=1.55, S D=0.85), t(52)=-1.15, p=.257$, or positive affect (experimental condition: $M=2.69, S D=0.95$; control condition: $M=$ 2.79, $S D=1.06), t(52)=0.39, p=.701$. We supported these findings with an ancillary pretest study that revealed no differences in the measures of emotions, anxiety, stress, and hunger (details available through Supplementary Information File available on OSF).

\subsubsection{Measures}

The experts' ratings yielded foods ranging from 166 to 711 calories $(M=367, S D=122)$; hence we created a response slider scale from 0 to 1000 calories with one-point intervals. Participants in Studies 1-3 responded on this sliding scale as we wanted to capture their 
subjective perceptions of the caloric content of foods to test the hypothesis that they will prefer foods they deem to be higher in calories in the experimental conditions (climate change-induced food scarcity). Participants stated preferences by answering the question, "Would you eat this food now?" on a similar sliding scale ranging from definitely not $(-1)$ to definitely yes (1) with 0.01 intervals. Hunger plays a vital role in food-related decision-making (Orquin \& Kurzban, 2016). Thus, we measured hunger on a four-item scale $(1=$ disagree strongly, $7=$ agree strongly; Otterbring \& Sela, 2020). These items and sample tasks are publicly available (https://osf.io/4qu7v/).

\subsubsection{Participants}

We ran a stochastic power simulation in $\mathrm{R}$ to estimate the required sample size to detect the main effect of treatment. We found that at least 82 participants were necessary to achieve 0.95 power, assuming Cohen's $d$ of 0.35 .

The Cognition and Behavior Lab's Human Subjects Committee at Aarhus University approved the data collection (approval no. ID276). We recruited 98 and 110 participants from the United States for Studies 1 (48 women, $M_{\text {age }}=31.9$ years, $S D=9.5$, range $=$ 18-69 years), and 2 (49 women, $M_{\text {age }}=36.8$ years, $S D=10.8$, range $=22-74$ years) on Amazon MTurk. The preregistered laboratory Study 3 employed 100 participants (44 women, $M_{\text {age }}=23.6$ years, $S D=5.3$, range $=18-64$ years) from the campus and participant pool at a Danish university, most of whom were students. 


\subsubsection{Procedure}

Participants first read and accepted the online consent form. Upon pressing the "start" button, they were randomly assigned to watch either the experimental (climate changeinduced food scarcity) or control video. After seeing their assigned video, they estimated the calorie content and stated their preferences for 30 foods. The order of each block (calories or preferences) and the order of foods within the blocks were both randomized. Lastly, participants provided demographic data and rated their levels of hunger. In Study 2 , one more control group was added that did not watch any video to ensure that the experimental manipulation drives the potential effects rather than confounds from the control video. Such a design allowed testing whether the two control groups differed in any of the critical measures.

\subsection{Results}

We performed a linear mixed-effects analysis of the relationship between calorie estimates and treatment. As Table 3.1 suggests, the interaction between treatment and calorie estimates was significant in all three studies. These results mean that climate change videos showing food scarcity increased preferences toward foods that participants deemed to be higher in calories. Further, Studies 1-2 revealed a three-way interaction between treatment, calorie estimates, and participants' sex. These findings imply that women preferred foods they thought to be higher in calories more than men did after watching climate change videos (see Figure 3.1). Although Study 3 did not find this three-way interaction at conventional levels of statistical significance $(p=.152)$, comparisons in Table 3.1 indicate a trend in the same direction across all three studies. These results, 
taken together, confirm both hypotheses.

As Study 2 sought to rule out potential confounds associated with the control video, we performed a similar analysis comparing the two control groups in this study (one exposed to the video showing obesity, and the other one proceeding directly to evaluating the food pictures). The main effects of treatment $(p=.650)$, calorie estimates $(p=.206)$, and their interaction $(p=.997)$ on food preferences were consistently nonsignificant. Moreover, these two control groups had similar hunger levels $(p>.38)$, with hunger used as a covariate across all studies. Thus, the potential confound from the control video is unlikely to have been the main driver of the results, and both control groups were merged for further analysis.

Table 3.1: Results corresponding to the main hypothesis (interaction: calories $\times$ treatment) and the secondary hypothesis (interaction: calories $\times$ treatment $\times$ sex).

\begin{tabular}{lllll}
\hline Fixed effects & $b(S E)$ & $t$ & $p$ & $95 \%$ CI \\
\hline Calories $\times$ Treatment & & & & \\
Study 1 & $0.029(0.011)$ & $t(2815.52)=2.74$ & .006 & {$[0.008,0.049]$} \\
Study 2 & $0.022(0.009)$ & $t(2905.42)=2.31$ & .021 & {$[0.003,0.040]$} \\
Study 3 & $0.027(0.011)$ & $t(2968.19)=2.35$ & .019 & {$[0.005,0.049]$} \\
Calories $\times$ Treatment & & & & \\
$\times$ Sex $($ men $)$ & & & & \\
Study 1 & & & & \\
Study 2 & $-0.063(0.021)$ & $t(2821.52)=-3.00$ & .003 & {$[-0.103,-0.021]$} \\
Study 3 & $-0.069(0.019)$ & $t(2916.47)=-3.62$ & $<.001$ & {$[-0.106,-0.032]$} \\
\hline
\end{tabular}


Importantly, our manipulation did not impact calorie judgments in any study (all $p s>$ $.47)$, and the effects reported above applied despite that the experimental group reported higher hunger scores in Study 1 (experimental condition: $M=5.23, S D=1.37$; control condition: $M=4.48, S D=1.75), t(96)=-2.37, p=.020$. Studies 2 and 3 did not reveal any differences in hunger between groups ( $F<1$ and $t<1$, respectively).

Figure 3.1: Mean food preferences as a function of mean calorie estimates for all participants in Studies 1 through $3(N=308)$. This plot suggests that women depreciate low-calorie foods and prefer high-calorie foods to a larger extent than men after exposure to food scarcity content.

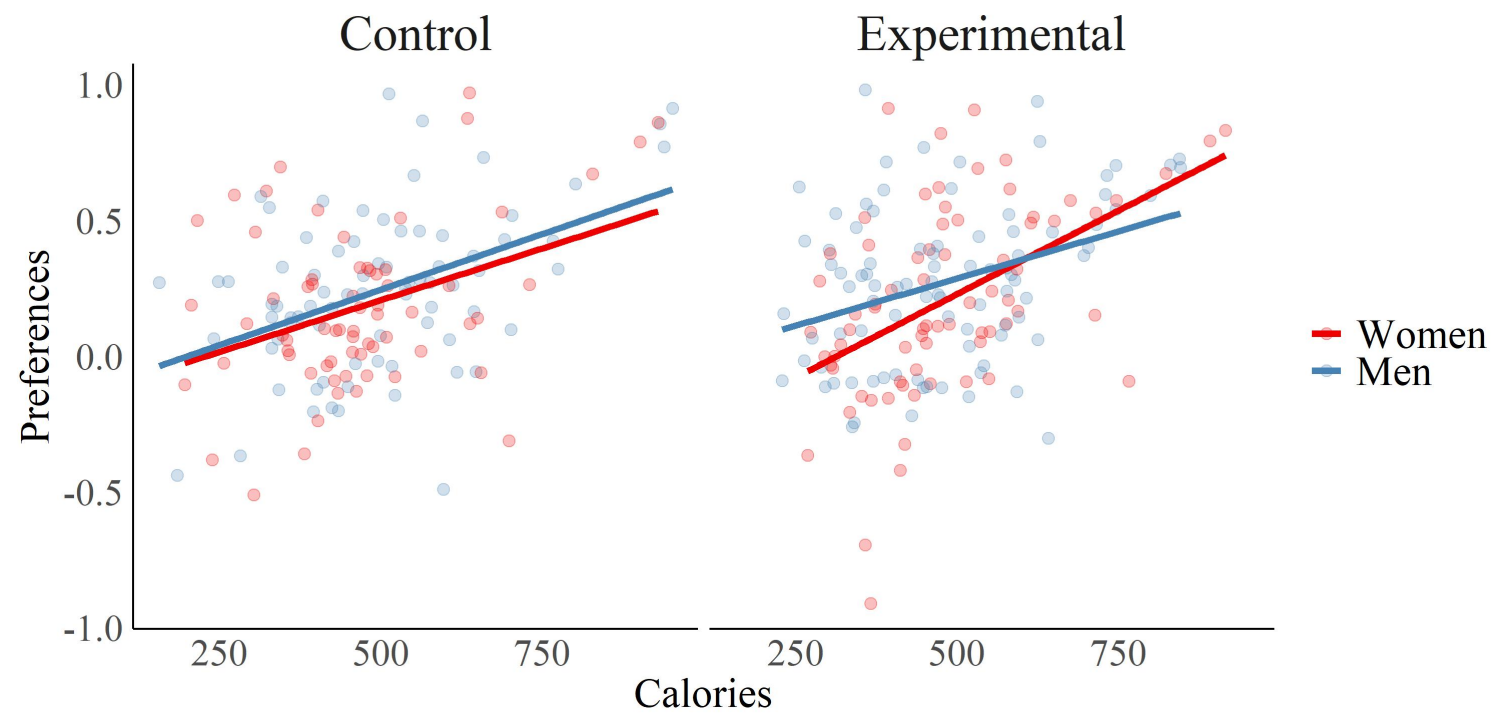

\subsection{Discussion}

Building on the insurance hypothesis (Nettle et al., 2017), we predicted that watching climate change-induced food scarcity content will make people prefer energy-dense foods. Three experiments confirm this notion by showing that such content makes people prefer 
high-calorie foods and that this effect is stronger for women.

Earlier research indicates that viewing specific body types may shift food preferences (Campbell \& Mohr, 2011; Otterbring \& Shams, 2019). We attempted to mitigate this potential confounding effect as the control video depicted obese individuals. The extensive pretesting revealed no differences between control and experimental groups in key measures except for anticipated food scarcity. Further, comparisons between the two control groups in Study 2, where participants in the first control group were exposed to the video depicting obese individuals while participants in the second control group were not exposed to any video, indicate that these groups did not differ in any measure. Thus, it is unlikely that the confounding effects from the control video are the main driver of the results reported herein.

Seen through the lens of the insurance hypothesis (Nettle et al., 2017), humans have evolved mechanisms that are activated as a response to environmental cues associated with food scarcity. Consequently, people prefer high-calorie foods that are a better buffer against the upcoming food unavailability than their low-calorie alternatives. These findings broaden the applicability of the insurance hypothesis by showing that it applies not only to actual but also to anticipated food scarcity. As such, mere exposure to distant food shortages - as in the case of climate change videos - seems to be a sufficient condition to increase the desire to acquire energy-dense foods.

Our findings also reveal that women prefer energy-dense over lowcalorie foods to a larger extent than men when exposed to food scarcity content. One plausible account explaining these differences can be sex-specific roles held in the past when women were responsible for foraging/gathering, and men were primarily concerned with hunting (Sil- 
verman \& Eals, 1992). Thus, the cost of carrying extra weight could have been higher for men than for women, and evolution likely fashioned different weight management strategies for both sexes during periods when access to food was uncertain.

The case of food scarcity communication also supports the evolutionary mismatch hypothesis (Li et al., 2018), which highlights that when evolved psychological mechanisms take in evolutionarily novel input or when the adaptive consequences have changed, the mechanisms may instead produce maladaptive responses. Whereas ancestral cues to food scarcity were associated with impending scarcity, climate change-induced scarcity occurs much later and does not pose a direct risk for all people; thus, it does not necessitate an immediate response to promote survival. As such, modern food scarcity cues highlighted in media may induce the favoring and overconsumption of high-calorie foods among populations who are not at risk of famine, thereby contributing to aversive health outcomes.

Several questions warrant future exploration. First, research should investigate whether other events threatening food availability, such as Brexit or trade wars, may produce similar results. Second, the role of anticipated food scarcity in shaping food choices and its potential contribution to obesity should be scrutinized. Third, studies may examine whether anticipated food scarcity affects decision-making in other contexts. Fourth, it is worth investigating if the effects reported here also apply to audio or textual information about food scarcity. Finally, it is vital to investigate whether anticipated food scarcity was indeed the key driver of the effects reported herein. Therefore, developing and validating a tool measuring this construct will be a fruitful avenue for future research.

Taken together, the present research shows that receiving information about food shortages distant in time and space can influence current food preferences that are impor- 
tant factors in the climate change debate. These findings contribute to the host of largely overlooked effects of climate change and its associated food scarcity communication on human psychology. Given that the majority of people in several countries are concerned about climate change (e.g., Clayton, 2019), our results warrant further evaluation of the consequences of climate change campaigns. These campaigns - when highlighting the issue of rising food scarcity — can increase preference for energy-dense foods. Notably, such foods are among the prime culprits of climate change (Wynes \& Nicholas, 2017), suggesting that climate change communication may have to be revised and potentially abstain from mentioning food scarcity issues.

\section{Declaration of Competing Interest}

The authors declare that they have no known competing financial interests or personal relationships that could have appeared to influence the work reported in this paper.

\section{Acknowledgments}

This research was funded by the Icelandic Research Fund (Doctoral Student Grant to Michal Folwarczny number 206880-051), the AUFF Visiting Researcher Grant to Michał Folwarczny, and the AUFF Starting Grant to Tobias Otterbring. We would like to thank Jacob Lund Orquin for his indispensable contribution to the project.

\section{Appendix A. Supplementary data}

Supplementary data to this article can be found online at https://osf.io/wurzv/. 


\subsection{References}

Aschemann-Witzel, J., \& Peschel, A. O. (2019). How circular will you eat? The sustainability challenge in food and consumer reaction to either waste-to-value or yet underused novel ingredients in food. Food Quality and Preference, 77, 15-20. https://doi.org/10.1016/j.foodqual.2019.04.012

Battisti, D. S., \& Naylor, R. L. (2009). Historical warnings of future food insecurity with unprecedented seasonal heat. Science, 323(5911), 240-244. https://doi.org/10. 1126/science.1164363

Campbell, M. C., \& Mohr, G. S. (2011). Seeing is eating: How and when activation of a negative stereotype increases stereotype-conducive behavior. Journal of Consumer Research, 38(3), 431-444. https://doi.org/10.1086/659754

Clayton, S. (2019). Psychology and climate change. Current Biology, 29(19), R992-R995. https://doi.org/10.1016/j.cub.2019.07.017

Cotter, J., \& Tirado, R. (2008). Food security and climate change: The answer is biodiversity. A review of scientific publications on climate change adaptation in agriculture. Exeter: Greenpeace.

De Boer, J., Hoogland, C. T., \& Boersema, J. J. (2007). Towards more sustainable food choices: Value priorities and motivational orientations. Food Quality and Preference, 18(7), 985-996. https://doi.org/10.1016/j.foodqual.2007.04.002

Gerend, M. A. (2009). Does calorie information promote lower calorie fast food choices among college students? Journal of Adolescent Health, 44(1), 84-86. https://doi. org/10.1016/j.jadohealth.2008.06.014 
Gulliford, M. C., Mahabir, D., \& Rocke, B. (2003). Food insecurity, food choices, and body mass index in adults: Nutrition transition in Trinidad and Tobago. International Journal of Epidemiology, 32(4), 508-516. https://doi.org/10.1093/ije/dyg100

Hoek, A., Pearson, D., James, S., Lawrence, M., \& Friel, S. (2017). Healthy and environmentally sustainable food choices: Consumer responses to point-of-purchase actions. Food Quality and Preference, 58, 94-106. https://doi.org/10.1016/j. foodqual.2016.12.008

Laureati, M., Jabes, D., Russo, V., \& Pagliarini, E. (2013). Sustainability and organic production: How information influences consumer's expectation and preference for yogurt. Food Quality and Preference, 30(1), 1-8. https://doi.org/10.1016/j. foodqual.2013.04.002

Li, N. P., van Vugt, M., \& Colarelli, S. M. (2018). The evolutionary mismatch hypothesis: Implications for psychological science. Current Directions in Psychological Science, 27(1), 38-44. https://doi.org/10.1177/0963721417731378

Nettle, D., Andrews, C., \& Bateson, M. (2017). Food insecurity as a driver of obesity in humans: The insurance hypothesis. Behavioral and Brain Sciences, 40. https: //doi.org/10.1017/S0140525X16000947

Ornstein, R. E., \& Ehrlich, P. R. (2000). New world new mind: Moving toward conscious evolution. ISHK.

Orquin, J. L., \& Kurzban, R. (2016). A meta-analysis of blood glucose effects on human decision making. Psychological Bulletin, 142(5), 546-567. https://doi.org/10. $1037 /$ bul0000035 
Otterbring, T., \& Sela, Y. (2020). Sexually arousing ads induce sex-specific financial decisions in hungry individuals. Personality and Individual Differences, 152, 109576. https://doi.org/10.1016/j.paid.2019.109576

Otterbring, T., \& Shams, P. (2019). Mirror, mirror, on the menu: Visual reminders of overweight stimulate healthier meal choices. Journal of Retailing and Consumer Services, 47, 177-183. https://doi.org/10.1016/j.jretconser.2018.11.019

Robaina, K. A., \& Martin, K. S. (2013). Food insecurity, poor diet quality, and obesity among food pantry participants in Hartford, CT. Journal of Nutrition Education and Behavior, 45(2), 159-164. https://doi.org/10.1016/j.jneb.2012.07.001

Rozin, P. (1996). Towards a psychology of food and eating: From motivation to module to model to marker, morality, meaning, and metaphor. Current Directions in Psychological Science, 5(1), 18-24. https://doi.org/10.1111/1467-8721.ep10772690

Schmidhuber, J., \& Tubiello, F. N. (2007). Global food security under climate change. Proceedings of the National Academy of Sciences, 104(50), 19703-19708. https: //doi.org/10.1073/pnas.0701976104

Siegrist, M., Visschers, V. H., \& Hartmann, C. (2015). Factors influencing changes in sustainability perception of various food behaviors: Results of a longitudinal study. Food Quality and Preference, 46, 33-39. https://doi.org/10.1016/j.foodqual.2015. 07.006

Silverman, I., \& Eals, M. (1992). Sex differences in spatial abilities: Evolutionary theory and data. In J. H. Barkow, L. Cosmides, \& J. Tooby (Eds.), The adapted mind: Evolutionary psychology and the generation of culture (pp. 533-549). 
Watson, D., Clark, L. A., \& Tellegen, A. (1988). Development and validation of brief measures of positive and negative affect: The PANAS Scales. Journal of Personality and Social Psychology, 54(6), 1063-1070.

Wheeler, T., \& Von Braun, J. (2013). Climate change impacts on global food security. Science, 341 (6145), 508-513. https://doi.org/10.1126/science.1239402

WHO. (2020). Obesity and overweight. https://www. who.int/news-room/fact-sheets/ detail/obesity-and-overweight

Willett, W., Rockström, J., Loken, B., Springmann, M., Lang, T., Vermeulen, S., Garnett, T., Tilman, D., DeClerck, F., Wood, A., et al. (2019). Food in the Anthropocene: the EAT-Lancet Commission on healthy diets from sustainable food systems. The Lancet, 393(10170), 447-492. https://doi.org/10.1016/S0140-6736(18)31788-4

Wisdom, J., Downs, J. S., \& Loewenstein, G. (2010). Promoting healthy choices: Information versus convenience. American Economic Journal: Applied Economics, 2(2), 164-78. https://doi.org/10.1257/app.2.2.164

Wynes, S., \& Nicholas, K. A. (2017). The climate mitigation gap: Education and government recommendations miss the most effective individual actions. Environmental Research Letters, 12(7), 074024. https://doi.org/10.1088/1748-9326/aa7541 


\title{
Chapter 4
}

\section{Seasonal cues to food scarcity and calorie cravings: Winter cues elicit preferences for energy-dense foods}

Another version of this paper published in Food Quality and Preference

\author{
Michał Folwarczny \\ Department of Business Administration, Reykjavik University \\ Tobias Otterbring \\ Department of Management, University of Agder, \\ Institute of Retail Economics
}

Valdimar Sigurdsson

Department of Business Administration, Reykjavik University

Agata Gasiorowska

Faculty of Psychology in Wroclaw, SWPS University of Social Sciences and Humanities 


\begin{abstract}
Winter cues signal a scarcity of food. Birds and mammals respond to such environmental cues by consuming more energy. They convert this surplus into body fat that serves as a buffer against impending food shortages. Similarly, humans exhibit higher obesity rates among food-insecure populations. However, to date, it has been unclear whether winter cues qualitatively affect consumers' food preferences. Results from five studies $(N$ $=865)$, with one of them preregistered, show that watching videos depicting winter cues elicits thoughts about energy-dense foods and survival. Such cues elicit higher preferences for energy-dense than low-calorie foods, with this effect likely differing between women and men. Taken together, our results support an evolutionary account postulating that humans have developed sex-specific responses to perceivable cues of food scarcity. As a result, winter cues induce people to favor products they deem higher in calories. Given the importance of limiting energy-dense food consumption for addressing environmental and public health issues, policymakers and marketers should be aware of this phenomenon when designing public communication campaigns.
\end{abstract}

Keywords: winter cues, food scarcity, food shortages, the insurance hypothesis, food preferences 


\subsection{Introduction}

Numerous mammals and birds consume excessive amounts of energy to build fat reserves before the winter and limit their physical activity over these dark and cold months (Blix, 2016). Humans appear to have developed similar mechanisms that protect them against periods of lower food availability in the environment (Humphries et al., 2017; Neel, 1962; Prentice et al., 2005). Indeed, according to Gallup, Americans consume fewer low-calorie products and exercise less in the winter than in warmer seasons, thus leading to fat gain (Mendes, 2011). Eating contexts and environmental cues - including those elicited in virtual environments - influence food choices and preferences (e.g., Ammann et al., 2020; Cardello et al., 2000; Cherulnik, 1991; Jaeger \& Rose, 2008; King et al., 2004; Pennanen et al., 2020). Their role in developing overweight and obesity has been acknowledged (Wells et al., 2007). Still, no studies have investigated if exposing people to environmental cues to winter facilitates energy-dense (vs. low-calorie) food preferences. This paper tests this possibility and conveys implications for public health, sustainability research, and policymaking because avoiding animal-source, energy-dense food is vital for addressing climate change and public health issues (Willett et al., 2019; Wynes \& Nicholas, 2017).

\subsubsection{Winter as a food scarcity cue}

Winter is an environmental cue to reduced food supply. In some regions of the world, cold temperatures, coupled with a lack of sunlight, stop most vegetation forms, leading to a lack of food resources across species inhabiting these lands (Blix, 2016). Such food scarcity forces animals to migrate to other places or adjust their foraging strategies (Humphries et al., 2017). Humans, too, have experienced food scarcity resulting from cold periods. 
The Little Ice Age - climate cooling between 1300 and 1850 resulted in numerous extreme food shortages. For instance, the Great Famine killed tens of thousands of people between 1315 and 1319, whereas the Year Without a Summer led to crop failures and pervasive famine worldwide in 1816 (Fagan, 2001). In fact, our ancestors rarely enjoyed easy access to food resources. Instead, they wandered between food availability and food scarcity, which led them to develop mechanisms protecting against the latter periods (Otterbring, 2020; Rozin, 1996). An example of how such adaptations operate is the case of the Dutch Hunger Winter that happened in 1944-1945 in the occupied Netherlands, which resulted in extreme malnutrition at a national level. Babies exposed to malnutrition in early gestation due to this famine were more likely to be obese in later life (Schulz, 2010). In sum, throughout evolutionary history, cues to winter have signaled periods of lower food availability among humans and other species. Thus, it is reasonable to assume that humans have developed food intake mechanisms protecting them against food scarcity.

\subsubsection{Adaptations to winter-induced food scarcity among hu- mans and other species}

Across the globe, plants and animals possess adaptations that allow them to endure seasonal temperature changes (Humphries et al., 2017). For instance, Arctic and Antarctic mammals and birds prepare for food scarcity during winter by depositing large amounts of fat during autumn and developing a considerable amount of brown adipose tissue vital for nonshivering thermogenesis (Blix, 2016). Adult humans, likewise, develop brown adipose tissue faster in the winter than in the summer, and its growth depends more on sunlight than on temperature, with this effect being particularly pronounced among women ( $\mathrm{Au}-$ 
Yong et al., 2009). Mirroring other species' behaviors, people consume more calories in the colder months, but also report being hungrier after meals (De Castro, 1991). In the fall, humans' diet composition changes - they consume more fat, which likely explains their $0.5 \mathrm{~kg}$ higher weight, on average, in the winter than in the summer (Ma et al., 2006). These calorie cravings may be partially due to increased heat production in the winter when humans are exposed to cold air (Van Ooijen et al., 2004).

\subsubsection{Evolutionary roots of human food preferences: The insur- ance hypothesis}

Thorough evolutionary history, humans have developed mechanisms guiding their food choices to promote survival. For instance, people have evolved to effectively detect contaminated foods, which elicit strong disgust reactions (Egolf et al., 2018; Siegrist et al., 2020). Likewise, the human body reacts to too low protein consumption by increased intake of fat and carbohydrates (Simpson \& Raubenheimer, 2005). Similarities in relative food preferences across cultures support the evolutionary account explaining food preferences in modern societies. For example, the Hadza foragers living in Tanzania show a bias toward energy-dense foods akin to the typically preferred foods in developed countries (Berbesque \& Marlowe, 2009).

According to the insurance hypothesis (Nettle et al., 2017), humans and other vertebrates have developed mechanisms protecting them against periods of food unavailability that work through an increased energy consumption above the maintenance level, thus favoring fat storage. A meta-analysis of epidemiological studies provides evidence for this evolutionary account and suggests that food insecurity is positively related to the 
prevalence of overweight and obesity in developed countries; however, this relationship is found only among women (Nettle et al., 2017). These differences could have arisen due to past, sex-specific roles in the society wherein men were primarily concerned with hunting and fighting. In contrast, women were preoccupied with foraging and offspring activities (Silverman \& Eals, 1992). Thus, given the importance of mobility, an excessive bodyweight would have had more devastating consequences for men than women. Such a weight-management pattern is observed among small birds that maintain less fat reserves in the winter whenever there are many predators in their environments; however, when predators are absent, these birds increase fat reserves, thereby boosting survival rates during this period (Gosler et al., 1995).

Although the literature implies that people experiencing food scarcity eat more (hence their weight gain), it remains unclear whether they make qualitatively different food choices and whether the mere exposure to winter cues is sufficient to alter their food preferences. Some studies indicate that people's fat intake increases in the fall-as opposed to the intake of other macronutrients (Ma et al., 2006); thus, they likely do not merely eat more when preparing for colder months; instead, their food preferences may shift.

Whereas winter cues signal lower food availability, advancements economically and technologically have provided a more stable and sufficient food supply during the modern era of human history, at least in developed countries. Therefore, people living in these countries may be insensitive to such cues, as a threat of famine is unlikely in their case. However, such relative prosperity is still a new phenomenon. Yet, our cognitive system has evolved slowly, through thousands of years, implying that this system is adjusted 
to cope with challenges found in ancestral rather than current environments (Tooby \& Cosmides, 1990). Consequently, people often fail to distinguish between actual threats and cues associated with threats found in the distant past. For example, although snakes and spiders pose little danger in modern cities, people tend to be afraid of them more than cars and other more recent phenomena (cf. Griskevicius et al., 2012; Öhman et al., 2001; Öhman \& Mineka, 2001; Ornstein \& Ehrlich, 2000). Therefore, cues to food scarcity may activate mechanisms responsible for coping with past challenges, causing a mismatch between evolutionarily old mechanisms and our current needs (Li et al., 2018).

The mismatch account has received recent empirical support (Folwarczny, Christensen, et al., 2021). The authors exposed participants - primarily from Denmark and the United States - to videos depicting climate change-induced food scarcity (e.g., famine, drought, crop failures) happening in distant parts of the world, such as southern Africa. Crucially, this scarcity was depicted as distant in time, with the video clips mentioning future rather than current threats. Although the videos displayed food scarcity not threatening participants directly, their food preferences shifted toward higher-calorie foods, with this effect being more pronounced among women (Folwarczny, Christensen, et al., 2021). Hill et al. (2013) conducted a series of studies that further support the thesis that cues to environmental harshness (e.g., food scarcity) may yield sex-specific effects on food preferences. The authors found that women who grew up in harsh environments by means of receiving less parental investment and living in lower socioeconomic status (SES) households were more strongly influenced by cues of environmental harshness than men, who were relatively insensitive to such cues. In the case of women-but not men - the authors found that women exposed to environmental harshness drew larger (vs. smaller) cookies when 
their childhood SES was lower (vs. higher); an effect that did not emerge after exposure to control stimuli. Additionally, conditions of environmental harshness resulted in low childhood SES women taking more snacks when leaving a laboratory, expressing more negative attitudes toward dieting, and reporting a weaker desire to prevent weight gain (Hill et al., 2013).

\subsubsection{Research aims}

In the present research, we explore the possibility that exposing people to winter (vs. summer) cues makes them more inclined to think about energy-dense foods, survival, and scarcity, but not about low-calorie products. We also test if winter cues affect people's food preferences as a function of the calorie content of different food options and whether this potential effect is sex-specific.

Drawing from the insurance hypothesis (Nettle et al., 2017), we contend that winter cues that used to signal food scarcity in the past may activate the same food acquiring mechanisms among people as actual food scarcity does. Consequently, consumers' preferences may shift under such circumstances, with a stronger emphasis directed toward energy-dense foods that increase overall energy intake above maintenance levels.

The energetic density of various food items is usually expressed in calories and the literature suggests that information about calorie content plays a vital role in food choices, reducing overall calorie intake (Wisdom et al., 2010). However, on average, only women lower their calorie intake when they know the calorie content of dishes they consume (Gerend, 2009). Challenging this earlier literature, we hypothesize that exposure to winter cues will trigger preferences for higher-calorie foods among women but not men, even when 
the calorie content of different food options is highly salient (cf. Nettle et al., 2017).

\subsection{General method and overview of studies}

We conducted a pretest to ensure that both experimental videos yielded similar affective responses (see Supplementary Online Materials for details). The results of Studies 1a and 1b confirmed that our experimental manipulation was successful. Here, we investigated whether exposure to winter cues makes people think about energy-dense (vs. low-calorie) foods, scarcity, and survival. In Studies 2a-2c, we tested our central hypotheses and demonstrated that exposing participants to videos depicting winter cues increases their preferences toward energy-dense foods, with this effect being different for women and men.

Data, materials, PsyToolkit scripts (Stoet, 2010, 2017), and analysis code are publicly available under this project's Open Science Framework (OSF) webpage. Studies 2a and 2b followed the same analytic protocol as the preregistered Study 2c; the preregistration can be accessed through this link. Regression coefficients and standard errors were multiplied by 100 across Studies 2a-2c when we report them for kilocalorie estimates. We did so for readability purposes and to make coefficients more meaningful-people measure hundreds of kilocalories rather than every single kilocalorie in complex meals.

This project adheres to ethical guidelines specified in the APA Code of Conduct and has been approved by the Ethics Committee for Human Research of SWPS University of Social Sciences and Humanities, Faculty of Psychology in Wroclaw. We recruited all participants through Prolific.co. To ensure high data quality, we recruited different participants for each experiment whose submission acceptance rate was $99 \%$ or higher. 


\subsection{Study $1 \mathrm{a}$}

Study 1a was conducted to test whether our experimental manipulation (winter cues vs. summer cues) influences people's propensity to think about energy-dense foods and scarcity-related concepts. Here, we used the word fragment completion task. This procedure is widely applied in experimental research and can be used to investigate if primes increase the accessibility of prime-related thoughts (Gasiorowska et al., 2018; Nelson et al., 1989; Roediger et al., 1992; Tulving et al., 1982).

\subsubsection{Method}

Participants. We recruited 106 U.S. participants on Prolific Academic (48 females, $M_{\text {age }}=36.37$ years, $\left.S D=13.26\right)$ to take part in a study in exchange for $£ 0.50$. The word fragment completion tasks that we employ in Studies 1a-1b yield middle-to-large effect sizes (e.g., Gasiorowska et al., 2018). We performed a stochastic power simulation in $\mathrm{R}$ (Bolker, 2007), which revealed that this sample size provided .90 power to detect a significant effect of this magnitude; that is, equal to Cohen's $d=0.65$. We used Prolific's prescreening features to ensure that only people without dietary restrictions (e.g., veganism, gluten-free diets) participated in the study.

Procedure. After accepting an informed consent form, participants were randomly assigned to one of the two conditions. They watched either a video showing a forest walk in the winter or in the summer.

Next, they performed the word fragment completion task. Participants had to complete 15 different word fragments. For example, the word S P _ S E could be completed 
as sparse or spouse. Seven of these word fragments could be completed in a way related to scarcity (scarce, poor, sparse, restrict, short, scanty, and skimpy). Four words could be completed in a way related to energy-dense foods (burger, steak, fries, and taco), and the remaining four words (sponge, door, change, phone) served as filler tasks to prevent participants from guessing the study-specific hypothesis.

We used conditional statements in $\mathrm{R}$ to find whether participants created words of a correct length (they could complete a word fragment in two ways: by typing the whole word or typing missing letters only; hence, there were two valid alternatives), and the "grepl" function served to find whether participants answered questions according to the predefined key (e.g., "arc" in the word "scarce," shown as S C _ _ E). We calculated (1) the number of words related to scarcity, (2) the number of words related to energydense foods, and (3) the overall number of correct words provided by participants. The word was counted as correct when it was found in one of several online dictionaries used for predefining correct responses, and was not counted when a participant failed to respond, created words of incorrect length, or created a word that was not found in online dictionaries. We calculated a proportion of words related to scarcity and energy-dense foods, respectively, by dividing the number of words related to scarcity and energy-dense foods by the total number of correct words and used them as dependent variables. The study concluded by participants providing demographic details.

\subsubsection{Results and discussion}

Scarcity-related words. An independent samples $t$-test on the proportion of words related to scarcity found no difference between conditions $\left(M_{\text {winter }}=.17, S D=.14\right.$; 
$\left.M_{\text {summer }}=.17, S D=.13\right), t(104)=0.08, p=.933, d=0.02$.

Words related to energy-dense foods. A similar analysis performed on the proportion of words denoting energy-dense foods revealed that participants who watched a video depicting winter (vs. summer) cues created more words denoting energy-dense foods $\left(M_{\text {winter }}=.25, S D=.16 ; M_{\text {summer }}=.16, S D=.12\right), t(104)=-3.32, p=.001, d$ $=0.65$.

Discussion. Findings from Study 1a suggest that the video depicting winter cues made participants think about energy-dense foods to a more considerable extent than the video depicting summer cues. However, neither video prompted participants to think more about scarcity.

\subsection{Study $1 \mathrm{~b}$}

The results from Study 1a revealed that participants viewing winter forest walks were more inclined to think about energy-dense foods than participants viewing summer forest walks, whereas our experimental manipulation did not influence the accessibility of scarcity-related concepts. In Study 1b, we tested whether winter (vs. summer) cues may also activate survival-related concepts while simultaneously examining whether our experimental manipulation affects the accessibility of thoughts about low-calorie foods.

\subsubsection{Method}

Participants. We recruited 105 U.S. participants on Prolific Academic (48 females, $M_{\text {age }}=35.16$ years, $\left.S D=11.43\right)$ to take part in a study in exchange for $£ 0.50$. Following 
the approach used in Study 1a, this sample size should be sufficient to detect the effect size of interest. We applied the same prescreening criteria as those described in Study 1a.

Procedure. After accepting an informed consent form, participants were randomly assigned to one of the two conditions. They watched either a video showing a forest walk in the winter or in the summer. Similar to Study 1a, participants then completed 15 different word fragments. Seven of these word fragments could be completed in a way related to survival (survive, endure, resist, persist, sustain, withstand, fight), four words could be completed in a way related to low-calorie foods (salad, apple, milk, peach), and the remaining four words (sponge, door, change, phone) served as filler tasks to prevent participants from hypothesis guessing. We applied the same procedure to calculate dependent variables and detect keyed responses as in Study 1a. The study concluded by participants providing demographic details.

\subsubsection{Results and discussion}

Survival-related words. An independent samples $t$-test on the proportion of words related to survival found that participants who watched a video showing winter (vs. summer $)$ cues created more words related to survival $\left(M_{\text {winter }}=.26, S D=.14 ; M_{\text {summer }}\right.$ $=.17, S D=.13), t(103)=-3.22, p=.002, d=0.65$.

Words related to low-calorie foods. Aa similar analysis performed on the proportion of words denoting low-calorie foods revealed no significant difference between conditions $\left(M_{\text {winter }}=.18, S D=.12 ; M_{\text {summer }}=.20, S D=.13\right), t(103)=0.58, p=.566, d=0.18$. 
Discussion. Findings from Study 1b indicate that participants exposed to winter cues have higher accessibility to thoughts related to survival, but not to low-calorie foods. Combined with the results from Study 1a, which found that watching winter cues made people think more about energy-dense foods, it is plausible that people link high-calorie foods to survival in harsh winter environments.

\subsection{Study $2 \mathrm{a}$}

We conducted Study 2a to estimate the desired sample size before commencing the preregistration (Study 2c). We hypothesized that (1) exposing participants to winter (vs. summer) cues would increase their preferences toward energy-dense foods, and that (2) this effect should be more pronounced among women than men.

\subsubsection{Method}

Participants. We recruited 119 U.S. participants on Prolific Academic (59 females, $M_{\text {age }}=36.40$ years, $\left.S D=13.74\right)$ to take part in a study in exchange for $£ 0.64$.

Procedure. After accepting an informed consent form, participants were randomly assigned to one of the two conditions. They watched either a video showing a forest walk in the winter or in the summer.

After watching their given video, they estimated the caloric content and stated their preferences for 30 foods. We used food images from Folwarczny, Christensen, et al. (2021). This set of 30 simple foods and complex dishes has been pretested among certified nutritionists and athletes who daily measure the caloric content of foods. The set covers 
a broad spectrum in calorie estimates $\left(M_{\text {calories }}=367, S D=122\right.$, range $\left.=166-711\right)$ and has been applied in experimental research (Folwarczny, Christensen, et al., 2021). To evaluate the calorie content of foods ("How many calories does this food contain? [the serving you see]"), participants used a sliding scale ranging from 0 to 1000 kilocalories. We considered certified nutritionists' estimation of the calorie content of foods when creating this response format. Participants answered questions regarding their preferences toward foods ("Would you eat this food now?") on a sliding scale ranging from $-1=$ Definitely not to $1=$ Definitely yes, with .01 point intervals. The order of these two tasks (estimating calories and stating preferences) was randomized. Likewise, the order of the 30 food images within each task was randomized. The study concluded by participants providing demographic details.

\subsubsection{Results and discussion}

Primary hypothesis tests. Due to the nested data structure, we performed a mixedeffects analysis of the relationship between the two independent variables (treated as fixed effects; calorie estimates, and experimental condition) with interactions between them and the dependent variable (food preferences) using the "Ime4" package for R (Bates et al., 2015). As random effects, we used intercepts for participants and foods. The visual inspection of residual plots suggested no apparent deviations from homoscedasticity or normality. We estimated significance with Satterthwaite's method applied by the "ImerTest" package for R (Kuznetsova et al., 2017).

This analyses revealed no main effects of experimental condition $(b=-7.863, S E=$ 7.117, $t=-1.10, p=.270)$ or calorie estimates $(b=0.010, S E=0.009, t=1.14, p=$ 
.254) on food preferences. However, we found a marginally significant interaction between condition and calorie estimates $(b=0.020, S E=0.011, t=1.89, p=.059)$. Further simple slope analysis found that the relation between calories estimate and food preference was non-significant for participants exposed to videos featuring summer cues $(b=0.010, S E$ $=0.009, t=1.14, p=.254)$, but it was significant and positive for participants exposed to videos depicting winter cues $(b=0.030, S E=0.008, t=3.53, p<.001)$. This pattern of results suggests that participants who watched videos depicting winter cues showed a stronger preference toward energy-dense foods than toward foods low in energy, while their peers exposed to videos depicting summer cues preferred foods to the same extent, regardless of their calorie content (Figure 4.1).

Secondary hypothesis tests. We added participants' biological sex as a moderator to test the hypothesis about sex differences in responses to the experimental manipulation. The results from this model (see Supplementary Online Materials for details), along with comparisons shown in Figure 4.1, indicate that the interaction effect between condition and calorie estimates on food preferences was different for women compared to men $(b=$ 0.065, $S E=0.021, t=3.07, p=.002)$. Thus, we decomposed this three-way interaction by investigating the effects of calories, experimental manipulation, and their interaction on food preference separately for men and women. For men, we found a significant main effect of calories $(b=0.030, S E=0.012, t=2.54, p=.011)$, but the interaction between condition and calorie estimates was non-significant $(b=-0.011, S E=0.014, t=-0.77, p=$ .443). For women, however, in line with our predictions, we found a significant interaction between condition and calorie estimates $(b=0.053, S E=0.016, t=3.26, p=.001)$. We performed a simple slope analysis separately for both experimental conditions to further 
quantify this interaction. For women exposed to winter cues, the relation between calorie estimates and food preferences was significant $(b=0.038, S E=0.014, t=2.80, p=$ .005), but for women exposed to summer cues this relationship was non-significant $(b=$ $-0.015, S E=0.013, t=-1.13, p=.259)$. These results indicate that women watching videos depicting winter cues show a stronger preference toward energy-dense foods than toward low-calorie foods, whereas women watching videos featuring summer cues do not exhibit this response pattern.

Discussion. Results from Study 2a provide preliminary evidence for both our hypotheses. We found people exposed to winter cues, but not summer cues, to exhibit a stronger preference toward energy-dense foods than toward low-calorie foods. Furthermore, this effect was different for men and women. Men preferred foods they deemed higher in calories, regardless of whether they were exposed to winter or summer cues, whereas women showed a "craving for calories" only after exposure to winter cues.

\subsection{Study $2 b$}

The results from Study 2a provided initial evidence for our theorizing. However, based on these findings, we cannot rule out that the effects observed in Study 2a emerged as a function of summer rather than winter cues. Therefore, we conducted Study $2 \mathrm{~b}$ with a third condition, where participants did not watch any video before evaluating the foods. We hypothesized that exposing participants to summer cues would not alter their food preferences compared to participants who were not exposed to any visual stimuli. In contrast, exposing participants to winter cues should increase their preferences toward 
higher-calorie foods.

\subsubsection{Method}

Participants. We recruited 120 U.S. participants on Prolific Academic (74 females, $M_{\text {age }}=34.52$ years, $\left.S D=11.54\right)$ to take part in a study in exchange for $£ 0.64$.

Procedure. After accepting an informed consent form, participants were randomly assigned to one of the three conditions. They watched a video showing a forest walk in the winter, in the summer, or no video at all. The remaining procedure was the same as that of Study 2a.

\subsubsection{Results and discussion}

Primary hypothesis tests. Again, we performed a mixed-effects analysis of the relationship between the two independent variables: calorie estimates and experimental condition (watching a summer forest walk, winter forest walk, or no video) with interactions between them and the dependent variable - food preferences. As random effects, we used intercepts for participants and foods. The visual inspection of residual plots suggested no apparent deviations from homoscedasticity or normality.

As a reference condition, we used a group that was not exposed to any video. The analysis indicated no main effect of calorie estimates $(b=0.008, S E=0.009, t=0.96, p$ $=.339)$. We found no main effect of the summer video $(b=-0.512, S E=8.575, t=-0.06$, $p=.952)$, but a significant main effect of the winter video $(b=-23.847, S E=9.481, t$ $=-2.52, p=.012$ ), suggesting that this video may decrease food preferences compared to not watching any video. The interaction between condition and calorie estimates was 
non-significant for participants exposed to the video showing summer cues $(b=-0.010, S E$ $=0.011, t=-0.91, p=.364)$, but significant for participants exposed to the video showing winter cues $(b=0.037, S E=0.013, t=2.94, p=.003)$. To further understand the nature of this interaction, we performed a simple slope analysis for each experimental condition. For participants who did not watch any video $(b=0.008, S E=0.009, t=0.96, p=.339)$, and their counterparts who watched the video depicting summer cues $(b=-0.002, S E=$ $0.009, t=-0.18, p=.856)$, the slope of calories was non-significant. However, this slope was positive and significant for participants exposed to the video showing winter cues $(b$ $=0.046, S E=0.011, t=4.25, p<.001)$, suggesting a stronger preference for energydense foods than toward low-calorie foods. Given no major differences in key measures between the conditions in which participants either watched a video depicting summer cues or those who did not watch any video, we merged these two conditions to facilitate parsimonious analysis (cf. Griskevicius et al., 2009; Griskevicius et al., 2010; Otterbring, Gidlöf, et al., 2020).

Next, we conducted the same analysis as in Study 2a. The main effect of calories was non-significant $(b=0.003, S E=0.007, t=0.50, p=.620)$. We found a main effect of experimental condition $(b=-23.458, S E=8.397, t=-2.79, p=.006)$, implying that participants exposed to winter videos showed lower overall preferences toward foods than participants in the other conditions. Crucially, and mirroring the findings from Study $2 \mathrm{a}$, we found a significant interaction between calorie estimates and condition $(b=0.042$, $S E=0.011, t=3.72, p<.001)$. Hence, we performed a simple slope analysis across conditions. For participants who did not watch any video or who watched a video featuring summer cues, the slope of calories was non-significant $(b=0.003, S E=0.007, t=0.50$, 
$p=.620)$, but it was significant for those exposed to winter cues $(b=0.046, S E=0.011$ $, t=4.25,<.001)$, thus replicating the results from Study $2 \mathrm{a}-$ participants exposed to winter cues showed a stronger preference for energy-dense foods than low-calorie foods.

Secondary hypothesis tests. We added participants' biological sex as a moderator to test the hypothesis about sex differences in responses to the experimental manipulation. In contrast to the findings from Study 2a, the interactional effect between condition and calorie estimates on food preferences did not differ across sexes $(b=-0.002, S E=0.023$, $t=-0.10, p=.923)$.

Discussion. The results from Study $2 \mathrm{~b}$ provide more substantive evidence for the notion that winter cues rather than summer cues alter consumers' food preferences and their cravings for calories. Specifically, exposure to winter cues increased participants' preferences for energy-dense foods. This effect did not occur for participants exposed to summer cues or who were not exposed to any visual stimuli before indicating their food preferences. However, unlike Study 2a, we did not find this effect to vary between men and women.

\subsection{Study $2 \mathrm{c}$}

The results from Study 2a confirmed both our hypotheses, and the findings from Study $2 \mathrm{~b}$ confirmed our primary but not secondary hypothesis. In Study 2c, we preregistered both these focal hypotheses in a well-powered final study, where we specified our design and data analysis plan. 


\subsubsection{Method}

Participants. Based on the observed power of Study 2a, as computed through the "simr" package for R (Green \& MacLeod, 2016), we plotted a power curve to estimate the number of participants needed to achieve .95 power to detect the significant interaction between condition and calorie estimates on food preferences. This procedure suggested that 420 participants were needed to achieve .95 power to detect the effect size of interest. Thus, we recruited 420 U.S. participants on Prolific Academic to take part in the study in exchange for $£ 0.75$, of whom 415 completed the tasks and were included in the analysis (204 females, $M_{\text {age }}=36.90$ years, $\left.S D=13.03\right)$.

Procedure. After accepting an informed consent form, participants were randomly assigned to one of the two conditions. They watched either a video showing a forest walk in the winter or in the summer. The remaining procedure mirrored that applied in Studies $2 a-2 b$.

\subsubsection{Results and discussion}

Primary hypothesis tests. We followed the preregistered data analysis protocol, which is identical to that of Studies $2 \mathrm{a}-2 \mathrm{~b}$. We found no obvious deviations from homoscedasticity or normality. The analyses revealed a marginally significant main effect of condition $(b=7.027, S E=3.689, t=1.91, p=.057)$, implying that participants exposed to winter cues showed higher overall preferences toward foods. The main effect of calories was significant $(b=0.034, S E=0.004, t=8.00, p<.001)$, meaning that participants preferred foods they deemed higher in calories. However, in contrast to Studies 2a-2b, 
the results from Study 2c revealed no significant interaction between calorie estimates and condition $(b=-0.008, S E=0.005, t=-1.57, p=.117)$.

Secondary hypothesis tests. Next, in line with the preregistered protocol, we added participants' biological sex as a moderator to test the hypothesis about sex differences in responses to the experimental manipulation. The results from this model (see Supplementary Online Materials for details) indicated that the effect of condition and calorie estimates on food preferences was different for women compared to men $(b=0.035, S E$ $=0.010, t=3.50, p<.001)$. Thus, we decomposed this interaction by investigating the effects of calories, experimental manipulation, and their interaction on food preference separately for men and women. For men, we found a significant main effect of calories ( $b$ $=0.048, S E=0.005, t=8.70, p<.001)$, indicating a higher preference for foods deemed to contain more calories. We also found a significant main effect of condition $(b=12.940$, $S E=5.153, t=2.51, p=.012)$, implying a higher overall preference toward foods among men exposed to winter than to summer cues. Finally, the interaction between experimental condition and calorie estimates was significant for men $(b=-0.024, S E=0.007, t=$ $-3.66, p<.001)$. Further simple slope analysis revealed that men exposed to winter $(b=$ 0.023, $S E=0.006, t=4.24, p<.001)$ and summer $(b=0.048, S E=0.005, t=8.70, p$ $<$.001) cues showed a higher preference for energy-dense foods than low-calorie foods.

For women, we found a significant main effect of calorie estimates $(b=0.020, S E=$ $0.007, t=3.01, p=.003)$, indicating a higher preference for foods deemed to contain more calories. However, the effect of condition was non-significant $(b=0.710, S E=5.265, t$ $=0.14, p=.893)$, as was the interaction between condition and calorie estimates $(b=$ 0.009, $S E=0.007, t=1.28, p=.202)$. 
Discussion. Results from Study 2c did not support our primary hypothesis, as the interaction between experimental condition and calorie estimates did not emerge. As per our secondary hypothesis tests - we found the predicted three-way interaction. However, decomposing this interaction did not reveal the hypothesized pattern of results, as the interaction between calorie estimates and condition was non-significant for women, but it was significant for men. Still, for women, we observed a trend in the same direction as in Study 2a.

Figure 4.1: Differences in responses to winter (vs. summer) cues across Studies 2a-2c
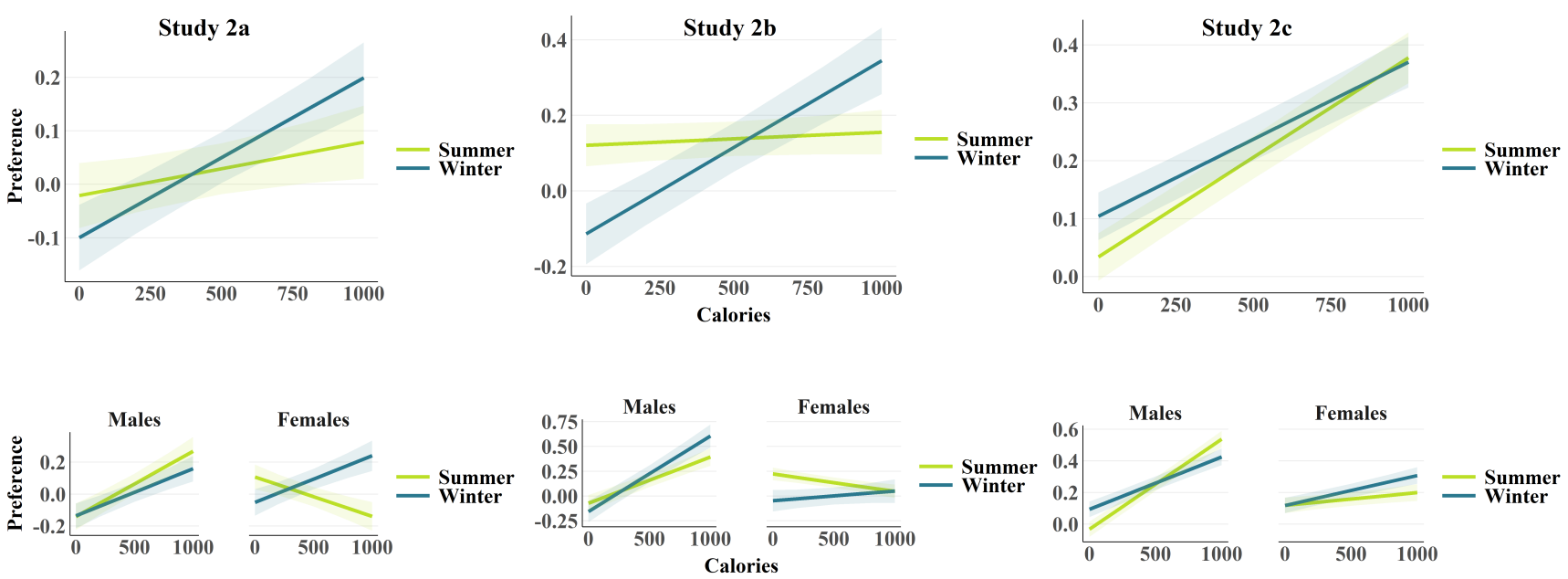

\subsection{General discussion}

Across five studies, we investigated if exposure to winter cues increases preferences toward energy-dense (vs. low-calorie) foods and whether this effect differs between men and women. Studies 1a-1b indicated that watching videos depicting winter (vs. summer) cues 
increased the accessibility of concepts linked to survival and energy-dense foods. Winter cues, however, did not prompt people to think about low-calorie foods or scarcity to a larger extent than did summer cues. Studies $2 \mathrm{a}-2 \mathrm{c}$ jointly demonstrated that exposure to winter (vs. summer) cues elicited preferences for energy-dense (vs. low-calorie) foods. Additionally, this effect may be more substantial for women, but the current findings are not conclusive and beg for additional experiments exploring sex-specific effects.

Our work extends the earlier research by Folwarczny, Christensen, et al. (2021). Whereas the authors used vivid and explicit food scarcity manipulations, we expose participants to subtle, unemotional food scarcity cues — videos showing a winter forest walk. Further, Folwarczny, Christensen, et al. (2021) used videos depicting obese individuals in their control condition. We purposely avoided videos showing humans in the control condition, as such stimuli also alter food preferences (Banovic \& Otterbring, 2021; Otterbring \& Shams, 2019). We further extend these earlier findings by showing that winter cues elicit thoughts associated with survival and energy-dense foods.

Our results provide empirical support for the insurance hypothesis (Nettle et al., 2017), postulating that humans and other vertebrates - through their evolutionary historieshave developed adaptations protecting them against periods of food scarcity, which facilitate energy consumption over the maintenance levels, thus contributing to weight gain. Indeed, food insecurity is linked to obesity in developed countries, but this effect is only found among women (Nettle et al., 2017). The current findings, too, indicate that exposing participants to winter cues - a proxy for food scarcity across species - directionally shifts food preferences toward energy-dense (vs. low-calorie) products mainly among women. To our knowledge, existing literature does not provide a well-supported account 
explaining these potential sex differences.

Over a third of adults worldwide are overweight and obese, and this public health issue becomes prevalent also among children (Perkovic et al., 2021; WHO, 2020). Excessive body weight - associated with numerous illnesses such as cardiovascular disease or diabetes mellitus - leads to millions of premature deaths globally each year and became an imminent problem in developing countries, despite being traditionally present exclusively in affluent societies (GBD 2015 Obesity Collaborators, 2017). Aside from health hazards, overweight and obesity causes a significant economic burden for individuals and public healthcare systems, as direct and indirect costs of excessive bodyweight over lifetime exceed $\$ 150,000$ per person (Hamilton et al., 2018). Consequently, the recent Lancet Commission called for urgent development of healthy and sustainable food systems (Willett et al., 2019). Whereas our findings do not provide insights into how environmental cues can be used to facilitate healthier eating habits, we provide evidence that winter cues and likely other similar cues to food scarcity may prompt consumers to prefer energy-dense foods over low-calorie alternatives, with the former being key culprits of excessive bodyweight (WHO, 2020).

Effective pro-environmental campaigns need to encourage choosing products and services that have the most negligible impact on the environment. However, such campaigns are often filled with cues that may attenuate their effectiveness. For example, an emotional campaign by Greenpeace International highlighting the issue of melting Arctic ice is filled with winter cues (Morgan, 2016). Because our studies found such cues to increase preferences toward energy-dense foods, which contribute to climate change (Wynes \& Nicholas, 2017), environmental organizations and policymakers may have to reevaluate 
their communication strategies. Likewise, marketing communication should be carefully designed, as it is often filled with winter cues, with the well-known Coca-Cola winter ads just constituting one salient example.

\subsubsection{Limitations and future research}

Winter has been associated with food scarcity for centuries among humans (Fagan, 2001). Thus, it is plausible that exposure to winter cues makes people think about scarcity in general. Interestingly, the current studies show that videos depicting winter cues trigger thoughts about survival and energy-dense foods, but not about scarcity. Future studies should further explore the underlying mechanisms of such diverging findings. Ideally, a psychometrically validated tool measuring anticipated food scarcity would provide evidence behind the proposed mechanisms activated as a response to exposure to winter cues (for example, see Folwarczny, Li, et al., 2021).

Notably, the current work focused solely on stated food preferences that may not necessarily be predictive of actual food choices; hence, our findings should be treated with caution until field studies employing behavioral measures have verified the replicability, generalizability, and real-world impact of our theorizing (cf. Machín et al., 2020; Otterbring, 2021; Otterbring, Sundie, et al., 2020). At a minimum, laboratory studies where participants can choose snacks with different calorie content as a part of their reward for taking part in a study should be commenced.

To minimize the burden associated with lengthy survey elements, we collected minimal data needed to test our predictions, omitting variables such as body mass index (BMI), which is a common variable to include in the food choice literature (e.g., Gidlöf et al., 
2021). Although research including BMI as a predictor of food preferences is inconclusive, with a possibility that overweight and obese individuals prefer high-fat foods rather than vegetables (e.g., Czyzewska \& Graham, 2008; Drewnowski et al., 1992; Wardle et al., 2001), additional studies should include BMI indicators, potentially treating this variable as a moderator of the effects reported herein. Also, it is plausible that overweight and obese participants are dieting more often than their peers within the healthy weight range. As being on a diet is linked to a higher likelihood of failures in food intake control, such participants may be particularly prone to indulging in high-calorie foods (Wardle, 1988). Thus, participants in future studies should be asked whether they are on a diet.

Another possible limitation of our research is that we did not collect data regarding participants' socioeconomic status (SES). Earlier research suggests that women-but not men-who experienced lower levels of parental investment and grew up in poorer environments respond to cues to environmental harshness with an increased desire for calories compared to their counterparts who grew up in higher SES families (Hill et al., 2013). Hence, future research should investigate whether effects reported across Studies 1a-2c are moderated by participants' current and childhood SES.

\subsubsection{Concluding remarks}

Five studies jointly suggest that exposure to winter cues may increase consumers' preferences for energy-dense foods. Due to the importance of limiting consumption of such foods to tackle environmental and public health issues, the present findings offer potential implications for environmental organizations and policymakers. 


\subsection{Supplementary online materials}

\section{Pretest}

Various affective states - predominantly negative emotions - can influence food preferences and induce people to favor high-calorie products (Macht, 2008; Van Strien et al., 2013). Therefore, we conducted a pretest to rule out this potential confound and ensure that both experimental videos yielded similar levels of anxiety as well as positive and negative affect.

\section{Method}

\section{Participants}

We recruited 140 U.S. participants on Prolific Academic (68 females, $M_{\text {age }}=34.98$ years, $S D=12.80)$ to take part in a pretest in exchange for $£ 0.50$.

\section{Procedure}

After accepting an informed consent form, participants were randomly assigned to one of the two conditions. They watched either a video showing a forest walk in the winter or in the summer. Both videos lasted 50 seconds. No humans or animals appeared in any scene. The video entitled "Summer forest walk" showed trees covered with leaves and other vegetation typical for the summer. The video entitled "Winter forest walk" showed trees and vegetation covered by snow, typical for the winter.

After watching their assigned video, participants filled out the six-item short-form of the Spielberger State-Trait Anxiety Inventory $(\alpha=.85)$, with responses ranging from 1 
$=$ Not at all to $4=$ Very much (Marteau \& Bekker, 1992). We also measured positive $(\alpha=.92)$ and negative $(\alpha=.93)$ affect elicited by the videos using the short version of Positive and Negative Affect Schedule (Watson et al., 1988). The positive and negative affect scales consisted of 10 items each, and were anchored at $1=$ very slightly or not at all, and $5=$ extremely. The pretest concluded with participants providing demographic details.

\section{Results and discussion}

\section{Anxiety}

An independent samples $t$-test on the anxiety measure index revealed that the videos elicited similar levels of state anxiety $\left(M_{\text {winter }}=1.89, S D=0.72 ; M_{\text {summer }}=1.97, S D\right.$ $=0.62), t(138)=0.61, p=.542, d=0.10$.

\section{Positive and negative affect}

A comparable analysis performed on the positive affect index indicated no significant differences between conditions $\left(M_{\text {winter }}=2.73, S D=0.83 ; M_{\text {summer }}=2.95, S D=1.00\right)$, $t(138)=1.44, p=.153, d=0.25$. Likewise, comparing negative affect across conditions revealed no differences between them $\left(M_{\text {winter }}=1.53, S D=0.68 ; M_{\text {summer }}=1.61, S D\right.$ $=0.82), t(138)=0.62, p=.537, d=0.11$.

\section{Discussion}

Results from the pretest provide evidence for the adequacy of our stimuli-we found no significant differences between conditions in anxiety, positive, or negative affect. There- 
fore, the potential confounds associated with affective states are unlikely to act as the main drivers of the results in our subsequent main studies.

\section{The total number of completed words}

\section{Study 1a}

An independent samples $t$-test on the sum of the total number of words completed revealed a marginally significant difference between conditions $\left(M_{\text {winter }}=8.41, S D=2.30\right.$; $\left.M_{\text {summer }}=9.09, S D=1.61\right), t(104)=1.78, p=.078, d=0.35$, indicating that participants exposed to winter cues created fewer words than those exposed to summer cues.

\section{Study 1b}

An independent samples $t$-test with the sum of the total number of correct words completed as the dependent variable revealed no significant difference between conditions $\left(M_{\text {winter }}=9.15, S D=1.91 ; M_{\text {summer }}=8.70, S D=2.44\right), t(103)=-1.00, p=.319, d=$ 0.20 . 


\section{Supplementary tables with full model outputs across}

\section{Studies 2a-2c}

In the main text, we report coefficients multiplied by 100 for readability. Below, we report raw coefficients, that is, before multiplication and additional results that were not reported in the main text for brevity.

Table S1: Study 2a primary hypothesis test results

\begin{tabular}{lc}
\hline & Preference \\
\hline Intercept & -0.02086 \\
& {$[-0.13984,0.09812]$} \\
Condition (winter) & -0.07863 \\
& {$[-0.21812,0.06085]$} \\
Calories & 0.00010 \\
Condition (winter) $\times$ Calories & {$[-0.00007,0.00027]$} \\
& $0.00020^{*}$ \\
\hline
\end{tabular}

Note:

${ }^{*} \mathrm{p}<0.1 ;{ }^{* *} \mathrm{p}<0.05 ;{ }^{* * *} \mathrm{p}<0.01$

Brackets show $95 \%$ CIs 
Table S2: Study 2a secondary hypothesis test results

\section{Preference}

Intercept

$-0.14072^{*}$

$[-0.30287,0.02144]$

Condition (winter)

0.00560

$[-0.19491,0.20611]$

Calories

$0.00041^{* * *}$

$[0.00018,0.00064]$

Sex (woman)

$0.24809^{* *}$

$[0.04874,0.44745]$

Condition (winter $) \times$ Calories

$-0.00012$

$[-0.00040,0.00017]$

Condition $($ winter $) \times$ Sex $($ woman $)$

$-0.16464$

$[-0.44661,0.11732]$

Calories $\times$ Sex $($ woman $)$

$-0.00066^{* * *}$

$[-0.00096,-0.00036]$

Condition $($ winter $) \times$ Calories $\times$ Sex $($ woman $)$

$0.00065^{* * *}$

$[0.00024,0.00107]$

Note:

${ }^{*} \mathrm{p}<0.1 ;{ }^{* *} \mathrm{p}<0.05 ;{ }^{* * *} \mathrm{p}<0.01$

Brackets show 95\% CIs 
Table S3: Study 2b primary hypothesis test results

Preference

$\begin{array}{lr}\text { Intercept } & 0.12099^{* *} \\ & {[0.01219,0.22978]} \\ \text { Condition (winter) } & -0.23458^{* * *} \\ & {[-0.39916,-0.06999]} \\ \text { Calories } & 0.00003 \\ & {[-0.00010,0.00017]} \\ \text { Condition (winter) } \times \text { Calories } & 0.00042^{* * *} \\ & {[0.00020,0.00065]}\end{array}$

Note:

${ }^{*} \mathrm{p}<0.1 ;{ }^{* *} \mathrm{p}<0.05 ;{ }^{* * *} \mathrm{p}<0.01$

Brackets show 95\% CIs 
Table S4: Study 2b secondary hypothesis test results

\section{Preference}

Intercept

$-0.07249$

$[-0.23692,0.09195]$

Condition (winter)

$-0.08337$

$[-0.33160,0.16486]$

Calories

$0.00047^{* * *}$

$[0.00026,0.00067]$

Sex (woman)

$0.29626^{* * *}$

$[0.11476,0.47776]$

Condition (winter $) \times$ Calories

$0.00030^{*}$

$[-0.00004,0.00063]$

Condition $($ winter $) \times$ Sex $($ woman $)$

$-0.18747$

$[-0.52204,0.14711]$

Calories $\times$ Sex (woman)

$-0.00064^{* * *}$

$[-0.00088,-0.00041]$

Condition $($ winter $) \times$ Calories $\times$ Sex $($ woman $)$

$-0.00002$

$[-0.00048,0.00043]$

Note:

${ }^{*} \mathrm{p}<0.1 ;{ }^{* *} \mathrm{p}<0.05 ;{ }^{* * *} \mathrm{p}<0.01$

Brackets show 95\% CIs 
Table S5: Study 2c primary hypothesis test results

Preference

Intercept

0.03408

$[-0.04613,0.11429]$

Condition (winter)

$0.07027^{*}$

$[-0.00204,0.14258]$

Calories

$0.00034^{* * *}$

$[0.00026,0.00043]$

Condition $($ winter $) \times$ Calories

$-0.00008$

$[-0.00018,0.00002]$

Note:

${ }^{*} \mathrm{p}<0.1 ;{ }^{* *} \mathrm{p}<0.05 ;{ }^{* * *} \mathrm{p}<0.01$

Brackets show 95\% CIs 
Table S6: Study 2c secondary hypothesis test results

\section{Preference}

Intercept

$-0.03283$

$[-0.12620,0.06054]$

Condition (winter)

$0.12633^{* *}$

$[0.02513,0.22753]$

Calories

$0.00057^{* * *}$

$[0.00047,0.00068]$

Sex (woman)

$0.15178^{* * *}$

$[0.05053,0.25304]$

Condition (winter) $\times$ Calories

$-0.00024^{* * *}$

$[-0.00038,-0.00010]$

Condition $($ winter $) \times$ Sex $($ woman $)$

$-0.12720^{*}$

$[-0.27154,0.01714]$

Calories $\times$ Sex (woman $)$

$-0.00049^{* * *}$

$[-0.00063,-0.00035]$

Condition $($ winter $) \times$ Calories $\times$ Sex $($ woman $)$

$0.00035^{* * *}$

$[0.00015,0.00054]$

Note:

${ }^{*} \mathrm{p}<0.1 ;{ }^{* *} \mathrm{p}<0.05 ;{ }^{* * *} \mathrm{p}<0.01$

Brackets show 95\% CIs 
Figure S1: Video stimuli used across Studies 2a-2c

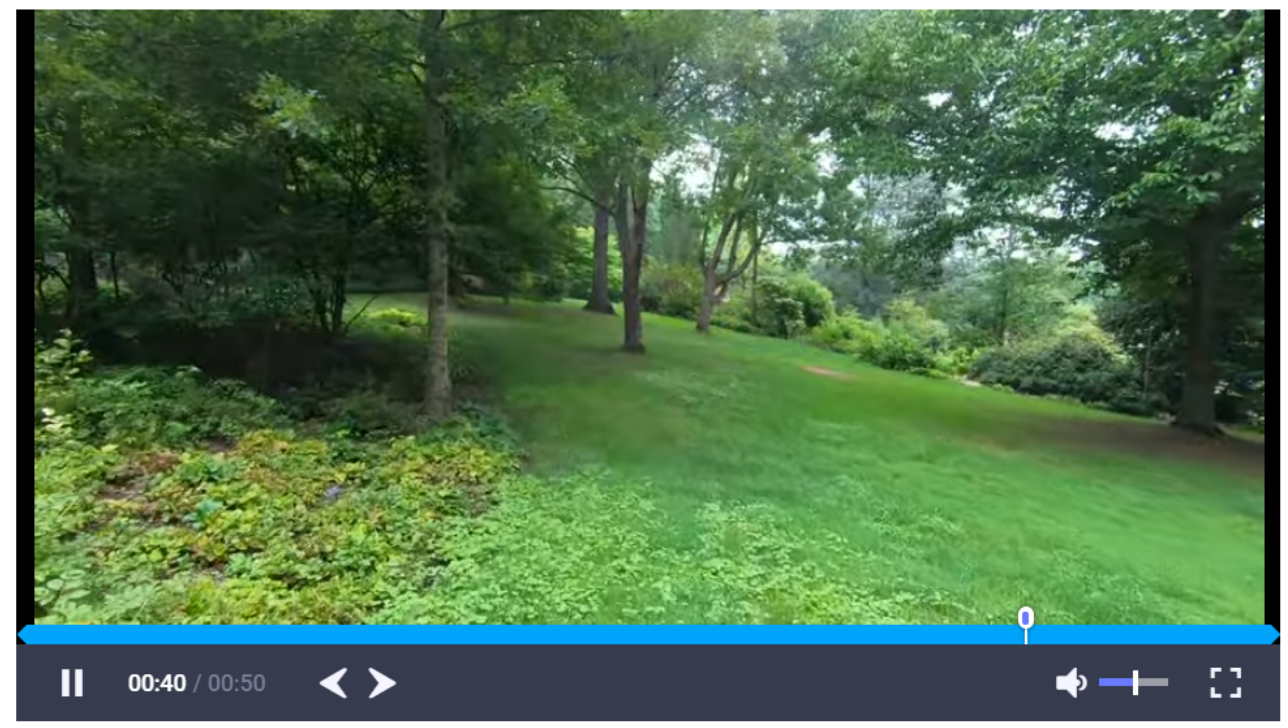

\section{Click this button to continue}

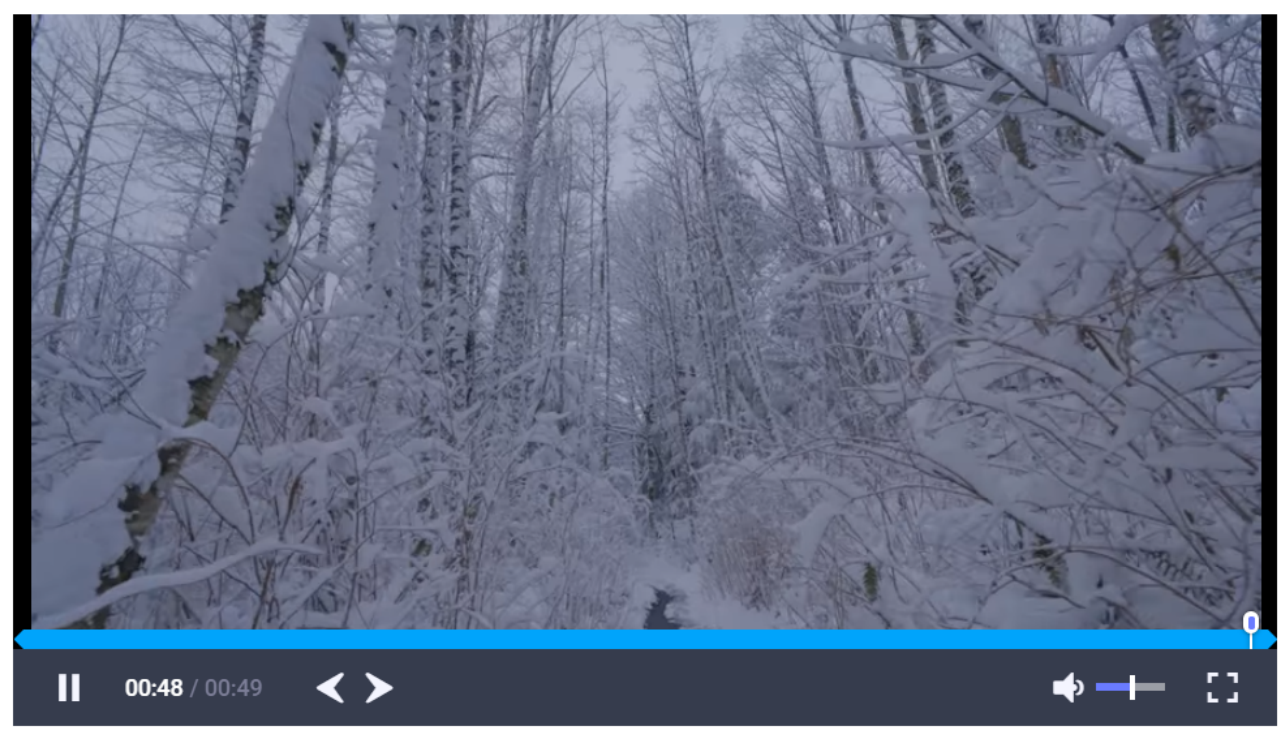


Figure S2: Sample tasks used across Studies 1a-1b

Complete words using the given letters

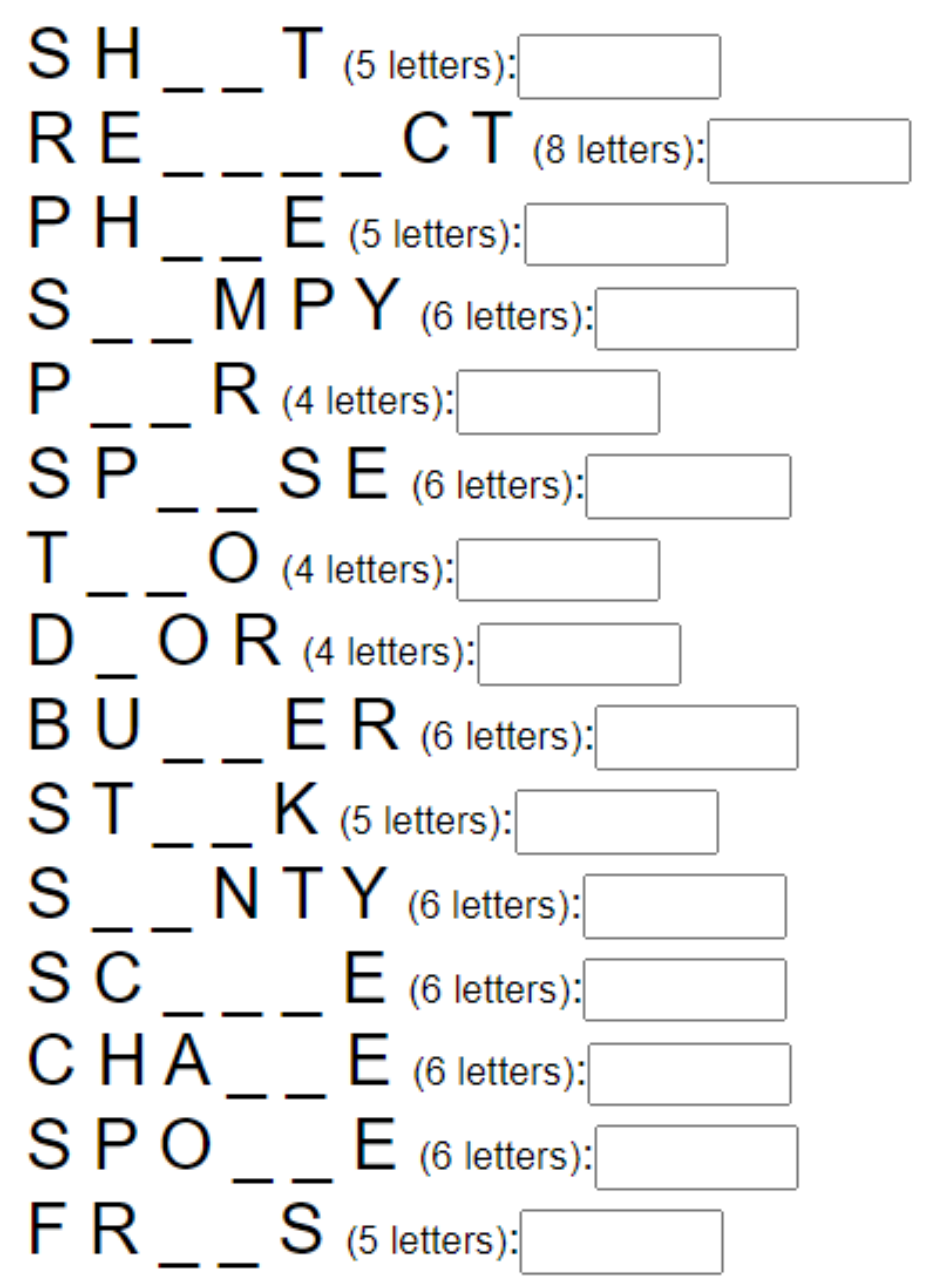


Figure S3: Sample tasks used across Studies 2a-2c

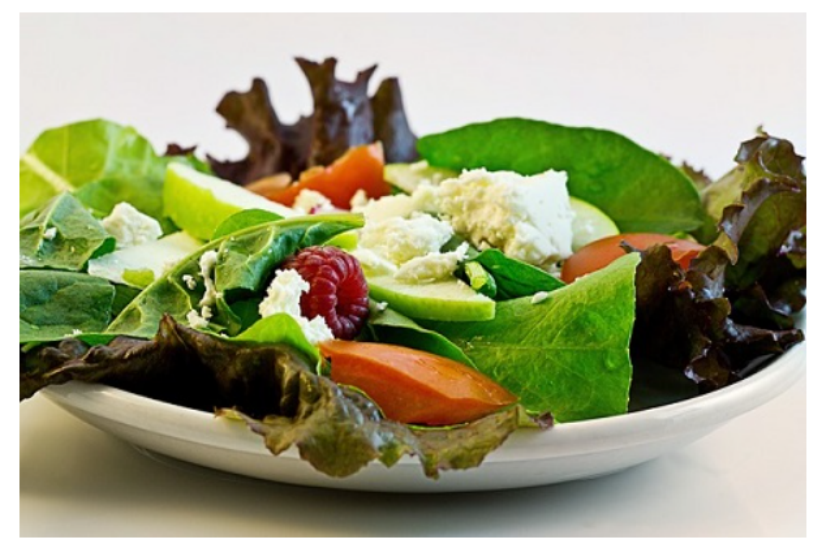

Would you eat this food now?

Click this button to continue

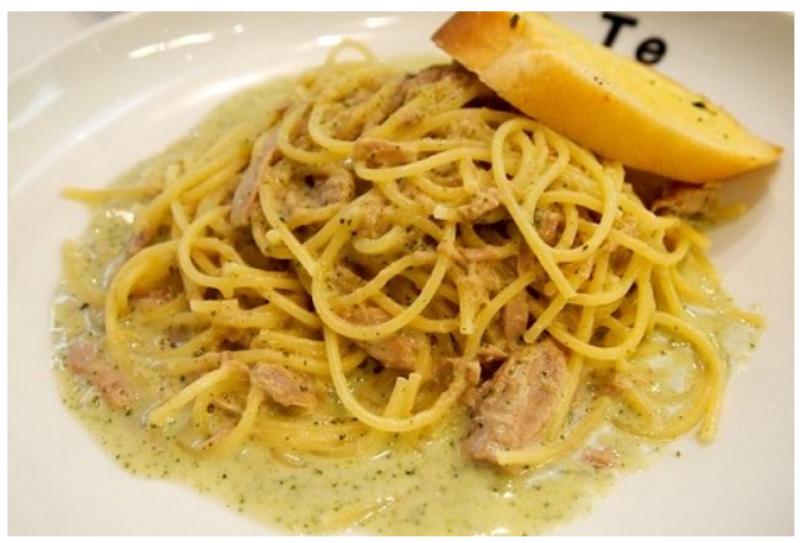

How many calories does this food contain? (the serving you see) 


\subsection{References}

Ammann, J., Hartmann, C., Peterhans, V., Ropelato, S., \& Siegrist, M. (2020). The relationship between disgust sensitivity and behaviour: A virtual reality study on food disgust. Food Quality and Preference, 80, 103833. https://doi.org/10.1016/j. foodqual.2019.103833

Au-Yong, I. T., Thorn, N., Ganatra, R., Perkins, A. C., \& Symonds, M. E. (2009). Brown adipose tissue and seasonal variation in humans. Diabetes, 58(11), 2583-2587. https://doi.org/10.2337/db09-0833

Banovic, M., \& Otterbring, T. (2021). Athletic abs or big bellies: The impact of imagery, arousal levels, and health consciousness on consumers' attitudes towards plantbased protein products. Food Quality and Preference, 87, 104067. https://doi.org/ 10.1016/j.foodqual.2020.104067

Bates, D., Mächler, M., Bolker, B., \& Walker, S. (2015). Fitting linear mixed-effects models using lme4. Journal of Statistical Software, 67(1), 1-48. https://doi.org/ 10.18637/jss.v067.i01

Berbesque, J. C., \& Marlowe, F. W. (2009). Sex differences in food preferences of Hadza hunter-gatherers. Evolutionary Psychology, 7(4), 147470490900700409. https:// doi.org/10.1177/147470490900700409

Blix, A. S. (2016). Adaptations to polar life in mammals and birds. Journal of Experimental Biology, 219(8), 1093-1105. https://doi.org/10.1242/jeb.120477

Bolker, B. (2007). Stochastic simulation and power analysis. https://ms.mcmaster.ca/ bolker/emdbook/chap5A.pdf 
Cardello, A. V., Schutz, H., Snow, C., \& Lesher, L. (2000). Predictors of food acceptance, consumption and satisfaction in specific eating situations. Food Quality and Preference, 11(3), 201-216. https://doi.org/10.1016/S0950-3293(99)00055-5

Cherulnik, P. D. (1991). Reading restaurant facades: Environmental inference in finding the right place to eat. Environment and Behavior, 23(2), 150-170. https://doi. org $/ 10.1177 / 0013916591232002$

Czyzewska, M., \& Graham, R. (2008). Implicit and explicit attitudes to high-and lowcalorie food in females with different BMI status. Eating Behaviors, 9(3), 303-312. https://doi.org/10.1016/j.eatbeh.2007.10.008

De Castro, J. M. (1991). Seasonal rhythms of human nutrient intake and meal pattern. Physiology \& Behavior, 50(1), 243-248. https://doi.org/10.1016/0031-9384(91) $90527-\mathrm{u}$

Drewnowski, A., Kurth, C., Holden-Wiltse, J., \& Saari, J. (1992). Food preferences in human obesity: Carbohydrates versus fats. Appetite, 18(3), 207-221. https://doi. org/10.1016/0195-6663(92)90198-F

Egolf, A., Siegrist, M., \& Hartmann, C. (2018). How people's food disgust sensitivity shapes their eating and food behaviour. Appetite, 127, 28-36. https://doi.org/10. 1016/j.appet.2018.04.014

Fagan, B. (2001). The Little Ice Age: how climate made history 1300-1850. Basic Books.

Folwarczny, M., Li, N. P., Sigurdsson, V., Tan, L. K., \& Otterbring, T. (2021). Development and psychometric evaluation of the Anticipated Food Scarcity Scale (AFSS). Appetite, 166, 105474. https://doi.org/10.1016/j.appet.2021.105474 
Folwarczny, M., Christensen, J. D., Li, N. P., Sigurdsson, V., \& Otterbring, T. (2021). Crisis communication, anticipated food scarcity, and food preferences: Preregistered evidence of the insurance hypothesis. Food Quality and Preference, 91, 104213. https://doi.org/10.1016/j.foodqual.2021.104213

Gasiorowska, A., Zaleskiewicz, T., \& Kesebir, P. (2018). Money as an existential anxiety buffer: Exposure to money prevents mortality reminders from leading to increased death thoughts. Journal of Experimental Social Psychology, 79, 394-409. https: //doi.org/10.1016/j.jesp.2018.09.004

GBD 2015 Obesity Collaborators. (2017). Health effects of overweight and obesity in 195 countries over 25 years. New England Journal of Medicine, 377(1), 13-27. https://doi.org/10.1056/NEJMoa1614362

Gerend, M. A. (2009). Does calorie information promote lower calorie fast food choices among college students? Journal of Adolescent Health, 44(1), 84-86. https://doi. org/10.1016/j.jadohealth.2008.06.014

Gidlöf, K., Ares, G., Aschemann-Witzel, J., \& Otterbring, T. (2021). Give us today our daily bread: The effect of hunger on consumers' visual attention towards bread and the role of time orientation. Food Quality and Preference, 88, 104079. https: //doi.org/10.1016/j.foodqual.2020.104079

Gosler, A. G., Greenwood, J. J., \& Perrins, C. (1995). Predation risk and the cost of being fat. Nature, 377(6550), 621-623. https://doi.org/10.1038/377621a0

Green, P., \& MacLeod, C. J. (2016). SIMR: An R package for power analysis of generalized linear mixed models by simulation. Methods in Ecology and Evolution, 7(4), 493498. https://doi.org/10.1111/2041-210X.12504 
Griskevicius, V., Cantú, S. M., \& Van Vugt, M. (2012). The evolutionary bases for sustainable behavior: Implications for marketing, policy, and social entrepreneurship. Journal of Public Policy \& Marketing, 31(1), 115-128. https://doi.org/10.1509/ jppm.11.040

Griskevicius, V., Goldstein, N. J., Mortensen, C. R., Sundie, J. M., Cialdini, R. B., \& Kenrick, D. T. (2009). Fear and loving in Las Vegas: Evolution, emotion, and persuasion. Journal of Marketing Research, 46(3), 384-395. https://doi.org/10. 1509/jmkr.46.3.384

Griskevicius, V., Tybur, J. M., \& Van den Bergh, B. (2010). Going green to be seen: Status, reputation, and conspicuous conservation. Journal of Personality and Social Psychology, 98(3), 392-404. https://doi.org/10.1037/a0017346

Hamilton, D., Dee, A., \& Perry, I. (2018). The lifetime costs of overweight and obesity in childhood and adolescence: A systematic review. Obesity Reviews, 19(4), 452-463. https://doi.org/10.1111/obr.12649

Hill, S. E., Rodeheffer, C. D., DelPriore, D. J., \& Butterfield, M. E. (2013). Ecological contingencies in women's calorie regulation psychology: A life history approach. Journal of Experimental Social Psychology, 49(5), 888-897. https://doi.org/10. 1016/j.jesp.2013.03.016

Humphries, M. M., Studd, E. K., Menzies, A. K., \& Boutin, S. (2017). To everything there is a season: Summer-to-winter food webs and the functional traits of keystone species. Integrative and Comparative Biology, 57(5), 961-976. https://doi.org/10. 1093/icb/icx119 
Jaeger, S. R., \& Rose, J. M. (2008). Stated choice experimentation, contextual influences and food choice: A case study. Food Quality and Preference, 19(6), 539-564. https: //doi.org/10.1016/j.foodqual.2008.02.005

King, S. C., Weber, A. J., Meiselman, H. L., \& Lv, N. (2004). The effect of meal situation, social interaction, physical environment and choice on food acceptability. Food Quality and Preference, 15(7-8), 645-653. https://doi.org/10.1016/j.foodqual. 2004.04.010

Kuznetsova, A., Brockhoff, P. B., Christensen, R. H., et al. (2017). lmerTest package: Tests in linear mixed effects models. Journal of Statistical Software, 82(13), 1-26. https://doi.org/10.18637/jss.v082.i13

Li, N. P., van Vugt, M., \& Colarelli, S. M. (2018). The evolutionary mismatch hypothesis: Implications for psychological science. Current Directions in Psychological Science, 27(1), 38-44. https://doi.org/10.1177/0963721417731378

Ma, Y., Olendzki, B. C., Li, W., Hafner, A. R., Chiriboga, D., Hebert, J. R., Campbell, M., Sarnie, M., \& Ockene, I. S. (2006). Seasonal variation in food intake, physical activity, and body weight in a predominantly overweight population. European Journal of Clinical Nutrition, 60(4), 519-528. https://doi.org/10.1038/sj.ejcn. 1602346

Machín, L., Curutchet, M. R., Gugliucci, V., Vitola, A., Otterbring, T., de Alcantara, M., \& Ares, G. (2020). The habitual nature of food purchases at the supermarket: Implications for policy making. Appetite, 155, 104844. https://doi.org/10.1016/j. appet. 2020.104844 
Macht, M. (2008). How emotions affect eating: A five-way model. Appetite, 50(1), 1-11. https://doi.org/10.1016/j.appet.2007.07.002

Marteau, T. M., \& Bekker, H. (1992). The development of a six-item short-form of the state scale of the Spielberger State - Trait Anxiety Inventory (STAI). British Journal of Clinical Psychology, 31(3), 301-306. https://doi.org/10.1111/j.20448260.1992.tb00997.x

Mendes, E. (2011). U.S. health habits continue sharp winter decline. https://news.gallup. com/poll/151424/health-habits-continue-steep-winter-decline.aspx

Morgan, J. (2016). The melting Arctic ice calls for protecting what I love. https:// www . greenpeace . org / international / story / 7028 / the - melting - arctic - ice - calls for-protecting-what-i-love/

Neel, J. V. (1962). Diabetes mellitus: A "thrifty" genotype rendered detrimental by "progress"? American Journal of Human Genetics, 14(4), 353-362.

Nelson, D. L., Keelean, P. D., \& Negrao, M. (1989). Word-fragment cuing: The lexical search hypothesis. Journal of Experimental Psychology: Learning, Memory, and Cognition, 15(3), 388-397. https://doi.org/10.1037/0278-7393.15.3.388

Nettle, D., Andrews, C., \& Bateson, M. (2017). Food insecurity as a driver of obesity in humans: The insurance hypothesis. Behavioral and Brain Sciences, 40. https: //doi.org/10.1017/S0140525X16000947

Öhman, A., Flykt, A., \& Esteves, F. (2001). Emotion drives attention: Detecting the snake in the grass. Journal of Experimental Psychology: General, 130(3), 466-478. https://doi.org/10.1037/0096-3445.130.3.466 
Öhman, A., \& Mineka, S. (2001). Fears, phobias, and preparedness: Toward an evolved module of fear and fear learning. Psychological Review, 108(3), 483-522. https: //doi.org/10.1037/0033-295X.108.3.483

Ornstein, R. E., \& Ehrlich, P. R. (2000). New world new mind: Moving toward conscious evolution. ISHK.

Otterbring, T. (2020). Appetite for destruction: Counterintuitive effects of attractive faces on people's food choices. Psychology $\&$ Marketing, 37(11), 1451-1464. https://doi. $\operatorname{org} / 10.1002 / \operatorname{mar} .21257$

Otterbring, T. (2021). Evolutionary psychology in marketing: Deep, debated, but fancier with fieldwork. Psychology \& Marketing, 38(2), 229-238. https://doi.org/10.1002/ mar.21453

Otterbring, T., Gidlöf, K., Rolschau, K., \& Shams, P. (2020). Cereal deal: How the physical appearance of others affects attention to healthy foods. Perspectives on Behavior Science, 43(3), 451-468. https://doi.org/0.1007/s40614-020-00242-2

Otterbring, T., \& Shams, P. (2019). Mirror, mirror, on the menu: Visual reminders of overweight stimulate healthier meal choices. Journal of Retailing and Consumer Services, 47, 177-183. https://doi.org/10.1016/j.jretconser.2018.11.019

Otterbring, T., Sundie, J., Li, Y. J., \& Hill, S. (2020). Evolutionary psychological consumer research: Bold, bright, but better with behavior. Journal of Business Research, 120, 473-484. https://doi.org/10.1016/j.jbusres.2020.07.010

Pennanen, K., Närväinen, J., Vanhatalo, S., Raisamo, R., \& Sozer, N. (2020). Effect of virtual eating environment on consumers' evaluations of healthy and unhealthy 
snacks. Food Quality and Preference, 82, 103871. https://doi.org/10.1016/j. foodqual.2020.103871

Perkovic, S., Otterbring, T., Schärli, C., \& Pachur, T. (2021). The perception of food products in adolescents, lay adults, and experts: A psychometric approach. Journal of Experimental Psychology: Applied. https://doi.org/10.1037/xap0000384

Prentice, A. M., Rayco-Solon, P., \& Moore, S. E. (2005). Insights from the developing world: Thrifty genotypes and thrifty phenotypes. Proceedings of the Nutrition Society, 64(2), 153-161. https://doi.org/https://doi.org/10.1079/PNS2005421

Roediger, H. L., Weldon, M. S., Stadler, M. L., \& Riegler, G. L. (1992). Direct comparison of two implicit memory tests: Word fragment and word stem completion. Journal of Experimental Psychology: Learning, Memory, and Cognition, 18(6), 1251-1269. https://doi.org/10.1037//0278-7393.18.6.1251

Rozin, P. (1996). Towards a psychology of food and eating: From motivation to module to model to marker, morality, meaning, and metaphor. Current Directions in Psychological Science, 5(1), 18-24. https://doi.org/10.1111/1467-8721.ep10772690

Schulz, L. C. (2010). The Dutch Hunger Winter and the developmental origins of health and disease. Proceedings of the National Academy of Sciences, 107(39), 1675716758. https://doi.org/10.1073/pnas.1012911107

Siegrist, M., Bearth, A., \& Hartmann, C. (2020). Food disgust sensitivity influences the perception of food hazards: Results from longitudinal and cross-cultural studies. Appetite, 153, 104742. https://doi.org/10.1016/j.appet.2020.104742 
Silverman, I., \& Eals, M. (1992). Sex differences in spatial abilities: Evolutionary theory and data. In J. H. Barkow, L. Cosmides, \& J. Tooby (Eds.), The adapted mind: Evolutionary psychology and the generation of culture (pp. 533-549).

Simpson, S. J., \& Raubenheimer, D. (2005). Obesity: The protein leverage hypothesis. Obesity Reviews, 6(2), 133-142. https://doi.org/10.1111/j.1467-789X.2005.00178.x

Stoet, G. (2010). PsyToolkit: A software package for programming psychological experiments using Linux. Behavior Research Methods, 42(4), 1096-1104. https://doi. org/10.3758/BRM.42.4.1096

Stoet, G. (2017). PsyToolkit: A novel web-based method for running online questionnaires and reaction-time experiments. Teaching of Psychology, 44(1), 24-31. https://doi. org $/ 10.1177 / 0098628316677643$

Tooby, J., \& Cosmides, L. (1990). The past explains the present: Emotional adaptations and the structure of ancestral environments. Ethology and Sociobiology, 11(4-5), 375-424. https://doi.org/10.1016/0162-3095(90)90017-Z

Tulving, E., Schacter, D. L., \& Stark, H. A. (1982). Priming effects in word-fragment completion are independent of recognition memory. Journal of Experimental Psychology: Learning, Memory, and Cognition, 8(4), 336-342. https://doi.org/10. 1037/0278-7393.8.4.336

Van Ooijen, A., van Marken Lichtenbelt, W., Van Steenhoven, A., \& Westerterp, K. (2004). Seasonal changes in metabolic and temperature responses to cold air in humans. Physiology \&6 Behavior, 82(2-3), 545-553. https://doi.org/10.1016/j. physbeh.2004.05.001 
Van Strien, T., Cebolla, A., Etchemendy, E., Gutierrez-Maldonado, J., Ferrer-Garcia, M., Botella, C., \& Baños, R. (2013). Emotional eating and food intake after sadness and joy. Appetite, 66, 20-25. https://doi.org/10.1016/j.appet.2013.02.016

Wardle, J. (1988). Cognitive control of eating. Journal of Psychosomatic Research, 32(6), 607-612. https://doi.org/10.1016/0022-3999(88)90009-8

Wardle, J., Guthrie, C., Sanderson, S., Birch, L., \& Plomin, R. (2001). Food and activity preferences in children of lean and obese parents. International Journal of Obesity, 25(7), 971-977. https://doi.org/10.1038/sj.ijo.0801661

Watson, D., Clark, L. A., \& Tellegen, A. (1988). Development and validation of brief measures of positive and negative affect: The PANAS Scales. Journal of Personality and Social Psychology, 54(6), 1063-1070.

Wells, N. M., Ashdown, S. P., Davies, E. H., Cowett, F. D., \& Yang, Y. (2007). Environment, design, and obesity: Opportunities for interdisciplinary collaborative research. Environment and Behavior, 39(1), 6-33. https://doi.org/10.1177/ 0013916506295570

WHO. (2020). Obesity and overweight. https://www. who.int/news-room/fact-sheets/ detail/obesity-and-overweight

Willett, W., Rockström, J., Loken, B., Springmann, M., Lang, T., Vermeulen, S., Garnett, T., Tilman, D., DeClerck, F., Wood, A., et al. (2019). Food in the Anthropocene: the EAT-Lancet Commission on healthy diets from sustainable food systems. The Lancet, 393(10170), 447-492. https://doi.org/10.1016/S0140-6736(18)31788-4 
Wisdom, J., Downs, J. S., \& Loewenstein, G. (2010). Promoting healthy choices: Information versus convenience. American Economic Journal: Applied Economics, 2(2), 164-78. https://doi.org/10.1257/app.2.2.164

Wynes, S., \& Nicholas, K. A. (2017). The climate mitigation gap: Education and government recommendations miss the most effective individual actions. Environmental Research Letters, 12(7), 074024. https://doi.org/10.1088/1748-9326/aa7541 


\section{Chapter 5}

\section{Development and psychometric evaluation of the Anticipated}

\section{Food Scarcity Scale (AFSS)}

Published in Appetite

Michał Folwarczny

Department of Business Administration, Reykjavik University

Norman P. Li

School of Social Sciences, Singapore Management University

Valdimar Sigurdsson

Department of Business Administration, Reykjavik University

Lynn K. L. Tan

School of Social Sciences, Singapore Management University

Tobias Otterbring

Department of Management, University of Agder,

Institute of Retail Economics 


\begin{abstract}
Mass media extensively inform societies about events threatening the global food supply (e.g., pandemics or Brexit). Consumers exposed to such communication may perceive food resources as becoming scarcer. In line with an evolutionary account, these perceptions can shift decision-making in domains such as food preferences or prosociality. However, existing literature has solely focused on actual and past food insecurity experiences threatening mostly low-income families, thus neglecting the future-oriented perceptions among the general population. This paper broadens the food insecurity research scope by developing a new construct - anticipated food scarcity (AFS) - which is defined as the perception that food resources are becoming less available (in the future). We have developed and psychometrically validated the 8-item Anticipated Food Scarcity Scale (AFSS) in eight studies $(N=1333)$. The 8-item AFSS is unidimensional and has good psychometric qualities. The scale is sensitive to food scarcity cues and, therefore, can be used in experimental research. Moreover, its relatively narrow set of items makes it an exceptionally potent tool for use in online surveys, field settings, and lab studies. Taken together, the AFSS presents an alternative approach to food scarcity measurement in affluent societies and, consequently, can foster novel research on food waste, prosocial behaviors, and other similar topic areas.
\end{abstract}

Keywords: food scarcity, food shortages, food insecurity, the insurance hypothesis, evolutionary mismatch 


\section{$5.1 \quad$ Introduction}

Amid the COVID-19 pandemic, people around the world have been panic-buying food (Benker, 2021). According to a BBC report (Lufkin, 2020), in Singapore, consumers grabbed up lots of rice and instant noodles, leading to shortages of these products in supermarkets. In Auckland, shoppers spent $40 \%$ more on groceries than they did a year ago. Similar behaviors have been observed in the past, such as during the 1962 Cuban missile crisis and in preparation for Y2K, when Americans stockpiled canned foods in their basements (Lufkin, 2020). Experts have warned that Brexit may trigger even more intense panic buying among consumers (Casalicchio, 2020). These shopping sprees often result in excessive food waste. Crucially, the United Nations Development Programme (UNDP, 2020) points at limiting unnecessary consumption as one of the foremost steps in achieving sustainable development.

Although such events usually do not cause actual food shortages in developed countries, it is plausible that receiving information about such turmoil may induce consumers to anticipate food scarcity. As a result, consumers may purchase, consume, or waste more food than usual due to unjustified food stockpiling (see Nettle et al., 2017, for an overview of the role that cues to food scarcity play in food decision-making) and consumption (Folwarczny et al., 2021). To investigate this possibility, a scale measuring anticipated food scarcity (AFS) is vital. Existing tools used in affluent countries are typically retrospective and focus on the actual insufficiency of food resources (e.g., Ashby et al., 2016; Nettle et al., 2019). For example, an established tool for measuring food insecurity-HFIASfocuses on the frequency of experiencing food unavailability in the past (Coates et al., 2007). In other words, these tools focus on the actual experience of food shortages in 
specific populations. What is missing is a tool to measure expectations of impending food shortage. Accordingly, we developed the Anticipated Food Scarcity Scale (AFSS) to capture perceptions of food resources becoming less available in the future among the general population.

Our focal construct differs from the existing literature (cf. Ashby et al., 2016) in that it focuses on an increasing scarcity of food resources rather than on food insecurity, which tends to denote emotions such as fear and anxiety (Merriam-Webster, 2021). Indeed, the results presented in Table 5.2 suggest that AFS and affective states are only weakly related.

\subsubsection{Anticipated food scarcity (AFS)}

Major global concerns such as climate change, water scarcity, or resource depletion will have more severe consequences for food resources in the future that what is currently the case (Hanjra \& Qureshi, 2010). Hence, our construct of interest is future-oriented. When defining the construct, we draw from work on past experiences of food insecurity by Coates et al. (2007). As such, in the remainder of this article, we define AFS as "the perception of future food resources becoming insufficient in terms of availability and accessibility (e.g., certain foods might disappear or become less affordable)." Availability refers to the physical existence of food resources (e.g., food production), whereas accessibility refers to individuals' ability to obtain food (e.g., having enough money for groceries). Webb et al. (2006) discuss how these dimensions are understood in the literature on food insecurity.

The perception of future food scarcity relies on past experiences of food unavailability, beliefs concerning the influence of various worldly events and factors, and beliefs in 
wielding power over others. As AFS is a perception, its magnitude can vary over time. In sum, whereas AFS is informed by top-down processes such as present knowledge about future food production or beliefs that one can control what happens in politics, it is also informed by bottom-up processes such as exposure to cues related to food scarcity. Importantly, food scarcity cues may influence our immediate reactions regardless of whether they suggest food scarcity that is distant in time and space or more proximate in nature (e.g., neighbors who have to rely on food stamps).

\subsubsection{Perceivable cues related to food scarcity}

The basic principles of evolutionary mismatch shed light on why perceivable cues to food scarcity may trigger the same response mechanisms as an actual experience of food scarcity (Li et al., 2018; Tooby \& Cosmides, 1990). These mechanisms likely evolved so that humans would be prepared to cope with immediate threats and opportunities (e.g., a lion approaching, a drought that leads to famine, an attractive person who appears available). Because our ancestors did not routinely face technology-induced processes such as global warming that have far-reaching future-focused consequences, our threathandling mechanisms did not evolve to differentiate cues that indicate immediate dangers from cues that suggest more distant dangers (Griskevicius et al., 2012; Ornstein \& Ehrlich, 2000). Hence, human psychological mechanisms respond to most threat cues as if they were indicating an impending danger. Accordingly, cues related to evolutionarily novel threats that are distant in time (e.g., food scarcity occurring this year vs. food scarcity occurring in three decades) or space (e.g., one's local neighborhood vs. a country in another continent) may activate the same mechanisms that produce immediate responses 
to mitigate those threats in the current environment (cf. Li et al., 2018).

Crucially, whereas actual food unavailability always entails the physical experience of food insufficiency such as hunger, anticipated food scarcity induced by, for instance, reports about Brexit does not necessitate physical experiences. As such, AFS is distinct from food insecurity as it is defined in the current literature. According to the Food and Agriculture Organization of the United Nations (FAO), "Food security exists when all people, at all times, have physical and economic access to sufficient, safe and nutritious food to meet their dietary needs and food preferences for an active and healthy life" (FAO, 1996). This definition does not encompass any form of anticipation and perceptions about future food availability.

Notably, a recent study has suggested that exposing participants to videos showing food scarcity induced by climate change occurring in distant parts of the world increases their current preferences toward energy-dense foods while decreasing their preferences toward low-calorie alternatives (Folwarczny et al., 2021). These results support the view that psychological mechanisms have not evolved to differentiate between current and distant threats; rather, they imply that exposure to any cues related to food scarcity may shift food preferences toward energy-dense products. However, tools measuring related constructs, such as the United States Department of Agriculture's Food Security Survey Module (FSSM), are typically retrospective and primarily capture food insecurity defined as the physical unavailability of food resources (Ashby et al., 2016). Thus, these tools cannot predict a shift in food preferences resulting from exposure to food scarcity cues, especially if these cues are related to scarcity distant in time (e.g., happening in two decades) and space (e.g., happening on another continent). 


\subsubsection{Media exposure and AFS}

Many events can serve as perceivable cues to upcoming food scarcity, especially when mass media vividly feature such cues. For example, people across the globe have been extensively informed about lockdowns imposed as a response measure to control the spread of the COVID-19 pandemic. These lockdowns have triggered labor deficiencies and thus insufficient food production (Galanakis, 2020). Climate change - another issue causing heated debates in media - threatens the global food supply chain, but its effects are much slower than the effects of pandemics (Wheeler \& Von Braun, 2013). Brexit is yet another prominent event that can make consumers perceive future food resources as scarcer, at least in the United Kingdom (Lang \& McKee, 2018). In short, numerous events pose a risk of upcoming food scarcity over time. Notably, people who are not at risk of direct exposure to such events may overestimate related threats (in particular, their immediacy) due to, for instance, media communication with photographs depicting large crowds or diminishing food supplies (e.g., Garfin et al., 2020).

\subsubsection{Research aims and overview of the studies}

Thus far, no scale has been developed to capture the perception that future food resources are becoming scarcer. We address this critical shortcoming by developing and psychometrically validating the 8-item AFSS.

Studies 1a-1c aimed to develop a preliminary item pool for subsequent psychometric evaluation. Study 2 was conducted to shorten the scale to a desirable length and to assess its psychometric properties. Studies 3a and 3b confirmed the scale's unidimensionality and examined its convergent and discriminant validity to rule out the possibility that 
AFS is a ramification of general anxiety or other emotional states. In line with an evolutionary account, Study 3b revealed that AFS might be linked to prosociality. Although several items in the final AFSS (see Table 3.1) refer to predictability rather than mere scarcity of food resources, analyses reported in Studies 2-3a clearly show that the scale is unidimensional; hence these items capture the same construct. Finally, as the scale was developed primarily for experimental research, Study 4 showed that the AFSS is sensitive to experimentally manipulated food scarcity.

\subsection{Method}

\subsubsection{Analytic approach}

We applied nonparametric item response theory to evaluate the psychometric properties of the AFSS. The advantage of nonparametric item response theory over parametric item response theory is that nonparametric item response theory makes fewer assumptions about the distribution of latent variables and requires smaller sample sizes (Sijtsma \& Molenaar, 2002). Parametric models assume that latent variables are continuous, and this may not always be the case in the social sciences.

For nonparametric item response theory, we performed a Mokken scale analysis (MSA; Van der Ark, 2007, 2012). A Mokken scale analysis investigates whether responses to scale items correspond to an increasing level of the latent variable of interest (Van Schuur, 2003). Specifically, we tested the scale's unidimensionality, monotonicity, local independence, and invariant item ordering. If the first three criteria are met, then a tested set of items meets the requirements for a monotone homogeneity model and can be considered a 
scale, whereas meeting the invariant item ordering criterion (nonintersecting item response functions) is required for the double monotonicity model to hold (Mokken, 1971; Van der Ark, 2007, 2012). We investigated unidimensionality - which is the quality of a set of items that enables them to be located on a continuum of the hypothesized latent variable according to the probability of obtaining high total scores (Van Schuur, 2003) by evaluating the coefficients of homogeneity $H$ that range from 0 to 1 . The former number suggests no association between the items, whereas the latter number suggests a perfect association (Van der Ark, 2007). We also applied the automated item selection procedure (AISP) to further explore scale unidimensionality. This algorithm positions items into scales at increasing homogeneity thresholds (Hemker et al., 1995). If several items start forming another scale at a particular homogeneity threshold, this suggests that a scale may have more than one dimension (Dima, 2018). Monotonicity, local independence, and invariant item ordering were scrutinized separately with tools provided in the "Mokken" package (Van der Ark, 2007).

We performed all analyses in $\mathrm{R}$. Clean data sets, the data analysis code, the $\mathrm{R}$ markdown files, Supplementary Information, and additional analyses following the recently developed - and modified for this research - six-step psychometric protocol in R (Dima, 2018) have been made publicly available through the Open Science Framework (OSF; https://osf.io/kqf3g/). All the studies have been programmed in PsyToolkit (Stoet, 2010, 2017), and the source code has been made available therein.

We followed the local regulations on research involving human subjects; hence, a formal approval from an institutional review board was not needed. All participants approved an informed consent form before taking part in the studies. Data were collected between 
March 2020 and February 2021. Only participants whose Prolific submission acceptance rate was $99 \%$ and higher and who had not taken part in any of our earlier experiments were included to ensure high data quality. Data exclusions were performed as reported in Studies 2 and 3a; however, including all participants in these studies did not materially change the results.

\subsubsection{Study 1a: Item development}

We aimed to develop at least three times more items than the desired number for the final scale (Boateng et al., 2018). First, we reviewed the academic literature and think tank reports on future food scarcity. Recent reports by the Food and Agriculture Organization of the United Nations (FAO, 2016), the Centers for Disease Control and Prevention (CDC, 2019), and the Center for Strategic and International Studies (Sova et al., 2019) served as a basis for item generation. We chose these reports because they focus on threats to future food supply worldwide. Crucially, we assume that threats to the global food supply are necessary for AFS to occur. Whereas threat is not the subject of our study, AFS would not emerge without factors threatening the availability and access to food resources. This first step in scale development yielded 32 items. When generating items, it is crucial to ask nonexperts recruited from the target population of a scale for suggestions regarding items measuring the construct of interest; doing so increases the construct's coverage beyond that proposed by researchers (Boateng et al., 2018). Thus, we recruited ten native English speakers through Prolific. Their task was to read the AFS definition and propose three items that measure this construct. Participants created 30 items in total, but 14 of them were irrelevant or referred to unlikely situations in developed countries (e.g., 
"mass starvation" or "availability of grocery stores"); thus, these items were removed. The remaining 16 items were reworded and added to the initial pool of items. Both these steps generated 48 items. We did not develop negatively worded items, as such items may bias the results (Podsakoff et al., 2003). Finally, the items were analyzed with the "Hemingway Editor" software (Long, 2020). This software is used for assessing text difficulty, and it indicated that U.S. pupils in the second grade should be able to understand our item pool.

\subsubsection{Study 1b: Face validity}

We conducted a face validity study on a target sample to increase the chance that the items were deemed relevant to the construct of interest (Haynes et al., 1995). This study also aimed to reduce the pool of items to those that were the most relevant for measuring AFS.

\section{Participants and procedure}

We recruited 26 native English speakers through Prolific. Similar sample sizes have been used in other face validity studies involving nonexperts recruited online (e.g., Umanath \& Coane, 2020). Participants first accepted a consent form and read a definition of AFS. Then, they answered three questions regarding each item ("How relevant is each statement to anticipated food scarcity?"; "How easy is the statement below to understand?"; and "Is the statement below grammatically correct?"). They gauged the relevance of each item to AFS on a four-point scale ranging from $0=$ Not at all relevant to $3=$ Very relevant. Participants evaluated how easy the items were to understand. We were not interested 
in the item difficulty index, which is commonly used in psychometrics, but rather in participants' impressions of how much effort it took to comprehend the statements. Hence, participants responded on a five-point scale ranging from $0=$ Very difficult to $4=$ Very easy.

Finally, they stated whether the items were grammatically correct on a binary scale, where $0=N o$ and $1=Y e s$. We randomized the order of these items. In the end, participants were provided with a blank space in which they could suggest improvements. The study ended with participants providing their demographic information.

\section{Results and discussion}

We calculated the intraclass correlation coefficient (ICC; Shrout \& Fleiss, 1979) to assess the agreement between the raters. The intraclass correlation coefficient was obtained by computing a mean-rating, consistency, two-way mixed-effects model (ICC $[3, \mathrm{k}])$ with 26 raters across 48 items measuring the perceived relevance to the AFS. The results (ICC $=.79,95 \% \mathrm{CI}=[.71, .86])$ suggested moderate-to-good reliability (Koo \& Li, 2016). We removed the items situated below the median scores in the task, where participants evaluated the relevance of the items to the AFS. This process yielded a 22-item pool. Items that were found to be difficult or grammatically incorrect were reworded.

\subsubsection{Study 1c: Pretesting}

We conducted a pretest study to primarily examine the performance of the 22 -item pool and to further reword the worst-performing items before conducting the main studies. 


\section{Participants and procedure}

A total of 52 native English speakers were recruited through Prolific. Participants first read and completed a consent form. Then, they read the instructions ("The statements below concern food security by $2050^{1}$. Indicate how strongly you disagree (1) or agree (7) with each statement") and stated how much they agreed with each item. We randomized the order of the items. After filling out the scale, participants were provided with a blank space in which they could suggest improvements. Finally, they provided demographic information.

We asked participants about food security rather than food scarcity in instructions because studies on sentence comprehension show that positive sentences are generally easier to understand (e.g., Sherman, 1973). Moreover, people infer the effort needed to complete the task from the difficulty of its instructions, and they are willing to engage less in tasks deemed difficult (Song \& Schwarz, 2008). The word "scarcity" receives approximately 50 times fewer search hits through the Google search engine than the word "security." Thus, we deemed the latter term as more straightforward to understand due to its more frequent use. Hence, we instructed participants to think about "food security" to facilitate comprehension and the effort put into the task.

\section{Results and discussion}

We first visually inspected the data. Most of the items, with a few exceptions, produced a full range of responses. Skewness and kurtosis outcomes indicated a normal distribution

\footnotetext{
${ }^{1}$ In the supplementary study reported in the Appendix, we asked participants to think about food security in the future and found that changing instructions had no significant effect on the scale's psychometric properties and mean scores.
} 
of responses. However, item 5 ("Groceries will be more expensive") produced highly skewed responses. Indeed, the statement in this item represents a truism; i.e., due to inflation, it is rational to expect all products to become more expensive over time. The mean and standard deviation of this item also suggested a ceiling effect. Therefore, item 5 was flagged for further inspection and rewording. The correlation matrix indicated that some items correlated poorly with the others. Thus, we computed corrected item-scale correlations (each item was correlated with the full scale except with itself). The mean item-scale correlation was .40. Two items did not meet the minimum item-scale correlation of .30 (Boateng et al., 2018) and were flagged for further inspection and rewording. Due to low discrimination and potential ceiling effects, we decided to reword seven items. These items were truisms in most cases (for instance, "Some foods will be more expensive"); thus, most respondents strongly agreed with them. Based on this process, we then made the items discussed above more specific (for example, "Food prices will rise faster than wages"). No item was removed from the pool after the pretest study; hence, the 22-item AFSS was psychometrically validated in Study 2.

\subsubsection{Study 2: Psychometric validation}

Study 2 was conducted to refine and shorten the 22-item pool and to evaluate its psychometric properties. This study yielded nine items for further inspection in Study 3a.

\section{Participants and procedure}

We recruited 303 native English speakers through Prolific. Participants were mostly from the United States and the United Kingdom. Sixteen participants failed the first 
attention check (instructional manipulation check) and were thus removed from analysis; three participants failed the second attention check (a question regarding the number of siblings; two-digit answers to this question were considered a failure) and were therefore removed from further analysis. This process yielded a final sample of 284 participants (178 women, $\left.M_{\text {age }}=34, S D=13\right)$.

Participants first read and accepted a consent form. Then, they read the instructions ("The statements below concern food security by 2050. Indicate how strongly you disagree (1) or agree (7) with each statement.") and stated how much they agreed with each item. We randomized the order of the items. Apart from filling out the scale items, participants responded to two attention checks and provided demographic information.

\section{Results and discussion}

We performed a Mokken scale analysis. The 22-item scale homogeneity $(H=.46, S E$ $=.03$ ) indicated a moderate scale (Mokken, 1971; Van der Ark, 2007, 2012). We used the automated item selection procedure algorithm to see how the items performed at increasing homogeneity thresholds. The items that fell below the threshold of .55 were removed from further analyses. Although this threshold was above the recommended minimum of .30 (Hemker et al., 1995), we decided to increase it to achieve a satisfactory scale length. This procedure removed 11 items from the initial pool. Two items violated the invariant item ordering (critical values over 80; Van Schuur, 2003), so they were removed from subsequent analyses, leaving nine items for further inspection. At this stage, none of the items showed an $H$ coefficient lower than .60 nor violated monotonicity, invariant item ordering, or local independence. Thus, the 9-item solution fulfilled the criteria for the double monotonicity model, and its homogeneity level $(H=.66, S E=$ 
.03) indicated a strong and unidimensional scale (Mokken, 1971; Van der Ark, 2007, 2012).

We explored the unidimensional model fit with a confirmatory factor analysis using the "lavaan" package (Rosseel et al., 2012). The model fit was good, with the following outcomes: $\chi^{2}(27)=67.52, p<.001$, comparative fit index $(\mathrm{CFI})=.98$, Tucker-Lewis index $(\mathrm{TLI})=.97$, root mean squared error of approximation $(\mathrm{RMSEA})=.07,90 \% \mathrm{CI}$ $=[.05, .09]$, and standardized root mean square residual $(\mathrm{SRMR})=.03$.

The 9-item AFSS had excellent reliability $(\alpha=.94)$.

\subsubsection{Study 3a: Further scale refinement, convergent and dis- criminant validity}

We conducted Study 3a to refine the 9-item AFSS further and test its convergent and discriminant validity. This procedure yielded the final AFSS consisting of 8 items.

\section{Participants and procedure}

We recruited 212 native English speakers through Prolific. Similar to Study 2, participants were mostly from the United States and the United Kingdom. One participant failed an attention check, which asked about the name of the prime minister or president located in the same country as the participant. This process yielded a final sample of 211 participants (148 women, $\left.M_{\text {age }}=32, S D=12\right)$.

The procedure and instructions to the AFSS were similar to those used in Study 2. Before filling out each questionnaire, we provided separate instructions to ensure that participants noticed the changing response formats throughout the study. These instructions were given to make participants aware of some negatively worded items and to help 
them notice the reversed response format of the HEXACO-60 short personality inventory (Ashton \& Lee, 2009), where the leftmost response denoted the highest agreement, as opposed to the AFSS and other scales, in which the leftmost response corresponded to the highest disagreement.

\section{Measures}

Aside from the AFSS, participants completed the questionnaires described below. We purposely avoided using the popular USDA Food Security Survey Module in this validation study, as this tool primarily captures the lack of financial resources needed to obtain enough food; thus, it may not cover the whole spectrum of factors contributing to food security (Ashby et al., 2016).

Food Insecurity Experience Scale (FIES). To assess the discriminant validity of the AFSS, we used the Food Insecurity Experience Scale developed by the Food and Agriculture Organization of the United Nations (FAO, 2014). The advantage of this experience-based measure is that it captures not only physical food unavailability but also the subjective experience of food insecurity. Specifically, one question asks respondents to state whether they are worried about food sufficiency (Saint Ville et al., 2019). Participants responded to each of eight statements on a binary scale, where $0=N o$ and $1=$ Yes. Higher scores correspond to higher levels of food insecurity.

Radimer/Cornell Measure of Hunger and Food Insecurity. Another scale that we applied to assess the discriminant validity was the Radimer/Cornell Measure of Hunger and Food Insecurity (Radimer et al., 1990). This tool has four items that encompass worry 
about food resources in various situations. Furthermore, it allows respondents to state how often such events happen in their lives. Participants responded to each of eight statements on a scale ranging from $1=$ No, never to $5=$ Yes, always. Higher scores correspond to higher levels of food insecurity.

Mini-K. Life-history strategy was measured with the Mini-K, which is a short, 20-item version of the Arizona Life History Battery (Figueredo et al., 2006). According to theory (Hill \& Kaplan, 1999), humans adopt either a fast or slow life-history strategy as a response to the low or high availability of resources in their environment to solve trade-offs between somatic effort (saving energy for growth and survival) and reproductive effort (investing energy in reproduction). Life-history strategies can determine variations in human behaviors such as risk-taking, temporal orientation, or proneness to approach temptations. Consequently, studies have found that people who grow up in areas of resource deprivation (environments facilitating fast life-history strategies) are more impulsive and risk-taking, and they approach temptations more quickly than other individuals (Griskevicius et al., 2013). We hypothesized AFS to be positively related to fast life-history strategies because a shortage of resources favors fast over slow life-history strategy (Figueredo et al., 2006; Griskevicius et al., 2013). Participants indicated their responses on the 20-item battery on a seven-point scale ranging from $-3=$ Disagree strongly to $3=$ Agree strongly. Higher scores reflect a slower life-history strategy.

HEXACO-60 Personality Inventory. We measured one personality dimension from the HEXACO-60 short personality inventory (Ashton \& Lee, 2009). Considering that environmental threats have been linked to higher anxiety levels (Twenge, 2000), we hy- 
pothesized that more emotional people perceive future food resources as being scarcer compared to the perception of less emotional people. Participants responded to the 10item measure of emotionality on a five-point scale ranging from $1=$ Strongly disagree to $5=$ Strongly agree. Higher scores correspond to higher levels of emotionality.

Generalized Sense of Power Scale. The 8-item Generalized Sense of Power Scale (Anderson \& Galinsky, 2006) was used to test the prediction that people who believe that they can wield power over others perceive future food resources as more secure as such people may see more ways of obtaining food and other resources than those who have a lower sense of power. Participants responded on a seven-point scale ranging from $1=$ Disagree strongly to $7=$ Agree strongly. Higher scores represent a higher sense of power.

Locus of Control Scale. The 29-item Locus of Control Scale (Rotter, 1966) measures the external versus internal locus of control among participants. Locus of control determines whether people perceive their actions as having an impact on the outcomes from many facets of their daily life. We hypothesized that people with a more external locus of control would score higher on the AFSS, as these individuals believe they do not have control over events such as agricultural turmoil. Each of the 29 items has two alternatives, and participants select the one that they agree with the most. Higher scores correspond to a more pronounced external locus of control. 


\section{Results and discussion}

One item lowered the alpha value of the 9-item scale, and its coefficient of variation was the highest; thus, this item was flagged for further inspection. This item also had a much lower item discrimination coefficient than the rest of the items (these indicators combined suggested that this item could have failed to differentiate well between participants at different levels of the latent variable).

We performed a Mokken scale analysis, as described in Study 2. The 9-item AFSS homogeneity coefficient $(H=.74, S E=.03)$ indicated a strong scale (Mokken, 1971; Van der Ark, 2007, 2012). The automated item selection procedure algorithm suggested that the scale was unidimensional; we did not find any group of items "departing" at a certain homogeneity level. No item violated the monotonicity or local independence. One item exceeded the suggested critical value of 80 for invariant item ordering (Van Schuur, 2003), but this violation was not significant. Therefore, the 9-item scale was found to meet the criteria for the double monotonicity model (Mokken, 1971). The item flagged for potential removal in the earlier step had the lowest homogeneity coefficient and violated monotonicity at lower rest score group sizes (Van der Ark, 2007). Thus, this item was removed from further analysis, yielding the final 8-item AFSS.

We explored the unidimensional model fit with a confirmatory factor analysis of our 8-item instrument. The model fit was acceptable, with outcomes as follows: $\chi^{2}(20)=$ 55.60, $p<.001$, comparative fit index $(\mathrm{CFI})=.98$, Tucker-Lewis index $(\mathrm{TLI})=.97$, root mean squared error of approximation $(\mathrm{RMSEA})=.09,90 \% \mathrm{CI}=[.06, .12]$, and standardized root mean square residual $(\mathrm{SRMR})=.02$.

Similar to Study 2, the 8-item AFSS had excellent reliability $(\alpha=.96)$. The mean 
corrected inter-item correlation was .76. The 8-item mean $(M=4.60$, range 4.34 to 4.82$)$ and standard deviation $(S D=1.47)$ indicated a lack of ceiling or floor effects (see Table 5.1 for the final items included in the scale). Scale skewness (-0.53) and kurtosis (-0.29), as well as a visual inspection of the histograms, indicated a normal distribution of the responses.

As results in Table 5.2 indicate, the 8-item AFSS showed low but statistically significant correlations with the Food Insecurity Experience Scale and the Radimer/Cornell Measure of Hunger and Food Insecurity. These results provide evidence that anticipated food scarcity is a different construct than the food insecurity construct, as studied in the existing literature, which refers to retrospective/actual experiences of food unavailability. Interestingly, the AFSS did not correlate with the Mini-K, suggesting that life-history strategies and anticipated food scarcity are unrelated constructs. As predicted, the AFSS correlated positively with the Locus of Control Scale and with the emotionality dimension of the HEXACO-60 short personality inventory. These outcomes suggest that people with an external locus of control and those who are more emotional perceive future food resources as being scarcer. Finally, we found a negative correlation between the AFSS and the Generalized Sense of Power Scale. This result is in line with our prediction that people who believe that they can convince others to do what they want perceive future food resources as more secure, perhaps because they are more capable of finding ways to access food and other resources.

Studies 2 and 3a jointly confirmed the good psychometric properties of the 8-item AFSS. Although we found significant correlations according to our predictions, the AFSS was only weakly correlated with the scales mentioned above. This means that anticipated 
food scarcity is a novel construct. To further support this notion, we performed additional analyses where we controlled for the two existing food insecurity measures described above. These analyzes revealed that the AFSS was positively related to emotionality $(p=.010)$. However, both the Food Insecurity Experience Scale and the Radimer/Cornell Measure of Hunger and Food Insecurity were not related to this personality trait (both $p s>.549$ ). Similarly, only the AFSS $(p=.003)$ was related to locus of control, but the remaining two scales were not (both $p s>.401$ ). Further, both the AFSS and the Radimer/Cornell Measure of Hunger and Food Insecurity were marginally related to the Generalized Sense of Power Scale (both $p s<.082)$, as opposed to the Food Insecurity Experience Scale $(p$ $=.771$ ). Interestingly, the existing tools were related or marginally related to life-history strategy (both $p s<.079)$, but the AFSS was not $(p=.712)$.

The low correlations between the AFSS and the scales described in Table 5.2 are unsurprising given that AFS is a perception. In contrast, the scales we compared it against reflect personality traits and past experiences. It is plausible that current perceptions of future food resources as scarce are affected by past experiences of food unavailability; hence, the FIES and Radimer/Cornell Measure of Hunger and Food Insecurity are weakly but positively associated with scores on the AFSS. Considering that emotionality is positively related to neuroticism, and multiple items capturing this trait focus on anxiety and fearfulness (Ashton \& Lee, 2009), it is justified to expect that AFS, to some extent, captures affective reactions (e.g., anxiety triggered by cues related to food scarcity). Indeed, Studies 3a and 4 partially support this notion. Study 3a provided evidence that people who believe that they have little influence over what happens in the world around them (i.e., having an external locus of control and a low sense of power) score higher on the 
AFSS. These results align with our definition of this construct and the items capturing it. People who believe they can wield power over others and those who have an internal locus of control likely also think that they can obtain access to food resources despite these becoming scarcer. In sum, Study 3a showed that the AFSS is a construct distinct from the existing food insecurity measures.

Table 5.1: The final set of items included in the AFSS

AFS 1 Food shortages will occur more frequently

AFS 2 Food resources will become increasingly scarce

AFS 3 There will be less food available

AFS $4 \quad$ Food availability will be more uncertain

AFS $5 \quad$ More people will be hungry

AFS 6 The demand for food will be higher than the supply

AFS $7 \quad$ There may not be enough food for everyone

AFS $8 \quad$ People will compete for food resources

\subsubsection{Study 3b: Additional tests of convergent and discriminant validity}

Study 3a shows that AFS is a distinct construct to food insecurity, the latter of which is commonly treated in the literature as the physical experience of food insufficiency. However, Study 3a did not investigate if AFS merely reflects general anxiety or other emotional states. Thus, Study $3 \mathrm{~b}$ tested this possibility. Additionally, we investigated whether AFSS could predict social attitudes in terms of support for Universal Basic 
Income and attitudes toward welfare recipients.

\section{Participants and procedure}

We recruited 140 participants from the United States through Prolific (68 women, $M_{a g e}=$ $35, S D=13)$. The data were collected in connection to another research project, which examined the influence of seasonal cues on food preferences.

After accepting an informed consent form, participants provided their Prolific IDs and watched a 50-second video showing either a winter or summer forest walk from the firstperson perspective. These videos were devoid of emotionally laden stimuli. Participants then filled out the scales described below. The study concluded by participants providing demographic data and answering an attention check regarding the video content.

\section{Measures}

We measured AFS, positive and negative affect, as well as anxiety. Moreover, we investigated if the AFSS was linked to gradients of prosocial behavior.

Positive and Negative Affect Schedule (PANAS). Positive and negative affect was captured on a 20-item (10 for positive and 10 for negative affect) Positive and Negative Affect Schedule (Watson et al., 1988), with responses ranging from 1 = very slightly or not at all to $5=$ extremely. Higher scores correspond to a higher positive/negative affect.

Short form of the State-Trait Anxiety Inventory (STAI). We measured anxiety using a six-item short-form of the Spielberger State - Trait Anxiety Inventory (Marteau \& Bekker, 1992), with responses ranging from $1=$ Not at all to $4=$ Very much. Higher scores correspond to a higher anxiety. 
Prosociality: support for Universal Basic Income and attitudes toward welfare recipients. Several theories propose that food scarcity and social behavior may be related. The hunger hypothesis (Nettle, 2017) postulates that people of lower socioeconomic status are more impulsive, irritable, aggressive, and experience more anxiety than people of higher socioeconomic status partly due to food insufficiency and food insecurity prevalent in their environments. According to the conservation of resources theory (Hobfoll, 1989), people facing threats (e.g., food scarcity) strive to keep resources to themselves rather than sharing these with others. Hence, as anticipating food scarcity may prompt people to maximize their own (vs. societal) welfare, we predict that AFS will be positively related to support for Universal Basic Income and negatively related to attitudes toward welfare recipients.

Participants read a definition of the Universal Basic Income and stated their support for this idea ("How bad or good an idea would it be to introduce a Universal Basic Income in your country?") on a sliding scale ranging from $0=$ Bad idea to $100=$ Good idea (Nettle et al., 2020).

They voiced their attitudes toward welfare recipients by agreeing with the two statements ("Too many get social welfare without needing it"; "Many of the unemployed don't really want to find work.") on a scale ranging from $1=$ disagree to $5=$ agree (Petersen et al., 2014).

\section{Results and discussion}

Findings reported in Table 5.2 suggest that AFS is weakly related to negative affect, anxiety, and unrelated to positive affect. Thus, the construct cannot be deemed as a direct ramification of emotional states. Although AFS was unrelated to attitudes toward 
welfare recipients, we provide preliminary evidence that it can be predictive of other social behavior gradients, such as support for Universal Basic Income. Therefore, it is plausible that AFS can deepen the understanding of complex phenomena linked to social interaction and resource distribution.

Because participants watched a short video clip before filling out the scales, we tested whether these videos affected their responses. We performed a multivariate analysis of variance (MANOVA) with all the dependent variables and the two predictors: experimental condition (watching summer or winter cues) and participant sex. Neither participant sex $(p>.462)$, nor experimental condition $(p>.376)$ was related to any of our dependent measures. 
Table 5.2: Correlations between AFSS scores and scores on the other scales

\begin{tabular}{llll}
\hline Scale & Statistic & Coefficient & $p$-value \\
\hline FIES & Kendall's $\tau$ & .12 & $\mathbf{. 0 1 7}$ \\
Radimer/Cornell's & Kendall's $\tau$ & .14 & $\mathbf{. 0 0 6}$ \\
Mini-K & Pearson's $r$ & -0.01 & .867 \\
HEXACO-60 (emotionality) & Pearson's $r$ & .19 & $\mathbf{. 0 0 5}$ \\
Generalized Sense of Power Scale & Pearson's $r$ & -0.16 & $\mathbf{. 0 1 8}$ \\
Locus of Control Scale & Pearson's $r$ & .21 & $\mathbf{. 0 0 2}$ \\
PANAS (positive affect) & Pearson's $r$ & .04 & .634 \\
PANAS (negative affect) & Pearson's $r$ & .21 & $\mathbf{. 0 1 2}$ \\
STAI & Pearson's $r$ & .23 & $\mathbf{. 0 0 7}$ \\
Support for Universal Basic Income & Pearson's $r$ & .19 & $\mathbf{. 0 2 7}$ \\
Attitude toward welfare recipients & Pearson's $r$ & .03 & .723 \\
\hline
\end{tabular}

Note. We report the parametric correlation coefficient (Pearson's $r$ ) whenever the responses approach normal distributions and data are continuous. The nonparametric correlation coefficient (Kendall's $\tau$ ) is reported for highly skewed and ordinal data.

\subsubsection{Study 4: Sensitivity to food scarcity cues}

Anticipated food scarcity is a perception and thus should, to a certain extent, be under the short-term influence of external factors, such as exposure to news reports. According to dual coding theory (Clark \& Paivio, 1991; see also Otterbring et al., 2013), humans possess separate systems for processing verbal and visual stimuli; thus, presenting the 
same information in the form of a video versus text may yield different outcomes. Indeed, using videos or videos with text engages students more than presenting them only textual information (Yadav et al., 2011). Thus, Study 4 investigated if exposing participants to cues to food scarcity indeed increases their AFS and whether this effect depends on the media type.

\section{Participants and procedure}

We decided in advance to recruit at least 40 participants per cell. A stochastic power simulation (Bolker, 2007) revealed that this sample size would provide a power of .80 to detect a significant difference between two groups, assuming a medium-to-large effect size (Cohen's $d=0.65)$. We recruited 175 native English speakers (111 women, $M_{\text {age }}=34$, $S D=12$ ) through Prolific. Again, participants were mostly from the United States and the United Kingdom. No one failed the attention check ("Who is the prime minister or president of your country?").

Participants first read and accepted a consent form. Then, following a 2 (information type: control vs. experimental — food scarcity) $\times 2$ (medium type: text vs. video) design, participants were randomly assigned to one of four groups. Depending on their assigned condition, participants were either told to read a 500-word article or watch a 66 -second video and memorize critical facts from the content. Participants in the two experimental groups were exposed to food scarcity content, and those in the two control groups were exposed to stimuli unrelated to food. More specifically, the participants in the first control group read an article entitled "Why Are Swiss Watches So Expensive?," whereas those in the second control group watched a 67-second-long subtitled video entitled, "Airlines don't have to leave the middle seats on flights empty anymore." The participants assigned 
to the two experimental groups either read an article entitled "Food Insecurity Remains Long Term Problem," or watched a 66-second-long subtitled video entitled "Will COVID19 lead to a global food crisis?" All of the articles and videos are available through this project's OSF webpage. After reading the article or watching the video, participants completed the AFSS (we used the same instructions as these reported in Studies 1c-3a) and the short, 10-item version of the Positive and Negative Affect Schedule (Thompson, 2007).

\section{Measures}

Positive and negative affect elicited by the stimuli, as measured through the 10-item short version of the Positive and Negative Affect Schedule (I-PANAS-SF; Thompson, 2007), were included to control for potential affective differences between participants across the conditions. The I-PANAS-SF contains two subscales that measure positive and negative affect, with each subscale having five items. The order of items was randomized, and participants responded on a five-point scale ranging from $1=$ Very slightly or Not at all to $5=$ Extremely. High scores on these subscales are indicators of high levels of positive and negative affect, respectively.

\section{Results and discussion}

We averaged the scores from the AFSS $(\alpha=.95)$, positive $(\alpha=.76)$, and negative affect scales $(\alpha=.86)$. Next, we performed a two-way analysis of variance (ANOVA) on the AFS index with information type (control vs. experimental - food scarcity) and medium type (text vs. video) as the between-subjects factors. Participants exposed to information about food scarcity $(M=5.54, S D=1.11)$ reported higher anticipated food scarcity than 
their peers exposed to the control information $(M=4.73, S D=1.44), F(1,172)=15.87$, $p<.001, \eta_{p}^{2}=.08$. We found no main effect of medium type, $F(1,172)=1.91, p=.169$, $\eta_{p}^{2}=.01$, nor an interaction between information type and medium type, $F<1$.

To test the robustness of our findings and ensure that food scarcity exposure drove the increase in AFS scores, we conducted an analysis of covariance (ANCOVA) with the same between-subjects factors and with positive and negative affect as covariates. One covariate - negative affect-was significantly related to AFS scores, $F(1,172)=19.53$, $p<.001, \eta_{p}^{2}=.10$. However, including these covariates did not change the nature or significance of the earlier findings, with the main effect of information type still being significant, $F(1,169)=6.89, p=.009, \eta_{p}^{2}=.04$, and the effect of medium type and the interaction between medium type and information type remaining nonsignificant $(p s>$ .21). These results suggest that experimentally manipulated food scarcity, in terms of both visual and textual food scarcity content, increases AFS scores (see Figure 5.1). 
Figure 5.1: Differences between the groups in AFS

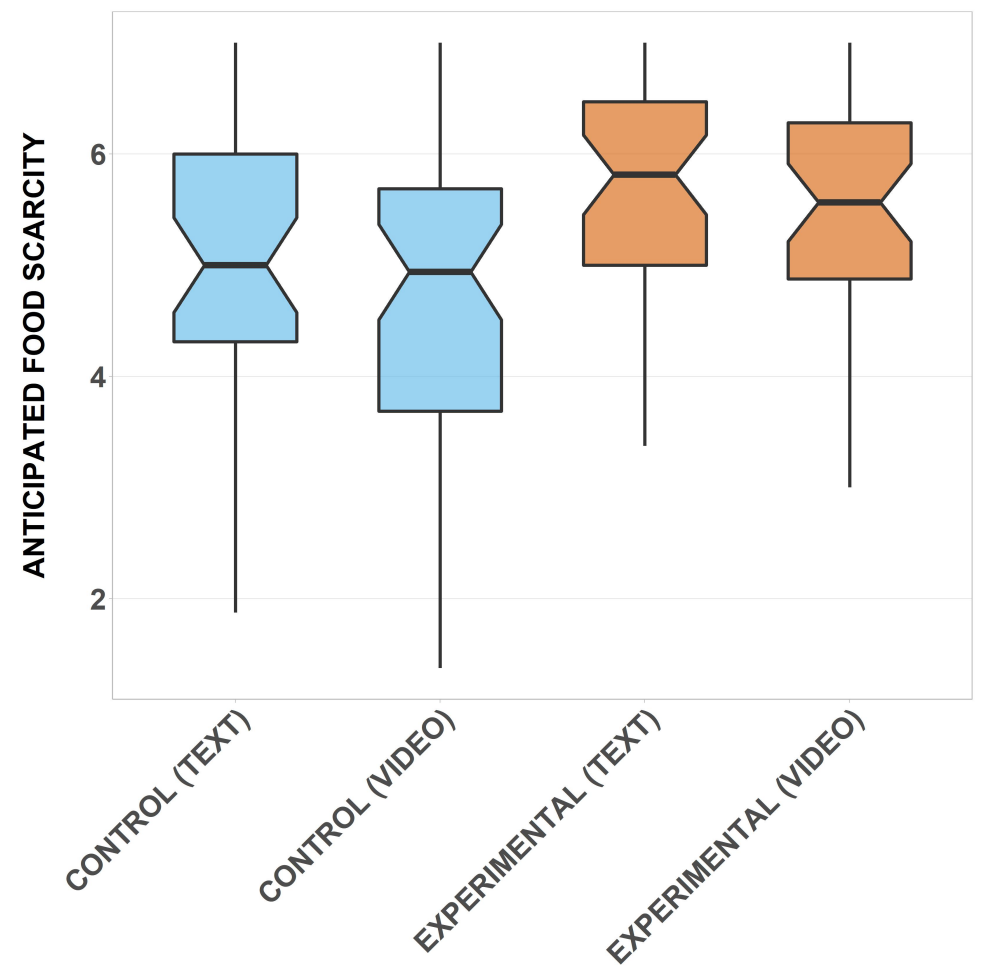

Note. Middle horizontal lines indicate medians. Notches around these lines denote 95\% confidence intervals. Horizontal lines around medians correspond to interquartile ranges. Whiskers extend 1.5 times the interquartile ranges.

\subsection{General discussion}

The current research examined the psychometric properties of the newly developed 8-item Anticipated Food Scarcity Scale (AFSS), which can be used to measure people's perceptions of food resources becoming less available. Anticipated food scarcity (AFS), as it is studied herein, is a new psychological construct that can contribute to the understanding of factors underlying food hoarding behaviors, impulsivity, or increased preferences 
toward energy-dense foods when consumers are exposed to food scarcity cues (cf. Folwarczny et al., 2021; Nettle et al., 2017). In contrast to the existing measures - such as HFIAS (Coates et al., 2007) — which focus on past experiences of food insecurity threatening relatively few people living in developed countries, the AFSS captures future-related perceptions among the general population.

The 8-item AFSS forms a strong, unidimensional scale that meets the criteria for the double monotonicity model (Van der Ark, 2007, 2012). The low correlations between the AFSS and Food Insecurity Experience Scale (FAO, 2014), as well as the Radimer/Cornell Measure of Hunger and Food Insecurity (Radimer et al., 1990), indicate that AFS and food insecurity, as treated in the current literature, are qualitatively distinct but presumably interrelated constructs. We also find that people with an external locus of control (Rotter, 1966), a lower sense of power (Anderson \& Galinsky, 2006), and higher levels of emotionality (Ashton \& Lee, 2009) perceive future food resources as being scarcer. We do not find a meaningful relationship between AFS scores and life-history strategy (Figueredo et al., 2006) or positive affect (Watson et al., 1988). Although the AFSS shows positive correlations with negative affect and anxiety (Marteau \& Bekker, 1992; Watson et al., 1988), these correlations are weak. More importantly, Study 4 shows that people exposed to food scarcity content score higher on the AFSS, with these results remaining significant even when controlling for negative affect (Thompson, 2007). Therefore, it is unlikely that the AFSS merely captures general anxiety or negative affect associated with fear of losing access to food resources. Building on the literature postulating that people facing difficulties keep resources to themselves rather than sharing them with others (Hobfoll, 1989), we predicted and found that AFS was positively related to support for Universal 
Basic Income (Nettle et al., 2020). However, the scale was not predictive of attitudes toward welfare recipients (Petersen et al., 2014). Taken together, these findings show that AFS may be linked to prosocial behaviors. The AFSS is sensitive to food scarcity cues. In Study 4, we exposed participants to either an article describing globally rising food scarcity, a video about COVID-19-related food scarcity, or control stimuli. Participants exposed to textual and visual food scarcity content reported higher AFS levels. This outcome suggests that the AFSS can be used in experimental work where researchers may be interested in manipulating AFS.

The results reported above support the evolutionary mismatch hypothesis (Li et al., 2018). A mismatch occurs when evolutionarily-old psychological mechanisms, which our ancestors developed across human history, interact with novel stimuli from our modern world, thereby producing maladaptive outcomes (Gidlöf et al., 2021; Otterbring, 2021). Consequently, our evolved mechanisms are often outdated and no longer help us maximize our adaptiveness in the modern world. Indeed, the environments that fashioned the adaptations that protected our ancestors against periods of food unavailability are vastly different from current environments. Nonetheless, psychological mechanisms did not evolve to distinguish between current and impending threats and those that might occur decades later because such distal threats are largely caused by technological developments that have only taken place recently. Thus, the evolutionarily outdated mechanisms may still respond to the same types of threat stimuli in similar ways that are now maladaptive (Li et al., 2018). Indeed, research suggests that watching climate change-induced food scarcity videos immediately increases preferences toward energy-dense foods (Folwarczny et al., 2021). The final study in this article revealed a similar increase in AFS scores after 
exposure to food scarcity content. Together, these findings provide convergent support for the evolutionary mismatch framework.

\subsubsection{Limitations and future research}

Although our participants were primarily from developed countries, half of them reported having a college degree, and only $18 \%$ reported being unemployed, it remains unknown whether any of them were the recipients of food stamps or related programs. One study found that all parents receiving food parcels worried about food insufficiency (Harvey, 2016). Thus, it is plausible that they should also react to food scarcity differently than other individuals. Considering that our participants were relatively highly educated, spoke English as their first language, and lived in developed countries, the mean AFSS scores reported herein may not indicate the magnitude of the latent variable among lesseducated participants and those living in less developed countries, where food insecurity is a more significant threat for societal well-being. Further, it is unknown how our construct would operate when translated to languages other than English. Hence, for reasons of generalizability, future studies should include more diverse samples in terms of educational backgrounds, cultural characteristics, and socioeconomic status as well as languages spoken, sociopolitical attitudes, and participants recruited from both developed and less developed countries (Henrich et al., 2010; Otterbring et al., 2020).

The degree to which people may experience food scarcity differs dramatically between developed and less developed countries. Due to potential habituation, the latter may not respond to the same manipulations used in Study 4. Thus, we cannot claim that our scale is sensitive to food scarcity cues found in countries where people are frequently 
threatened by actual hunger. Therefore, future research should investigate samples in which the experience of actual food scarcity is prevalent. Furthermore, we used overt cues to food scarcity in Study 4 (i.e., even the titles of the articles and videos used mentioned food unavailability). It is vital to determine whether the scale is sensitive to more subtle cues to food scarcity, such as reports showing rising global temperatures.

Finally, the AFSS has not been validated with behavioral measures. Study 4 showed that the scale is sensitive to food scarcity cues. Although these results are promising, the present findings do not imply that the scale has been validated comprehensively. More studies should establish the predictive validity of the scale by, for instance, testing whether high AFS scores correspond to choosing energy-dense over low-calorie foods in laboratory and field experiments. Likewise, it is vital to investigate whether AFS scores can predict the rate of obesity or overweight in populations of interest.

\subsubsection{Conclusions}

Existing food insecurity measures have been developed primarily to gauge the prevalence of food insufficiency among low-income populations. However, societies worldwide are consistently informed about publicized events in mass media, such as Brexit, climate change, or pandemics, which pose a threat to the food supply chain. As a result, social groups other than low-income populations may also perceive that food resources are becoming scarcer. Although numerous scientific tools exist to measure actual food insecurity (i.e., hunger), none of these tools capture anticipated food scarcity. To address this shortcoming, we developed and psychometrically validated the 8-item AFSS, which was found to be unidimensional and to have good psychometric qualities. Because the scale 
is sensitive to food scarcity cues, it can be used in experimental research. Its relatively narrow set of items makes it an exceptionally potent tool for use in online surveys, field settings, and lab studies. In sum, the AFSS presents an alternative approach to food scarcity measurement in affluent societies. The scale can help foster novel research on food waste, sustainability, and a multitude of prosocial behaviors.

\section{Acknowledgments}

We would like to thank Alexandra Dima for her support and suggestions on the analytical approach presented in this research. 


\subsection{Appendix}

Table S1: Overview of studies included in the AFSS development process

\begin{tabular}{|c|c|c|c|}
\hline Study & Aim & $N$ & Measures \\
\hline $1 \mathrm{a}$ & Develop the initial items pool & 10 & Proposed items \\
\hline \multirow[t]{2}{*}{$1 b$} & Investigate the face validity of the & 26 & Face validity, comprehension, and \\
\hline & items and reduce their number & & grammatical correctness \\
\hline $1 \mathrm{c}$ & Pretest the first scale, reword items & 52 & AFSS \\
\hline \multirow[t]{2}{*}{2} & Shorten the scale, evaluate its psy- & 303 & AFSS \\
\hline & chometric properties & & \\
\hline \multirow[t]{3}{*}{ Supp. } & Investigate the scale's psychometric & 415 & AFSS \\
\hline & properties under different instruc- & & \\
\hline & tions, test the criterion validity & & \\
\hline \multirow[t]{4}{*}{$3 \mathrm{a}$} & Refine the scale, test the convergent & 212 & AFSS, FIES, Radimer/Cornell, \\
\hline & and discriminant validity & & Mini-K, HEXACO-60 (emotional- \\
\hline & & & ity), Generalized Sense of Power, \\
\hline & & & Locus of Control \\
\hline \multirow[t]{3}{*}{$3 b$} & Further test the convergent and dis- & 140 & AFSS, PANAS, STAI, support for \\
\hline & criminant validity & & Universal Basic Income, attitude to- \\
\hline & & & ward welfare recipients \\
\hline 4 & Test whether the scale is sensitive & 175 & AFSS, I-PANAS-SF \\
\hline
\end{tabular}

Note. Participants in all the studies were recruited through Prolific. They were native English speakers, mostly from the United States and the United Kingdom. Participants could not take part in more than one study. 


\section{Supplementary Study}

In the earlier studies, the instructions for participants mentioned a specific and distant time frame, namely - the year 2050. Thus, we wanted to check whether more generic instructions yield a different pattern of responses. Further, we aimed to confirm the psychometric properties with a larger sample.

\section{Participants and procedure}

The data were collected in connection to another preregistered research project. We recruited 415 participants from the United States (204 women, $M_{a g e}=37, S D=13$ ) through Prolific.

Participants first read and accepted a consent form. Then, they provided their demographic data and filled out the 8-item AFS Scale ("The statements below concern food security in the future. Indicate how strongly you disagree (1) or agree (7) with each statement").

\section{Results}

We performed a Mokken scale analysis, as described in Studies 2-3a. The 8-item AFSS homogeneity coefficient $(H=.82, S E=.02)$ indicated a strong scale (Mokken, 1971; Van der Ark, 2007, 2012). The automated item selection procedure algorithm suggested that the scale was unidimensional; we did not find any group of items "departing" at a certain homogeneity level. No item significantly violated the monotonicity, local independence, or invariant item ordering (Van Schuur, 2003). Therefore, the 8-item scale was found to meet the criteria for the double monotonicity model (Mokken, 1971). 
We explored the unidimensional model fit with a confirmatory factor analysis. The model fit was acceptable, with outcomes as follows: $\chi^{2}(20)=105.19, p<.001$, comparative fit index $(\mathrm{CFI})=.98$, Tucker-Lewis index $(\mathrm{TLI})=.97$, root mean squared error of approximation $(\mathrm{RMSEA})=.10,90 \% \mathrm{CI}=[.08, .12]$, and standardized root mean square residual $(\mathrm{SRMR})=.02$.

Similar to Studies $2-3 \mathrm{a}$, the 8 -item AFSS had excellent reliability $(\alpha=.97)$. The mean corrected inter-item correlation was .76. The 8-item mean $(M=4.38$, range 4.18 to 4.64) and standard deviation $(S D=1.49)$ indicated a lack of ceiling or floor effects. Scale skewness (-0.32) and kurtosis (-0.66), as well as a visual inspection of the histograms, indicated a normal distribution of the responses.

\section{Discussion}

This study further confirmed that the AFSS has good psychometric properties, thus mirroring the findings from Studies 2 and 3a. 


\subsection{References}

Anderson, C., \& Galinsky, A. D. (2006). Power, optimism, and risk-taking. European Journal of Social Psychology, 36(4), 511-536. https://doi.org/https://doi.org/10. 1002/ejsp.324

Ashby, S., Kleve, S., McKechnie, R., \& Palermo, C. (2016). Measurement of the dimensions of food insecurity in developed countries: A systematic literature review. Public Health Nutrition, 19(16), 2887-2896. https://doi.org/https://doi.org/10.1017/ S1368980016001166

Ashton, M. C., \& Lee, K. (2009). The HEXACO-60: A short measure of the major dimensions of personality. Journal of Personality Assessment, 91 (4), 340-345. https: //doi.org/10.1080/00223890902935878

Benker, B. (2021). Stockpiling as resilience: Defending and contextualising extra food procurement during lockdown. Appetite, 156, 104981. https://doi.org/10.1016/j. appet.2020.104981

Boateng, G. O., Neilands, T. B., Frongillo, E. A., Melgar-Quiñonez, H. R., \& Young, S. L. (2018). Best practices for developing and validating scales for health, social, and behavioral research: A primer. Frontiers in Public Health, 6, 149. https://doi.org/ 10.3389/fpubh.2018.00149

Bolker, B. (2007). Stochastic simulation and power analysis. https://ms.mcmaster.ca/ wbolker/emdbook/chap5A.pdf

Casalicchio, E. (2020). Panic-buying in UK will return ahead of Brexit transition end, experts say. https://www - politico.eu/article/uk-panic-buying-set-to-returnahead-of-brexit-transition-end/ 
CDC. (2019). Climate change and public health. https://www.cdc.gov/climateandhealth/ effects/food_security.htm

Clark, J. M., \& Paivio, A. (1991). Dual coding theory and education. Educational Psychology Review, 3(3), 149-210. https://doi.org/10.1007/s12528-011-9042-y

Coates, J., Swindale, A., \& Bilinsky, P. (2007). Household Food Insecurity Access Scale (HFIAS) for measurement of food access: Indicator guide. https://www.fantaproject. org/sites/default/files/resources/HFIAS_ENG_v3_Aug07.pdf

Dima, A. L. (2018). Scale validation in applied health research: Tutorial for a 6-step Rbased psychometrics protocol. Health Psychology and Behavioral Medicine, 6(1), 136-161. https://doi.org/10.1080/21642850.2018.1472602

FAO. (1996). World Food Summit Plan of Action. http://www.fao.org/3/w3613e/ w3613e00.htm

FAO. (2014). Food Insecurity Experience Scale. http://www.fao.org/in-action/voices-ofthe-hungry/fies/en/

FAO. (2016). Climate change and food security: Risks and responses. http://www.fao. org/3/a-i5188e.pdf

Figueredo, A. J., Vásquez, G., Brumbach, B. H., Schneider, S. M., Sefcek, J. A., Tal, I. R., Hill, D., Wenner, C. J., \& Jacobs, W. J. (2006). Consilience and life history theory: From genes to brain to reproductive strategy. Developmental Review, 26(2), 243275. https://doi.org/10.1016/j.dr.2006.02.002

Folwarczny, M., Christensen, J. D., Li, N. P., Sigurdsson, V., \& Otterbring, T. (2021). Crisis communication, anticipated food scarcity, and food preferences: Preregistered 
evidence of the insurance hypothesis. Food Quality and Preference, 91, 104213. https://doi.org/10.1016/j.foodqual.2021.104213

Galanakis, C. M. (2020). The food systems in the era of the coronavirus (COVID-19) pandemic crisis. Foods, 9(4), 523. https://doi.org/10.3390/foods9040523

Garfin, D. R., Silver, R. C., \& Holman, E. A. (2020). The novel coronavirus (COVID2019) outbreak: Amplification of public health consequences by media exposure. Health Psychology. https://doi.org/10.1037/hea0000875

Gidlöf, K., Ares, G., Aschemann-Witzel, J., \& Otterbring, T. (2021). Give us today our daily bread: The effect of hunger on consumers' visual attention towards bread and the role of time orientation. Food Quality and Preference, 88, 104079. https: //doi.org/10.1016/j.foodqual.2020.104079

Griskevicius, V., Ackerman, J. M., Cantú, S. M., Delton, A. W., Robertson, T. E., Simpson, J. A., Thompson, M. E., \& Tybur, J. M. (2013). When the economy falters, do people spend or save? Responses to resource scarcity depend on childhood environments. Psychological Science, 24(2), 197-205. https:// doi.org/10.1177/ 0956797612451471

Griskevicius, V., Cantú, S. M., \& Van Vugt, M. (2012). The evolutionary bases for sustainable behavior: Implications for marketing, policy, and social entrepreneurship. Journal of Public Policy \& Marketing, 31(1), 115-128. https://doi.org/10.1509/ jppm.11.040

Hanjra, M. A., \& Qureshi, M. E. (2010). Global water crisis and future food security in an era of climate change. Food Policy, 35(5), 365-377. https://doi.org/10.1016/j. foodpol.2010.05.006 
Harvey, K. (2016). "When I go to bed hungry and sleep, I'm not hungry": Children and parents' experiences of food insecurity. Appetite, 99, 235-244. https://doi.org/10. 1016/j.appet.2016.01.004

Haynes, S. N., Richard, D., \& Kubany, E. S. (1995). Content validity in psychological assessment: A functional approach to concepts and methods. Psychological Assessment, 7(3), 238-247. https://doi.org/10.1037/1040-3590.7.3.238

Hemker, B. T., Sijtsma, K., \& Molenaar, I. W. (1995). Selection of unidimensional scales from a multidimensional item bank in the polytomous Mokken IRT model. $A p$ plied Psychological Measurement, 19(4), 337-352. https:// doi.org/10.1177/ 014662169501900404

Henrich, J., Heine, S. J., \& Norenzayan, A. (2010). Most people are not WEIRD. Nature, 466, 29. https://doi.org/10.1038/466029a

Hill, K., \& Kaplan, H. (1999). Life history traits in humans: Theory and empirical studies. Annual Review of Anthropology, 28(1), 397-430. https://doi.org/10.1146/annurev. anthro.28.1.397

Hobfoll, S. E. (1989). Conservation of resources: A new attempt at conceptualizing stress. American Psychologist, 44(3), 513-524. https://doi.org/10.1037/0003-066X.44.3. 513

Koo, T. K., \& Li, M. Y. (2016). A guideline of selecting and reporting intraclass correlation coefficients for reliability research. Journal of Chiropractic Medicine, 15(2), 155163. https://doi.org/10.1016/j.jcm.2016.02.012 
Lang, T., \& McKee, M. (2018). Brexit poses serious threats to the availability and affordability of food in the United Kingdom. Journal of Public Health, 40(4), e608-e610. https://doi.org/10.1093/pubmed/fdy073

Li, N. P., van Vugt, M., \& Colarelli, S. M. (2018). The evolutionary mismatch hypothesis: Implications for psychological science. Current Directions in Psychological Science, 27(1), 38-44. https://doi.org/10.1177/0963721417731378

Long, L. (2020). Hemingway editor. http://www.hemingwayapp.com/

Lufkin, B. (2020). Coronavirus: The psychology of panic buying. https:// www.bbc. com / worklife / article / 20200304- coronavirus- covid-19- update- why- people- arestockpiling

Marteau, T. M., \& Bekker, H. (1992). The development of a six-item short-form of the state scale of the Spielberger State - Trait Anxiety Inventory (STAI). British Journal of Clinical Psychology, 31(3), 301-306. https://doi.org/10.1111/j.20448260.1992.tb00997.x

Merriam-Webster. (2021). Insecurity. Merriam-Webster.com dictionary. Retrieved February 23, 2021, from https://www.merriam-webster.com/dictionary/insecure

Mokken, R. J. (1971). A theory and procedure of scale analysis: With applications in political research. De Gruyter Mouton. https://doi.org/10.1515/9783110813203

Nettle, D. (2017). Does hunger contribute to socioeconomic gradients in behavior? Frontiers in Psychology, 8, 358. https://doi.org/10.3389/fpsyg.2017.00358

Nettle, D., Andrews, C., \& Bateson, M. (2017). Food insecurity as a driver of obesity in humans: The insurance hypothesis. Behavioral and Brain Sciences, 40. https: //doi.org/10.1017/S0140525X16000947 
Nettle, D., Johnson, E., Johnson, M., \& Saxe, R. (2020). Why has the COVID-19 pandemic increased support for Universal Basic Income? https://doi.org/10.31234/osf.io/ $\operatorname{csr} 3 \mathrm{u}$

Nettle, D., Joly, M., Broadbent, E., Smith, C., Tittle, E., \& Bateson, M. (2019). Opportunistic food consumption in relation to childhood and adult food insecurity: An exploratory correlational study. Appetite, 132, 222-229. https://doi.org/10.1016/ j.appet.2018.07.018

Ornstein, R. E., \& Ehrlich, P. R. (2000). New world new mind: Moving toward conscious evolution. ISHK.

Otterbring, T. (2021). Evolutionary psychology in marketing: Deep, debated, but fancier with fieldwork. Psychology \& Marketing, 38(2), 229-238. https://doi.org/10.1002/ mar.21453

Otterbring, T., Shams, P., Wästlund, E., \& Gustafsson, A. (2013). Left isn't always right: Placement of pictorial and textual package elements. British Food Journal, 115(8), 1211-1225. https://doi.org/10.1108/BFJ-08-2011-0208

Otterbring, T., Sundie, J., Li, Y. J., \& Hill, S. (2020). Evolutionary psychological consumer research: Bold, bright, but better with behavior. Journal of Business Research, 120, 473-484. https://doi.org/10.1016/j.jbusres.2020.07.010

Petersen, M. B., Aarøe, L., Jensen, N. H., \& Curry, O. (2014). Social welfare and the psychology of food sharing: Short-term hunger increases support for social welfare. Political Psychology, 35(6), 757-773. https://doi.org/10.1111/pops.12062

Podsakoff, P. M., MacKenzie, S. B., Lee, J.-Y., \& Podsakoff, N. P. (2003). Common method biases in behavioral research: A critical review of the literature and rec- 
ommended remedies. Journal of Applied Psychology, 88(5), 879-903. https://doi. org $/ 10.1037 / 0021-9010.88 .5 .879$

Radimer, K. L., Olson, C. M., \& Campbell, C. C. (1990). Development of indicators to assess hunger. The Journal of Nutrition, 120(Suppl 11), 1544-1548. https://doi. org/10.1093/jn/120.suppl_11.1544

Rosseel, Y. et al. (2012). Lavaan: An R package for structural equation modeling. Journal of Statistical Software, 48(i02). https://doi.org/10.18637/jss.v048.i02

Rotter, J. B. (1966). Generalized expectancies for internal versus external control of reinforcement. Psychological Monographs: General and Applied, 80(1), 1-28. https: //doi.org/10.1037/h0092976

Saint Ville, A., Po, J. Y. T., Sen, A., Bui, A., \& Melgar-Quiñonez, H. (2019). Food security and the Food Insecurity Experience Scale (FIES): Ensuring progress by 2030. Food Security, 11, 483-491. https://doi.org/10.1007/s12571-019-00936-9

Sherman, M. A. (1973). Bound to be easier? The negative prefix and sentence comprehension. Journal of Verbal Learning and Verbal Behavior, 12(1), 76-84. https: //doi.org/10.1016/S0022-5371(73)80062-3

Shrout, P. E., \& Fleiss, J. L. (1979). Intraclass correlations: Uses in assessing rater reliability. Psychological Bulletin, 86(2), 420-428. https://doi.org/10.1037/00332909.86.2.420

Sijtsma, K., \& Molenaar, I. W. (2002). Introduction to nonparametric item response theory (Vol. 5). Sage. 
Song, H., \& Schwarz, N. (2008). If it's hard to read, it's hard to do: Processing fluency affects effort prediction and motivation. Psychological Science, 19(10), 986-988. https://doi.org/10.1111/j.1467-9280.2008.02189.x

Sova, C., Flowers, K., \& Man, C. (2019). Climate change and food security: A test of U.S. leadership in a fragile world. https://www.csis.org/analysis/climate-change-andfood-security-test-us-leadership-fragile-world

Stoet, G. (2010). PsyToolkit: A software package for programming psychological experiments using Linux. Behavior Research Methods, 42(4), 1096-1104. https://doi. org/10.3758/BRM.42.4.1096

Stoet, G. (2017). PsyToolkit: A novel web-based method for running online questionnaires and reaction-time experiments. Teaching of Psychology, 44 (1), 24-31. https://doi. $\operatorname{org} / 10.1177 / 0098628316677643$

Thompson, E. R. (2007). Development and validation of an internationally reliable shortform of the Positive and Negative Affect Schedule (PANAS). Journal of CrossCultural Psychology, 38(2), 227-242. https://doi.org/10.1177/0022022106297301

Tooby, J., \& Cosmides, L. (1990). The past explains the present: Emotional adaptations and the structure of ancestral environments. Ethology and Sociobiology, 11(4-5), 375-424. https://doi.org/10.1016/0162-3095(90)90017-Z

Twenge, J. M. (2000). The age of anxiety? the birth cohort change in anxiety and neuroticism, 1952-1993. Journal of Personality and Social Psychology, 79(6), 1007. https://doi.org/10.1037/0022-3514.79.6.1007

Umanath, S., \& Coane, J. H. (2020). Face validity of remembering and knowing: Empirical consensus and disagreement between participants and researchers. Per- 
spectives on Psychological Science, 15(6), 1400-1422. https://doi.org/10.1177/

\section{2}

UNDP. (2020). Goal 12: Responsible consumption and production. https://www.undp. org/content/undp/en/home/sustainable-development-goals/goal-12-responsibleconsumption-and-production.html

Van der Ark, L. A. (2007). Mokken scale analysis in R. Journal of Statistical Software, 20(11), 1-19. https://doi.org/10.18637/jss.v020.i11

Van der Ark, L. A. (2012). New developments in mokken scale analysis in R. Journal of Statistical Software, 48(5), 1-27. https://doi.org/10.18637/jss.v048.i05

Van Schuur, W. H. (2003). Mokken scale analysis: Between the Guttman scale and parametric item response theory. Political Analysis, 11(2), 139-163. https://doi.org/ $10.1093 / \mathrm{pan} / \mathrm{mpg} 002$

Watson, D., Clark, L. A., \& Tellegen, A. (1988). Development and validation of brief measures of positive and negative affect: The PANAS Scales. Journal of Personality and Social Psychology, 54(6), 1063-1070.

Webb, P., Coates, J., Frongillo, E. A., Rogers, B. L., Swindale, A., \& Bilinsky, P. (2006). Measuring household food insecurity: Why it's so important and yet so difficult to do. The Journal of Nutrition, 136(5), 1404S-1408S. https://doi.org/10.1093/jn/ 136.5.1404S

Wheeler, T., \& Von Braun, J. (2013). Climate change impacts on global food security. Science, 341 (6145), 508-513. https://doi.org/10.1126/science.1239402

Yadav, A., Phillips, M. M., Lundeberg, M. A., Koehler, M. J., Hilden, K., \& Dirkin, K. H. (2011). If a picture is worth a thousand words is video worth a million? Differences 
in affective and cognitive processing of video and text cases. Journal of Computing in Higher Education, 23(1), 15-37. https://doi.org/10.1007/s12528-011-9042-y 


\section{Chapter 6}

\section{Concluding discussion}

Michał Folwarczny

Department of Business Administration, Reykjavik University 


\subsection{Summary of the findings}

The central aim of this academic endeavor was to enrich an understanding of how cues to food scarcity affect food preferences qualitatively among people who physically do not experience food insufficiency, thus extending the generalizability of the insurance hypothesis (Nettle et al., 2017). Each of the four Academic Papers answered separate questions. In Paper I, we have briefly reviewed relevant literature and outlined few recommendations for governmental institutions that wish to foster healthier food choices. However, in Paper IV, we have learned that the construct of interest in this thesis may be applicable in research areas that appear unrelated to food choices (i.e., aspects of prosociality), leaving many unanswered questions for scholars with expertise in other disciplines. Below, I summarize the main findings and highlight the unique contribution of this investigation to academia and practice. Table 1.1 in Chapter I shows research problems that each of the Academic Papers aimed to solve, whereas Table 6.1 briefly summarizes the extent to which these goals were achieved.

In Paper I, we proposed several strategies for policymakers that may facilitate healthier food choices. We reviewed relevant literature to show that modern consumers' food preferences are shaped by eons of struggling against hostile forces of nature, leaving them with many mechanisms that used to be adaptive but nowadays may lead to maladaptive outcomes. As the law of law's leverage postulates (Jones, 2001), governmental institutions need to invest a considerable amount of resources in order to change behaviors that used to have a high adaptive value in the past; the reverse is true about changing behaviors that used to have a minimal adaptive value in the past. For example, consuming a variety of energy-dense foods was highly adaptive for our ancestors, given that they experienced 
frequent and often lethal periods of food shortages. On the other hand, consuming root vegetables and fruits low in carbohydrates was less critical for them. Thus, consumers do not need to be incentivized to eat burgers, but it is more challenging to encourage them to consume salads. Nonetheless, there are many strategies - inspired by the law of law's leverage (Jones, 2001) — such as making low-calorie and healthy foods appealing to evolutionarily old taste buds or making healthy foods convenient to buy and consume that may be applied as cost-effective strategies fostering healthier eating.

Studies reported in Paper II provide a piece of empirical evidence supporting the central tenets of the insurance hypothesis (Nettle et al., 2017). Precisely, we have predicted and found that exposing participants to food scarcity cues - although distant in time and space - elicits higher preferences toward energy-dense (vs. low-calorie) foods among them than among their peers exposed to control stimuli. Moreover, the second prediction drawn from the insurance hypothesis was also supported - the effects of food scarcity cues were more substantial for females than for males.

The empirical package in Paper III aimed to account for several drawbacks associated with the experimental stimuli that we used in Paper II. In Paper III, we used subtle cues to food scarcity, namely - a winter forest walk. We found that such subtle cues elicit higher accessibility to concepts related to survival and energy-dense foods but not to concepts related to scarcity and low-calorie foods. Moreover, findings reported in Papers II-III, constitute a solid piece of evidence behind the effects' generalizability across samples and stimuli, with different and arguably weaker manipulation yielding to similar conclusions.

Finally, in Paper IV, we strived to delineate a candidate psychological mechanismanticipated food scarcity (AFS) — that could partially explain why humans show a stronger 
preference toward foods they deem as higher in calories after exposure to food scarcity cues. We have developed and psychometrically validated the Anticipated Food Scarcity Scale (AFSS). The 8-item measure has good psychometric properties and was found correlated with certain aspects of prosociality. Thus, AFSS provides an alternative way of studying the impact of food shortages on food preferences and gradients of social behavior. Additionally, its narrow set of items and sensitivity to food scarcity cues makes the scale appropriate for experimental research focused on prosocial behaviors, food waste, food choices, and other related domains of consumer behavior. 
Table 6.1: Summary of findings

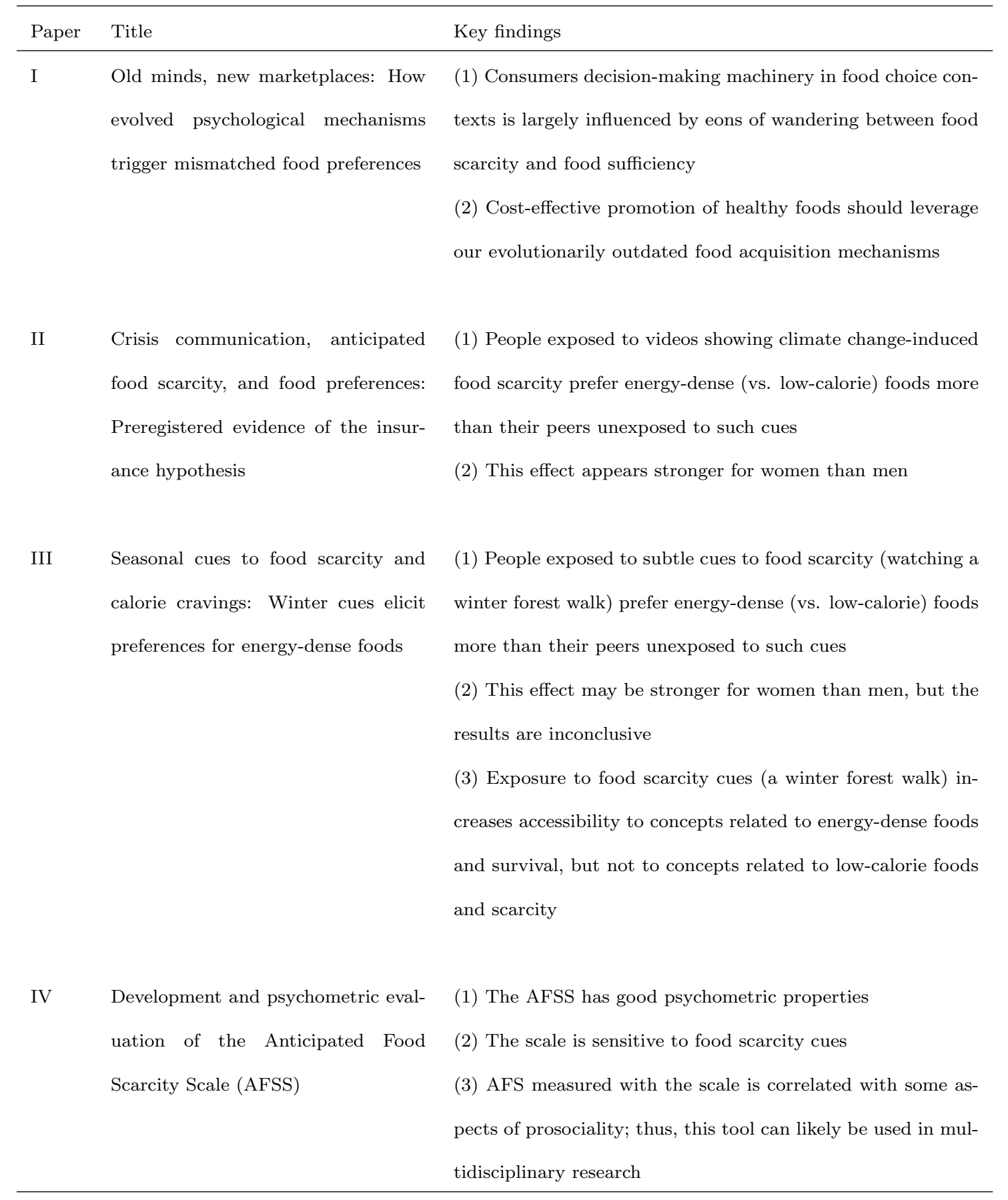




\subsection{Contribution to the academic literature}

The insurance hypothesis has been initially developed to explain the higher prevalence of obesity and overweight among food-insecure populations in developed countries (Nettle et al., 2017). However, this theoretical account neglected the role of cues to food scarcity in shaping food preferences among people who do not experience food insecurity understood as a physical experience of food unavailability (i.e., hunger). Additionally, Nettle et al. (2017) conducted a meta-analysis without providing experimental evidence supporting their theorizing. Finally, the authors have not proposed any candidate psychological mechanism that could contribute to a better understanding of why food scarcity cues affect food choices and preferences.

The findings presented in the thesis extend the generalizability of the insurance hypothesis by showing that cues to food scarcity affect food preferences among the population where food insecurity is relatively rare. In addition, participants in studies reported herein were recruited online from the US, UK, and - in the case of a laboratory experiment - from a Danish university, thus further increasing the generalizability of findings across samples. In Paper III, we used nonexplicit and subtle cues to food scarcity by exposing participants to a winter forest walk (vs. a summer forest walk in the control condition). Although not all of these studies yielded results supporting our primary hypothesis at conventional significance levels, when treated together, these findings provided a shred of evidence that the effects of food scarcity exposure are generalizable across stimuli of varying intensity, even if these stimuli do not show food scarcity explicitly.

Although the insurance hypothesis does not propose a psychological mechanism explaining a shift in food preferences after exposure to environmental cues to food scarcity 
(Nettle et al., 2017), results from the studies in Paper III show that food scarcity cues elicit higher accessibility to concepts related to survival and energy-dense foods. To propose a candidate psychological mechanisms that could contribute to a better understanding of why people exposed to food scarcity show higher calorie cravings, we have delineated anticipated food scarcity (AFS) - a new psychological construct. We also developed and validated a scale measuring this construct that was, surprisingly, correlated with support for Universal Basic Income. These findings align with the conservation of resources theory (Hobfoll, 1989), which postulates that people facing threats such as food shortages maximize the resources they keep for themselves. Supporting social welfare programs to a larger extent when facing difficulties fulfills these criteria-people benefit more from resources redistribution under such circumstances. As such, findings from this thesis show that the effects of exposure to food scarcity cues may wield influence on gradients of social behavior among people not experiencing food scarcity physically, thus suggesting that the insurance hypothesis is a theoretical account that may be applied across many disciplines (see Nettle, 2017, for a related discussion of how hunger impacts social behavior).

Overreliance on null-hypothesis significance testing has impaired scientific progress across disciplines, leading to an overrepresentation of findings confirming predictions in academic literature; hence, many effect sizes are inflated (Ioannidis, 2005). As a response to this crisis, Cumming (2014) outlined the principles on the new statistics, encouraging academic practices such as performing an internal meta-analysis, complete reporting of findings, replicating studies, preregistration, and making datasets and other materials publicly available. Notably, inferences should be made based on effect sizes, confidence intervals, and conclusions from empirical data should be treated as estimation, rather 
than a dichotomous decision that often hinges on conventionally used $p$-values (Cumming, 2014). With full reporting of findings, making all materials and analysis code publicly available, as well as including two preregistered studies in the empirical package, this thesis largely adheres to these methodological standards set to increase the replicability of findings.

\subsection{Managerial implications}

In Paper I, we argued that many marketing practices bear some responsibility for the current pandemic of overweight and obesity. However, to remain profitable in competitive markets, companies must maximize profits and minimize costs associated with their business activities. Although Papers II-III merely show that exposing participants to food scarcity cues increases their preferences toward foods deemed as higher in calories, Paper I draws straightforward suggestions for retailers and policymakers on how to remain profitable while phasing out strategies that yield negative consequences for public health. Consumers' decision-making machinery is essentially outdated and mismatched against present-day needs ( $\mathrm{Li}$ et al., 2018); in most cases, it is maladaptive to respond to food scarcity cues with increased preferences toward energy-dense foods. Thus, policymakers need to enforce strategies accounting for the specificity of consumers' evolutionarily outdated decision-making mechanisms when helping retailers stay profitable while selling low-calorie and healthier products.

There are several strategies that retailers may adopt to stay profitable when focusing on selling healthy foods. First, building on results from studies reported in Papers IIIII, it is crucial to consider eliminating food scarcity cues from the retail environment. 
For instance, some retailers organize campaigns where they collect money that is used to fight famine. Although we have not collected data in retail environments, it may be sensible to ask consumers for such donations no sooner than after they finish shopping (vs. before or during collecting a shopping basket). In fact, having paid a bill, consumers can be more generous due to the contrast effect, where small donations appear even smaller when contrasted against a receipt for the whole basket of groceries; hence, people may eventually donate more money for charitable purposes (e.g., Cialdini et al., 1975).

Although eliminating consumers' cravings for products that taste and appear like energy-dense foods is unrealistic, and our findings suggest that these products are especially desired among consumers exposed to food scarcity, retailers may offer substitutes of these products by selling healthier (lower-calorie) options "in disguise." For instance, the government of Singapore financially supports producers of vegan meat alternatives that typically are healthier and lower in calories than traditional meat (Ramli, 2021). As a result, retailers offering such products may remain exceptionally profitable. For example, the financial performance of Impossible Foods and Beyond Meat - the industry leaders - recently surpassed expectations (Ramli, 2021).

Even having a widespread awareness of how cues to food scarcity affect food preferences will not prevent these cues from occurring in communication campaigns. Critical challenges like, for instance, the spread of the COVID-19 pandemic, need to be publicized. Given that such publicized events may be received as cues to food scarcity, it is likely that these cues will elicit a desire for calories among consumers. Therefore, marketing practitioners may consider assuring consumers that food supplies will not be harmed. Importantly, however, it remains unknown whether it is possible to mitigate the consequences 
of food scarcity cues on food preferences by simply telling people not to worry about food supply. Additional studies may investigate the effectiveness of such communication in ameliorating, or possibly reversing, effects reported across Studies II-III.

In some cases, governmental institutions may have to resort to solid incentives to promote healthier eating habits. Still, such policies do not have to harm retailers. For example, the UK soft drink levy, also known as a "sugar tax," reduced the average sugar intake by a tenth per household without lowering overall sales of soft drinks, thus not harming retailers (Pell et al., 2021). Similar policies may be imposed to lower the average calorie content of more complex foods. Indeed, some countries successfully lowered the amount of fat and sugar in products known globally, without consumers being aware of that (The Center for Science in the Public Interest, 2016).

Applying an evolutionary approach to studying consumer behavior is still uncommon in marketing literature, with recent calls to develop this interdisciplinary stream of research (Durante \& Griskevicius, 2018; Griskevicius \& Kenrick, 2013; Otterbring et al., 2020; Saad, 2017, 2020a, 2020b, 2021). As such, the present studies contribute to this scarce body of literature by showing that consumer behavior in food-related domains is largely influenced by evolutionarily outdated mechanisms that have emerged to cope with challenges found in ancestral environments, and many modern problems can be addressed with evolutionarily informed theories such as the evolutionary mismatch hypothesis (Li et al., 2018; Li et al., 2020). 


\subsection{Limitations and future research}

There are at least several limitations and questions that warrant future investigation. Although in Paper IV we discussed anticipated food scarcity (AFS) as a potential psychological mechanism that could partially explain the results reported in Papers II-III, this construct has not been investigated in such a context, primarily due to lack of a psychometric scale measuring it when the studies reported in Papers II-III were conducted. Future studies may therefore apply the Anticipated Food Scarcity Scale (AFSS) and test AFS as a potential mediator of the effects (although results from mediation analysis should be treated with caution, often leaving at least several alternative explanations of psychological processes underlying changes in dependent measures; see Spencer et al., 2005, for a more detailed discussion of this issue).

The scale aimed at capturing AFS is yet to be comprehensively validated. Studies reported in Paper IV merely provide a piece of preliminary evidence behind this construct's distinctiveness from other potentially related constructs such as food insecurity or state anxiety. A comprehensive validation process is lengthy, requiring numerous studies and ruling out alternative explanations of a psychological phenomenon. Therefore, it is imperative to test the predictive validity of the AFSS, emphasizing whether the scale is predictive of food preferences and choices in ecologically valid contexts, including extra-laboratory settings.

There are at least several alternative explanations of results obtained from studies reported in Papers II-III. First, affective states, especially negative emotions, impact food preferences, often leading to increased desire to consume energy-dense products (Macht, 2008; Van Strien et al., 2013). We attempted to develop control and experimental stimuli 
so that both stimuli elicit similar affective responses. Nevertheless, the control video used in studies in Paper II elicited higher dominance captured by the Self-Assessment Manikin (Bradley \& Lang, 1994). Further, in these studies, we used only one control variable (hunger), whereas in studies reported in Paper III, we relied exclusively on pretesting without controlling for other potential confounds. Therefore, our results could have been partially driven by specific affective states that the experimental or control videos elicited among participants. Second, although controlling for participants' body mass index (BMI) is common in food-related research, likely due to that BMI has been discussed as a variable predicting certain food preferences (Czyzewska \& Graham, 2008; Drewnowski et al., 1992; Wardle et al., 2001), we have not collected such data. Therefore, we cannot rule out the possibility that potential differences in BMI between experimental groups, rather than our proposed psychological mechanism, have driven the pattern of the observed results. Third, studies conducted by Hill et al. (2013), which were informed by life history theory and the critical fat hypothesis, suggest that women who grew up in low socioeconomic status households react to environmental harshness with increased "calorie cravings," as compared to their female peers who grew up in more affluent families. Interestingly, such a pattern of results has not been present among men. Likewise, our findings suggest that the effects of food scarcity cues, which can be interpreted as cues to environmental harshness, might be more substantial or found only among women but not men. As such, findings reported by Hill et al. (2013) may provide at least several alternative explanations of our results, contesting our theorizing built upon the insurance hypothesis (Nettle et al., 2017).

This research was conducted in part to address public health threats. Whereas labo- 
ratory studies, including these in online settings, are essential for a deeper understanding of the phenomenon, their role is to optimize the effects that occur in field settings, ultimately leading to the development of large-scale behavioral interventions (Marteau et al., 2021). Because we only measured food preferences in the online studies, it is crucial to examine the external validity and boundary conditions of the phenomenon with meaningful behavioral outcomes (e.g., Doliński, 2018, 2020; Doliński et al., 2017; Folwarczny et al., 2018; Szczepanowski et al., 2019). The existing literature shows a discrepancy between stated preferences and actual behaviors measured in subsequent naturalistic studies. However, previous research has also shown a discrepancy between attitudes and behavioral outcomes in the same online study. For example, Byrka et al. (2019) investigated whether attitudes toward social groups captured in an online study were associated with donations to organizations representing those groups. When donation behaviors were measured before capturing attitudes, the authors found no relationship between the two. In contrast, when participants first reported their attitudes toward social groups, the latter were weakly related to their subsequent donations to organizations representing those groups. These results suggest that online measurements can change subsequent behavior per se, rather than a construct that such measurements attempt to capture. The current study is, therefore, a plea for real-world field studies to test whether food scarcity cues are indeed sufficient to change food-related behavior. For example, participants may be exposed to food scarcity cues or cues unrelated to food in laboratory settings. Then they can be asked to select one of several snacks as an additional reward for taking part in the study. These snacks can differ in their caloric density. Ideally, studies may be conducted in a retail environment, where experimenters can expose shoppers to food scarcity cues 
(e.g., they can be asked to donate for food charity and informed that their donations would help fight famine in the world) and test whether such cues increase their choices of energy-dense products.

These extra-laboratory studies should preferably include participants of different socioeconomic statuses, as this variable has been shown to predict dietary responses to environmental stressors, at least among women (Hill et al., 2013). Further, socioeconomic status is one of the key predictors of food insecurity worldwide (Pereira et al., 2017), with its experience or lack of thereof likely moderating effects reported across Academic Papers II-III Nettle et al. (cf. 2017). Notably, people are likely unaware of how their socioeconomic background affects their food preferences. Given that human behavior is largely driven by automatic processes that occur in response to environmental stimuli, successful behavioral interventions such as increasing the consumption of healthy foods should take this automaticity of decision-making into account (Marteau et al., 2012). This notion may be especially true for children, who may be less aware of how various environmental stimuli influence their decisions. Therefore, future studies, preferably in field settings, should include samples differing in age as well.

The current results were relatively generalizable across samples in developed countries. However, most people in the world do not live in these countries, with many aspects of human psychology bearing a considerable degree of variation across the globe (Henrich et al., 2010). Therefore, future research should be conducted on more diverse samples with respect to their cultural background, and places of residence. Such studies are critical in the context of the research reported in Papers II-III, as in some countries, more people experience food insecurity than relatively stable and secure access to food 
resources (Pereira et al., 2017). As a result of their frequent exposure to food scarcity, potentially leading to desensitization to such cues, the conclusions from this thesis may not apply to them.

This academic endeavor was primarily informed by evolutionary thinking, which has often been criticized for its broad level of analysis that often ignores inter-sample variability and the characteristics of many individuals (e.g., Nicholson \& Xiao, 2010; Saad, 2017). Thus, demonstrating that the present results can indeed be replicated, for example, among adolescents in less developed countries would invalidate this criticism and invite scholars from other disciplines to study the consequences of cues to food scarcity for shaping food preferences and, once behavioral data become available, food choices as well.

Findings in Paper IV suggest that AFS may be related to some aspects of prosociality. Thus, this construct should be further scrutinized through multidisciplinary research. Considering that low blood glucose and hunger have been discussed as linked to social behavior and decision-making in domains unrelated to food choices (Nettle, 2017; Orquin \& Kurzban, 2016; Orquin et al., 2020), it is plausible that AFS is a construct that may foster novel research on cooperation, prosociality, and other research areas.

Probably the most critical limitation of the findings reported in this thesis is an inconsistent pattern of results. In Paper II, all three studies supported our primary hypothesis postulating that exposure to climate change-induced food scarcity increases preferences toward foods deemed to be higher (vs. lower) in calories. In the same paper, results from two of three studies provided support for our secondary hypothesis, implying that this effect was likely stronger for women than men, aligning with predictions driven from the 
insurance hypothesis (Nettle et al., 2017). Additionally, the results from the third study therein directionally supported the secondary hypothesis.

Despite finding this initial support for both our predictions, the pattern of results in Paper III was less consistent, differing considerably from findings in Paper II. Although Studies 2a-2b in Paper III appear to confirm our primary hypothesis, these studies were likely underpowered, as a power curve estimated based on observed power analysis conducted on data from Study 2a suggested that at least 420 participants were needed for .95 power to detect the effect size of interest. Thus, results from these studies should be treated with caution. This may be true especially given that the results from the final, appropriately powered study (Study 2b) in Paper III did not confirm our primary hypothesis. Instead, we observed a trend in the opposite direction. Finally, barely one underpowered study (Study 2a) in Paper III provided results supporting our secondary hypothesis, where only women-but not men-responded to food scarcity (winter) cues with an increased preference toward foods deemed to be higher (vs. lower) in calories. Despite this, data from Study 2c, which had an appropriate sample size for testing both our hypotheses, suggest a trend in a hypothesized direction, with women potentially exhibiting more substantial "calorie cravings" than men after exposure to food scarcity (winter) cues than control (summer) stimuli. Therefore, more studies with different manipulations are warranted to establish the generalizability of the effects reported in Papers II-III. It is plausible that the manipulation we used in Paper III was too weak to trigger responses found in Paper II, where we exposed participants to vivid and overt cues to food scarcity: videos depicting drought, famine, and future threats to global food supply chains. 


\subsection{References}

Bradley, M. M., \& Lang, P. J. (1994). Measuring emotion: The Self-Assessment Manikin and the semantic differential. Journal of Behavior Therapy and Experimental Psychiatry, 25(1), 49-59. https://doi.org/10.1016/0005-7916(94)90063-9

Byrka, K., Grzyb, T., \& Dolinski, D. (2019). The question-behaviour effect in intergroup attitudes research: When do attitudes towards a minority predict a relevant behaviour? International Journal of Psychology, 54(3), 297-306. https://doi.org/10. 1002/ijop.12469

Cialdini, R. B., Vincent, J. E., Lewis, S. K., Catalan, J., Wheeler, D., \& Darby, B. L. (1975). Reciprocal concessions procedure for inducing compliance: The door-inthe-face technique. Journal of Personality and Social Psychology, 31(2), 206-215. https://doi.org/10.1037/h0076284

Cumming, G. (2014). The new statistics: Why and how. Psychological Science, 25(1), 7-29. https://doi.org/10.1177/0956797613504966

Czyzewska, M., \& Graham, R. (2008). Implicit and explicit attitudes to high-and lowcalorie food in females with different BMI status. Eating Behaviors, 9(3), 303-312. https://doi.org/10.1016/j.eatbeh.2007.10.008

Doliński, D. (2018). Is psychology still a science of behaviour? Social Psychological Bulletin, 13(2), 1-14. https://doi.org/10.5964/spb.v13i2.25025

Doliński, D. (2020). Do psychologists study behaviour? Health Psychology Report, 8(4), 385-390. https://doi.org/doi.org/10.1111/j.1745-6916.2007.00051.x

Doliński, D., Grzyb, T., Folwarczny, M., Grzybała, P., Krzyszycha, K., Martynowska, K., \& Trojanowski, J. (2017). Would you deliver an electric shock in 2015? Obedience in 
the experimental paradigm developed by Stanley Milgram in the 50 years following the original studies. Social Psychological and Personality Science, 8(8), 927-933. https://doi.org/10.1177/1948550617693060

Drewnowski, A., Kurth, C., Holden-Wiltse, J., \& Saari, J. (1992). Food preferences in human obesity: Carbohydrates versus fats. Appetite, 18(3), 207-221. https://doi. org/10.1016/0195-6663(92)90198-F

Durante, K. M., \& Griskevicius, V. (2018). Evolution and consumer psychology. Consumer Psychology Review, 1(1), 4-21. https://doi.org/10.1002/arcp.1001

Folwarczny, M., Kaczmarek, M. C., Doliński, D., \& Szczepanowski, R. (2018). Emotional See-Saw affects rationality of decision-making: Evidence for metacognitive impairments. Acta Psychologica, 186, 126-132. https://doi.org/10.1016/j.actpsy.2018.04. 012

Griskevicius, V., \& Kenrick, D. T. (2013). Fundamental motives: How evolutionary needs influence consumer behavior. Journal of Consumer Psychology, 23(3), 372-386. https://doi.org/10.1016/j.jcps.2013.03.003

Henrich, J., Heine, S. J., \& Norenzayan, A. (2010). Most people are not WEIRD. Nature, 466, 29. https://doi.org/10.1038/466029a

Hill, S. E., Rodeheffer, C. D., DelPriore, D. J., \& Butterfield, M. E. (2013). Ecological contingencies in women's calorie regulation psychology: A life history approach. Journal of Experimental Social Psychology, 49(5), 888-897. https://doi.org/10. 1016/j.jesp.2013.03.016 
Hobfoll, S. E. (1989). Conservation of resources: A new attempt at conceptualizing stress. American Psychologist, 44(3), 513-524. https://doi.org/10.1037/0003-066X.44.3. 513

Ioannidis, J. P. A. (2005). Why most published research findings are false. PLoS Medicine, 2(8), e124. https://doi.org/10.1371/journal.pmed.0020124

Jones, O. D. (2001). Time-shifted rationality and the law of law's leverage: Behavioral economics meets behavioral biology. Northwestern University Law Review, 95 (4), 1141-1205. https://doi.org/10.2139/ssrn.249419

Li, N. P., van Vugt, M., \& Colarelli, S. M. (2018). The evolutionary mismatch hypothesis: Implications for psychological science. Current Directions in Psychological Science, 27(1), 38-44. https://doi.org/10.1177/0963721417731378

Li, N. P., Yong, J. C., \& Van Vugt, M. (2020). Evolutionary psychology's next challenge: Solving modern problems using a mismatch perspective. Evolutionary Behavioral Sciences, 14(4), 362-367. https://doi.org/10.1037/ebs0000207

Macht, M. (2008). How emotions affect eating: A five-way model. Appetite, 50(1), 1-11. https://doi.org/10.1016/j.appet.2007.07.002

Marteau, T. M., Fletcher, P. C., Munafò, M. R., \& Hollands, G. J. (2021). Beyond choice architecture: Advancing the science of changing behaviour at scale. BMC Public Health, 21(1), 1-7. https://doi.org/10.1186/s12889-021-11382-8

Marteau, T. M., Hollands, G. J., \& Fletcher, P. C. (2012). Changing human behavior to prevent disease: The importance of targeting automatic processes. Science, 337(6101), 1492-1495. https://doi.org/10.1126/science.1226918 
Nettle, D. (2017). Does hunger contribute to socioeconomic gradients in behavior? Frontiers in Psychology, 8, 358. https://doi.org/10.3389/fpsyg.2017.00358

Nettle, D., Andrews, C., \& Bateson, M. (2017). Food insecurity as a driver of obesity in humans: The insurance hypothesis. Behavioral and Brain Sciences, 40. https: //doi.org/10.1017/S0140525X16000947

Nicholson, M., \& Xiao, S. H. (2010). On the evolutionary bases of consumer reinforcement. Journal of Organizational Behavior Management, 30(2), 127-144. https://doi.org/ $10.1080 / 01608061003756356$

Orquin, J. L., \& Kurzban, R. (2016). A meta-analysis of blood glucose effects on human decision making. Psychological Bulletin, 142(5), 546-567. https://doi.org/10. $1037 /$ bul0000035

Orquin, J. L., Dalgaard, C. J., \& Lagerkvist, C. J. (2020). A meta-analytical and experimental examination of blood glucose effects on decision making under risk. Judgment and Decision Making, 15(6), 1024-1036.

Otterbring, T., Sundie, J., Li, Y. J., \& Hill, S. (2020). Evolutionary psychological consumer research: Bold, bright, but better with behavior. Journal of Business Research, 120, 473-484. https://doi.org/10.1016/j.jbusres.2020.07.010

Pell, D., Mytton, O., Penney, T. L., Briggs, A., Cummins, S., Penn-Jones, C., Rayner, M., Rutter, H., Scarborough, P., Sharp, S. J., et al. (2021). Changes in soft drinks purchased by British households associated with the UK soft drinks industry levy: Controlled interrupted time series analysis. BMJ, 372. https://doi.org/10.1136/ bmj.n254 
Pereira, A. L., Handa, S., \& Holmqvist, G. (2017). Prevalence and correlates of food insecurity among children across the globe. UNICEF Office of Research, Innocenti Working Papers 2017/09. https://doi.org/10.18356/9206b37d-en

Ramli, D. (2021). Temasek makes rare seed investment in plant-based chicken maker. https:/ / www . bloomberg. com / news / articles / 2021-02-25/temasek- makes-rareseed-investment-in-plant-based-chicken-maker

Saad, G. (2017). On the method of evolutionary psychology and its applicability to consumer research. Journal of Marketing Research, 54(3), 464-477. https://doi.org/ 10.1509/jmr.14.0645

Saad, G. (2020a). Building a global database of nomological networks of cumulative evidence. Evolutionary Behavioral Sciences. https://doi.org/10.1037/ebs0000223

Saad, G. (2020b). The marketing of evolutionary psychology. Journal of Business Research, 120, 485-491. https://doi.org/10.1016/j.jbusres.2019.03.048

Saad, G. (2021). Addressing the sins of consumer psychology via the evolutionary lens. Psychology \& Marketing. https://doi.org/10.1002/mar.21446

Spencer, S. J., Zanna, M. P., \& Fong, G. T. (2005). Establishing a causal chain: Why experiments are often more effective than mediational analyses in examining psychological processes. Journal of Personality and Social Psychology, 89(6), 845. https://doi.org/10.1037/0022-3514.89.6.845

Szczepanowski, R., Folwarczny, M., Król, M., Doliński, D., \& Budzisz, J. (2019). Electrophysiological correlates of Emotional See-Saw Effect on a Go/No-Go task. Current Psychology, 38(2), 533-541. https://doi.org/10.1007/s12144-017-9626-4 
The Center for Science in the Public Interest. (2016, November 29). U.S. cereals higher in sugar and sodium than in certain other countries. https://cspinet.org/news/uscereals-higher-sugar-and-sodium-certain-other-countries-20161129

Van Strien, T., Cebolla, A., Etchemendy, E., Gutierrez-Maldonado, J., Ferrer-Garcia, M., Botella, C., \& Baños, R. (2013). Emotional eating and food intake after sadness and joy. Appetite, 66, 20-25. https://doi.org/10.1016/j.appet.2013.02.016

Wardle, J., Guthrie, C., Sanderson, S., Birch, L., \& Plomin, R. (2001). Food and activity preferences in children of lean and obese parents. International Journal of Obesity, 25(7), 971-977. https://doi.org/10.1038/sj.ijo.0801661 